\title{
Agile Delivery of Protein Therapeutics to CNS
}

\author{
Xiang Yi ${ }^{1},{ }^{,}$, Devika S. Manickam ${ }^{1}$, Anna Brynskikh², and Alexander V. Kabanov ${ }^{1,3,{ }^{*}}$ \\ ${ }^{1}$ Division of Molecular Pharmaceutics and Center for Nanotechnology in Drug Delivery, UNC \\ Eshelman School of Pharmacy, University of North Carolina at Chapel Hill, Chapel Hill, NC 27599 \\ ${ }^{2}$ Department of Pharmaceutical Sciences and Center for Drug Delivery and Nanomedicine, \\ University of Nebraska Medical Center, Omaha, NE 68198, USA \\ ${ }^{3}$ Faculty of Chemistry, M.V. Lomonosov Moscow State University, 119899 Moscow, Russia
}

\section{Abstract}

\begin{abstract}
A variety of therapeutic proteins have shown potential to treat central nervous system (CNS) disorders. Challenge to deliver these protein molecules to the brain is well known. Proteins administered through parenteral routes are often excluded from the brain because of their poor bioavailability and the existence of the blood-brain barrier (BBB). Barriers also exist to proteins administered through non-parenteral routes that bypass the BBB. Several strategies have shown promise in delivering proteins to the brain. This review, first, describes the physiology and pathology of the BBB that underscore the rationale and needs of each strategy to be applied. Second, major classes of protein therapeutics along with some key factors that affect their delivery outcomes are presented. Third, different routes of protein administration (parenteral, central intracerebroventricular and intraparenchymal, intranasal and intrathecal) are discussed along with key barriers to CNS delivery associated with each route. Finally, current delivery strategies involving chemical modification of proteins and use of particle-based carriers are overviewed using examples from literature and our own work. Whereas most of these studies are in the early stage, some provide proof of mechanism of increased protein delivery to the brain in relevant models of CNS diseases, while in few cases proof of concept had been attained in clinical studies. This review will be useful to broad audience of students, academicians and industry professionals who consider critical issues of protein delivery to the brain and aim developing and studying effective brain delivery systems for protein therapeutics.
\end{abstract}

\section{Keywords}

protein therapeutics; central nervous system; blood-brain barrier; protein delivery; administration route; brain delivery

\footnotetext{
(C) 2014 Elsevier B.V. All rights reserved.

*Corresponding authors: Eshelman School of Pharmacy, University of North Carolina at Chapel Hill, NC 27599. Tel. 1(919)962-1010; Fax. 1(919)962-9922; xiang_yi@unc.edu; akabanov@email.unc.edu.

This is a PDF file of an unedited manuscript that has been accepted for publication. As a service to our customers we are providing this early version of the manuscript. The manuscript will undergo copyediting, typesetting, and review of the resulting proof before it is published in its final citable form. Please note that during the production process errors may be discovered which could affect the content, and all legal disclaimers that apply to the journal pertain.
} 


\section{Introduction}

Protein therapeutics has made significant progress during the past 30 years, beginning with the invention of the first recombinant protein used in clinical practice, a human insulin [1]. Since then, development of protein therapeutics has been one of the biotech's most notable successes. In recent years, the number of protein-based therapeutics reaching the marketplace has increased exponentially. As of today, more than 130 proteins or peptides are used in clinics and many more are in development [2]. The currently marketed proteins include enzymes, antibodies, clotting factors, anticoagulants, modern insulins, growth hormone, follicle-stimulating hormone, hematopoietic growth factors, interferons, interleukins and others. The market of the therapeutic proteins holds tremendous potential for future growth and it is estimated that by the end of 2018, it may reach the mark of US $\$ 165$ billion as new products may enter the sector. As patents on first-generation proteins wind down, the industry seeks to protect their markets by introducing protein delivery technologies that provide for improved stability, bioavailability and safety of the therapeutic proteins. Such technologies aim to overcome obstacles to the clinical application of the proteins due to a lack of desirable attributes for adequate absorption or distribution. It therefore becomes critical to incorporate proteins in safe, stable and efficacious delivery systems. Because proteins face formidable enzymatic and penetration barriers, efficient protein delivery to its destination in the body remains a very challenging if not a formidable task.

There is a tremendous potential to develop protein therapeutics for the treatment of neurological and neurodegenerative disorders. Examples include Alzheimer's disease (AD), Parkinson's disease (PD), amyotrophic lateral sclerosis (ALS), human immunodeficiency virus 1 (HIV-1)-associated dementia (HAD) (or more generally HIV-associated cognitive dysfunction), multiple sclerosis (MS), lysosomal storage disorders (LSDs; Gaucher's disease, Niemann-Pick disease, Tay-Sachs disease and Sandhoff's disease, Krabbe's disease, Fabry's disease, metachromatic leukodystrophy amongst nearly 50 total disorders) and others. Other diseases associated with the central nervous system (CNS) include brain tumors, stroke, traumatic brain injury (TBI), and metabolic disorders. Some examples of potential protein therapeutics to treat these CNS related disorders include enzymes in LSDs, antibodies in $\mathrm{AD}$ and brain tumors, neurotrophic factors in PD and stroke, and gut-brain hormones in obesity.

Clinical use of these proteins, however, is extremely challenging because of the unique and complex environment imposed by the CNS. Systemic delivery of proteins to the brain inevitably encounters two major hurdles: the rapid serum clearance and the limited penetration at the blood-brain barrier (BBB). Some protein molecules, such as neurotrophic factors can cross the BBB to some extent but are rapidly cleared from the blood, whereas others, such as antibodies, are stable and long circulating in blood but absolutely not permeable at the BBB. In both cases systemic delivery of proteins does not allow to attain their sufficient brain concentration for effective treatment. Proteins can also access the brain through alternative delivery routes that allow bypassing the BBB, such as intracerebroventricular (i.c.v.), intraparenchymal, intranasal (i.n.) or intrathecal (i.t.) administration. However, in most cases the brain uptake of proteins following such 
administration routes is still surprisingly low, especially in the targeted brain regions where protein therapeutics needs to be delivered. It has been gradually accepted that serious biological barriers are associated with each of these alternative delivery routes.

Therefore a great deal of effort has been dedicated to developing the drug delivery systems and approaches that could help protein molecules crossing numerous barriers on their way to the site of action in the brain. Multiple drug delivery strategies were explored in the attempts to address this challenge. For example, chemical modification of proteins with poly(ethylene glycol) (PEG), known as PEGylation [3], or incorporation of proteins into poly(D,L-lacticco-glycolide) (PLGA) particles [4, 5] increased stability and bioavailability of certain proteins and resulted in development of the Food and Drug Administration (FDA) approved products for various peripheral diseases. However, neither of these technologies has shown much promise so far in delivering protein therapeutics to the brain for treatment of CNS related diseases. Several specific molecules (antibodies, peptides, etc.) that can target and cross BBB through intrinsic transport systems available in brain endothelium were identified and conjugated to protein of interest to create targeted therapeutic agents for CNS related diseases. However, no such conjugate has progressed far enough to enter clinical trials although similar conjugates with small molecule drugs seem to be somewhat more advanced (e.g. paclitaxel-Bp-2 ANG1005, Angichem, Inc). Some of the studies in this area go back nearly 30 years, and yet during this considerable period, despite consistent and steady effort by numerous capable researchers across the globe relatively little progress was achieved, which only underscores the enormity of the task.

However, analysis of previous experience in this field along with understanding of the recent achievements and trends in the drug delivery and nanomedicine science allow us to suggest that a new explosive development is just behind the corner. We believe that investigators should expect a very exciting journey during the next decade in pursuit of novel CNS technologies and therapeutics and that a critical mass of knowledge has been reached enabling new principal breakthroughs. In anticipation of this development we decided to critically analyze the past experiences from the current prospective that in our view in essential to achieve success in this field. We believe that the recent dramatic improvement in understanding the molecular physiology of CNS environment and the various barriers that exist on the way of successful protein delivery to the brain will be conductive to future progress. There is growing realization that the $\mathrm{BBB}$, as part of the neurovascular unit (NVU), represents an interactive, dynamic, regulatory interface between the CNS and peripheral tissues [6-15]. It is also clear that various pathological processes associated with neurological and neurodegenerative disorders alter the NVU and cause BBB dysfunction, which brings some opportunities and challenges to the design of protein therapeutics for these disorders. The choice of the routes of administration of these therapeutics is also pivotal and requires consideration of the disease stage (chronic or acute), location within the brain (widespread or local), and chemical nature of the compound to be delivered. We also believe, that there is a great opportunity in using nanomedicine approaches to improve the site-specific delivery and brain regional distribution of proteins administered though non-conventional routes allowing to avoid the BBB. It should be noted that due to small amounts of substances that can enter the brain, robust and reliable bioanalytical assays are needed for the analysis of the pharmacokinetics (PK) and 
biodistribution of the protein therapeutics. Carefully designed PK studies and proper interpretation involving analysis of PK and pharmacodynamics correlations and doseresponses are absolutely essential. Development of animal models that closely recapitulate human diseases and understanding of the limitations of these models are needed to carefully interpret results of the preclinical animal studies and use these results as for guidance for clinical trials. Here we present the readers with this review which briefly and sequentially considers the 1) BBB physiology and pathology in CNS related disorders; 2) main classes of protein and peptide therapeutics for CNS; 3 ) delivery routes for protein therapeutics; 4) chemical modification of proteins for CNS delivery; and 5) particle-based carriers for CNS delivery of proteins. We hope to disseminate and advance an in-depth understanding of each of these strategies and provide useful information for future design of protein delivery to the brain.

\section{BBB physiology and pathology in CNS related disorders}

Discovery of BBB is usually ascribed to the work of Paul Ehrlich and Edwin Goldman over a hundred years ago. They observed that intravenously injected dye stained all the organs with the exception of the brain and that the same dye exclusively stained the brain after injection into the brain $[16,17]$. Thomas Reese and Morris Karnowsky further demonstrated that the blood was separated from the brain at the level of brain microvessel endothelial cells (BMECs). Under high resolution electron microscopy it was shown that intravenously injected horseradish peroxidase (HRP), $43 \mathrm{kDa}$, stained only BMECs and the tight junctions (TJ) between BMECs but was not detectable beyond the vascular endothelium [18, 19]. Accordingly, the physiological BBB generally refers to the continuous layer of BMECs [20] (Figure 1). Different from the capillaries of peripheral tissues, BMECs are sealed by TJ, virtually excluding paracellular transport of any molecule from blood to brain. It is also characterized by 1) small number of vesicles at the luminal side of BMECs, 2) presence of the drug efflux pumps at the basal luminal side, and 3) high metabolic activity responsible for degradation of most internalized substances. Altogether these morphological and functional features result in limited transcytosis and endocytosis and thus explain why BBB acts as a formidable barrier for many substances to enter the brain. Adjacent to the brain capillaries along the basal luminal are perivascular cells (also called pericytes) which are now recognized to play important roles in the regulation of CNS homeostasis, the BBB integrity, the macrophage activity and modulation of blood flow [21]. A thin basement membrane (i.e. basal lamina) supports the abluminal surface of the endothelium surrounding the endothelial cells and pericytes. Another important cell type involved in the BBB function in the brain is astrocytes. One type of brain astrocytes completely envelops BMECs and pericytes with their end feet and this structure initially was thought to play a substantial role by aiding the maintenance of the BBB. However, more recent studies show that astrocytes are more important in the regulation of water and ion homeostasis and secretion of chemokines as a sensor of pathologic changes, which helps modulating the BBB function [22]. Along with adjacent glia and neurons, BMECs, pericytes, and astrocytes comprise NVU, a dynamic cellular interface that defines the functioning of the CNS [23].

Pathology of many neurological disorders, including AD and HIV-associated cognitive dysfunction, as well as stroke, brain tumors, and TBI involves BBB dysfunction (Figure 1) 
[6-15]. Failure of the BBB due to alteration of the TJ in many cases, like stroke or TBI, is a direct result of the disease pathology, while in other cases, like MS, it is a precipitous event of the disease [23]. Sometimes, like in the case of AD the BBB contributes to disease onset and progression and thus itself becomes a therapeutic target [24]. There are reports that the BBB could be compromised and associated with the neuropathology and disease deterioration in LSDs [13]. Disruption of the TJ of the BBB as a result of the diseaseinduced hypoxia has been thoroughly investigated [25, 26]. Disease-induced inflammation also contributes to the alteration of the BBB. Abnormal, monocyte migration across the $\mathrm{BBB}$ to the brain is probably induced by a release of inflammatory cytokines during pathological processes associated with the disease progression [27]. Structural and morphological alterations in the NVU and BBB associated with the disease, such as basal lamina degradation by metalloproteases in hemorrhagic transformation after human ischemic stroke were also described [28, 29]. Likewise, during ALS the BBB impairment was accompanied by a decreased mRNA expression of ZO-1 and occludin as well as agrin, a basal membrane constituent [30]. Disease may also affect functional components of BBB responsible for transport of various substances in and out of the brain. For example, increased number of pinocytic vesicles in the BMECs has been described in certain cases such as AD [31] HIV-related neuropathologies [32], some leukodystrophies [33], and exposure of the brain to microwave radiation [34]. Both down and upregulation of the expression of the P-glycoprotein (Pgp), a major outwardly drug efflux transporter at the luminal membrane of BMECs was observed during brain inflammation, oxidative stress, and HIV-1 infection [35]. In some cases the malfunction of the BBB transport systems is directly linked to the disease cause. For example, in obese patients function of BBB transporter of leptin, a peptide hormone that controls appetite and metabolism, is impaired. Leptin, is produced by fat tissues and reaches its target in the brain by crossing BBB via specific, saturable transport system in healthy individuals [36]. Inability to cross BBB is referred to as leptin resistance and results in metabolic dysfunction, which needs to be overcome to deliver sufficient amount of leptin to the brain [37-40].

Clearly, it is important to recognize and understand the pathological changes of the BBB when designing the delivery system for protein therapeutics to access the brain. However, one cannot simply rely on the breakdown of the BBB. First, not all neurological disorders are characterized by BBB dysfunction. In rat model of parkinsonism no changes in BBB functionality was observed and it was concluded that BBB dysfunction was not a specific characteristic of this disease [41]. Second, even in the cases when the BBB opening as a result of the disease was documented the extent of the opening remains unclear, as different results were obtained using low molecular mass and polymeric probes [42-45]. Third, the timing of the opening and its relation to the disease progression in many cases is not well understood [46-49]. Both the extent of the BBB opening and the timing, may be dependent on the disease progression and the animal model used to study these phenomena. For example, it is well known that the brain tumor vasculature is characterized by altered BBB. However, the nature and extent of these changes is defined by type of tumor. In low-grade astrocytomas barrier properties of tumor endothelium are close to normal, while in highgrade astrocytomas, glioblastomas, and brain metastases of systemic cancers the vasculature is leaky and lacks differentiated transport properties of normal brain endothelium [50]. 
Finally, it is unclear whether the areas of the brain that become accessible due to the BBB breakdown are really in need of delivery of a therapeutic agent, or if the therapies should be delivered to the brain areas, which not affected by the disease pathology to the extent resulting in the BBB compromise.

\section{Main classes of protein and peptide therapeutics for CNS}

Current efforts in development of CNS biotherapeutics have focused on several classes of molecules including gut-brain hormones, lysosomal enzymes, neurotrophic factors, antibodies, and peptides. Some of the proteins and peptides evaluated for various neurological disorder indications in patients or approved for clinical use are listed in Table 1. All these molecules are believed to act upon targets in the CNS, which underscores the importance of their delivery to the brain. One class is gut-brain hormones that are released from the gut and exert their biological function partially or exclusively within the CNS. These hormones along with circulating nutrients and neuronal peptides modulate appetite, feeding and metabolism. Accordingly, they provide a range of therapeutic opportunities for treatment of metabolic disorders (e.g. diabetes, obesity) [76]. All the gut-brain hormones are acidic, less than $5 \mathrm{kDa}$ in size (except for leptin, which is $16 \mathrm{kDa}$ ), they easily degrade and rapidly clear from circulation through renal clearance. As a result they have poor bioavailability after systemic administration, which otherwise would be most convenient and acceptable for these treatment needs (chronic, non-life threatening diseases, multiple dosing, patients self-use). Although hormones with peripheral site of action can certainly benefit from increasing their circulation time, most gut-brain hormones need to cross the BBB to exert physiological effect. In some cases, for example, leptin, the disease condition is associated with the impairment of a normal physiological transport mechanism at the BBB and therefore increasing permeability of such molecules at the BBB becomes crucial to ensure physiological effect $[77,78]$.

Lysosomal enzymes represent another major category of proteins that need to be delivered to the brain for treatment of LSDs that manifest neurological pathologies. There has been considerable success in development of enzyme replacement therapies (ERT) of LSDs with peripheral manifestations, such as type 1 Gaucher disease, Fabry disease, and Pompe disease [79]. For such diseases FDA has approved at least nine systemically administered ERT drugs. However, systemic therapies for LSDs associated with CNS pathologies appear to be less effective possibly due to limited penetration of the potential therapeutic agents at the BBB. Many lysosomal enzymes are homodimeric or heterodimeric glycoproteins of relatively large molecular weight $(>100 \mathrm{kDa})$. Almost all of them are tagged with mannose 6-phosphate (M6P) moieties, which ensure their lysosome sorting in the cells [80]. Unfortunately, the M6P-receptor is not expressed in brain endothelium in physiological conditions and cannot be used to target proteins to the BBB [81-83]. To the contrary, circulating enzymes are readily engulfed by macrophages via M6R receptor and thus are rapidly cleared from the blood [84]. Fast clearance, large molecular weight, hydrophilic nature arising from the attached glycans, and resulting inability to penetrate BBB are all obstacles to effective delivery of lysosomal enzymes to the CNS through systemic routes. Indeed one promising example of ERT for CNS related LSDs, evaluated in clinical trials involves treatment of mucopolysaccharidosis II (MPS II) patients with iduronate-2-sulfatase 
(I2S) through i.t. administration $[60,61]$. Therefore, bypassing the BBB by choosing an appropriate administration route as discussed below could be a valuable approach to delivery of such therapeutic agents.

Neurotrophic factors also known as "neurotrophins" represent family of proteins that are responsible for the growth and survival of developing neurons and the maintenance of mature neurons functionality. Examples include nerve growth factor (NGF), brain-derived neurotrophic factor (BDNF), glial cell-derived neurotrophic factor (GDNF), neurotrophin-3 (NT-3), fibroblast growth factor (FGF) and epidermal growth factor (EGF). These proteins commonly carry a positive charge $(\mathrm{pI}>8)$, have a molecular weight ranging from 5 to 30 $\mathrm{kDa}$ and exhibit potency at femtomolar to nanomolar concentrations [85]. Albeit neurotrophins have long been explored as potential neuroregenerative and neuroprotective therapeutic agents during various CNS-pathologies and some were tested in clinical trials, none of them have emerged as regulatory approved medicines. Interestingly, an active transport mechanism for some of neurotropic factors such as NGF, NGF and NT-3 does exist at the BBB allowing for transport of systemic proteins to the brain $[86,87]$. However, these agents still face multiple challenges to CNS delivery that are common for most CNS therapeutics, including low rapid enzymatic inactivation, multiple clearance processes, sequestration by serum proteins and peripheral tissues, and immunogenicity. Furthermore, there is an additional challenge due to a need of targeting a neurotrophic drug to a brain region relevant to its pathology. Indeed neurotrophin receptors and signaling pathways are spread throughout the brain where they play multiple physiological roles in impacting cell death, plasticity and survival. Thus there is a possibility for off-target effects unless neurotrophins are delivered precisely to their needed sites of action. On the other hand missing the proper point of delivery could result in the lack of the needed activity. Therefore, developing methods allowing for delivery of neurotrophins to specific brain regions is especially important. Examples, include GDNF treatment of PD patients, where a series of clinical trials have shown contradictory or negative effects possibly due to insufficient penetration of this neurotrophin to its site of action $[64,65,88]$ and new delivery methods are designed specifically to address this challenge.

Brain delivery of antibodies is currently mainly investigated for treating AD and brain tumors [89-93]. However, possibilities for antibody-based CNS therapeutics are enormous. A relatively long serum half-life, high potency, and limited off-target toxicity are all very desirable pharmacological advantages of antibodies for developing CNS therapeutics. However, due to a large molecular mass (e.g. $150 \mathrm{kDa}$ for $\mathrm{IgG}$ ), antibodies are generally restricted to extracellular space. Accordingly, whereas bioavailability is a much lesser concern for antibody delivery compared to other proteins, low permeability of antibodies at the BBB is a major issue that has been researched since early 1990s [94]. Some of the approaches to antibody delivery are considered below in Section 5.4, but generally these approaches has not yet not evolved to reach the clinical stage and efficient delivery of the antibodies to the brain remains a major unmet medical need.

"Peptides" are short chains of amino acid monomers linked by amide bonds and are considered here as a separate category due to their relatively small size (less than 20 amino acids and molecular mass less than $5 \mathrm{kDa}$ ) and common lack of secondary structure. They 
can function as receptor agonists or antagonists by activating or blocking central signaling pathways, and depending on the structure, can be used in treatment of numerous CNS related disorders, such as, schizophrenia, anxiety, depression, autism and others. Therapeutic peptides offer multiple advantages compared to small molecules: high specificity and potency, minimal cross-reactivity, no tissue accumulation, efficient metabolism, limited drug-drug interaction, minimal side effects and low immunogenicity. However, similar to most proteins, peptides exhibit very short serum half-life (min. to hrs.), low serum stability and poor permeability at the BBB, which hinder therapeutic use of these molecules for treatment of CNS disorders. Attempts to address these issues have involved various manipulations with the conformation and molecular structure of peptides as reviewed elsewhere [95]. Moreover, unlike most proteins discussed herein some especially lipophilic and short sequence peptides, are substrates of drug efflux transport system, Pgp overexpressed at the BBB [96]. Therefore bypassing or inhibiting this transport system is important for the successful delivery of such molecules.

Outside of the scope of this review are synthetic peptides and proteins used in vaccination, some of which have shown considerable promise in treating CNS related diseases. For example, a therapeutic vaccine, CDX-110 consisting of 14 amino acid peptide, rindopepimut conjugated to immunostimulator molecule, keyhole limpet hemocyanin (KLH) can activate anti-tumor immune response by targeting tumor-specific epidermal growth factor receptor, EGF receptor (EGFR) vIII. Both preclinical and clinical studies demonstrated that following intradermal injection, CDX-110 is effective in treating glioblastoma multiforme, the deadliest form of brain cancer [97, 98]. Another therapeutic vaccine PD01A, designed to target the alpha-synuclein tangles, an aggregated protein associated with pathological cell death in PD, has entered phase I trials [99, 100]. Extensive studies have shown potential of passive and active immunization for the treatment of $\operatorname{AD}[92,93]$. However, peptide or protein vaccines usually target the peripheral immune system rather than the brain. Therefore, successes in these vaccines development depend on different set of factors than those defining successes of CNS therapeutics. Hence we will not refer to vaccines in the context of our further consideration.

\section{Delivery routes for protein therapeutics}

The path of a therapeutic agent to its target organ and tissue begins at the site where the molecule is given to the body. Most current protein therapeutics including FDA approved products (e.g., antibodies and hormones) are administered by parenteral injection into fat tissue (subcutaneous, (s.c.)), muscles (intramuscular, (i.m.)) or veins (intravenous, (i.v.)). In few cases enteral and pulmonary routes were also explored to deliver protein therapeutics that require frequent dosing to attain the therapeutic window [101-103]. For example, oral delivery, one of the most convenient and least expensive enteral administration routes is used for non-CNS targeted therapeutic polypeptides such as insulin, calcitonin, interferons and human growth hormone [104]. Thee oral bioavailability of polypeptides can be further increased by their encapsulation into liposomes or nanoparticles or/and using permeation enhancers [105-108]. However, the oral route is nearly impossible for CNS therapeutics, because of the presence of two formidable barriers - the gastrointestinal lumen and BBB. 
Early approaches to delivery of protein therapeutics to CNS mainly focused on traditional parenteral injection routes - i.v., i.m. and s.c. In addition, there is a long history of using the central administration routes, i.c.v. and intraparenchymal, that bypass the BBB to deliver proteins to CNS, in particular, during life-threatening conditions (Figure 2). More recently, a non-invasive administration at the nasal cavity has attracted considerable attention and shown promise in delivery of therapeutics to the brain. Another way to bypass the BBB during delivery of therapeutics is to use i.t. route, an approach that has attracted attention in treatment of CNS disorders because of its relatively low invasiveness compared to the central administration. A comprehensive description and consideration of the administration routes is beyond the scope of the current review. However, it is useful to describe some general principles of these routes to determine potential opportunities and challenges for delivery of protein therapeutics to the CNS.

\subsection{Parenteral administration}

The substance delivered by traditional parenteral injection (i.v., i.m., or s.c.) can directly access systemic veins by bypassing the portal veins and hepatic first-pass elimination and ultimately be distributed to the whole body including the brain through the vascular system. A unique advantage of the systemic vascular route is the presence of the dense network of brain capillaries. These capillaries theoretically can allow for an instantaneous and even distribution of a therapeutic agent to the closest surrounding cells of the brain, which could be of great benefit for the treatment of CNS disorders that display widespread pathology or have unknown location in the brain. Evidently, an effective treatment using parenteral route relies on the ability to deliver effective amount of a therapeutic agent from the blood to the brain disease sites. This is often challenged by poor serum bioavailability of a therapeutic agent (rapid serum clearance, binding to serum proteins, degradation, and tissue distribution) and the existence of the BBB. Finally, the bioavailability of a therapeutic agent in the brain interstitial fluid is affected by the clearance of this agent from the cerebrospinal fluid (CSF) and degradation of this agent in extracellular space (ECS). All these factors collectively contribute to the actual concentration of therapeutics within the brain and a delivery system needs to be designed to maximize the efficiency at each step.

Notably, certain macromolecules that can circulate long in the blood and remain stable in circulation were detected in the brain in spite of their poor penetration at the BBB. For example, albumin, a BBB impermeable molecule, was detected in CSF at CSF/serum ratio of $0.5 \%$ [109]. The antibodies against amyloid $\beta(\mathrm{A} \beta)$ protein and erythropoietin both having long half-life in the blood, were shown to reach the brain at sufficient amounts to be effective in brain disease models [110-114]. The entry of these molecules to the brain is believed to be associated with an extracellular pathway due to the functional leakiness of the BBB, which could occur at a number of sites within the CNS, including the circumventricular organs, the arachnoid space/pial surface and the nasal epithelium [115, 116]. This extracellular pathway at BBB can be described by a nonsaturable and dosedependent uptake mechanism at least in the case of IgG [117]. Protein therapeutics candidates may enter the brain using similar mechanisms. The good candidates for this route are the molecules characterized by a small volume of distribution, high potency in the CNS, and absence of brain-to-blood efflux that could efficiently decrease their brain 
concentration. For example, an i.v. infusion of a high dose of recombinant human $\beta$ glucuronidase over long duration resulted in a brain uptake of this protein accompanied by reduction in toxic substrate storage in central neuronal lysosomes in a mucopolysaccharidosis VII mouse model [118]. Various methods were developed to increase serum bioavailability of proteins, such as their conjugation with hydrophilic polymers like PEG (PEGylation), or encapsulation of in micro- and nano-size particles [2, 119]. From a delivery viewpoint, these methods can increase the blood circulation time and serum stability of the delivered proteins. Accordingly, they could be benefit CNS delivery of proteins provided that the delivered materials 1) can still exploit the extracellular pathways, and 2) remain active in the CNS (or in the case of the nanocarriers are released into the brain). The key issue, however, is that diffusion of serum macromolecules to the brain via extracellular pathways is severely limited. Even in most pathological conditions that may be associated with some leakiness and/or "opening" of the BBB these pathways are not sufficient to secure a robust pharmacodynamic response. Therefore, in most cases, increasing transcellular permeability at the BBB is critical to overall improvement of the parenteral delivery and efficacy of a biotherapeutic agent in the CNS.

Relatively little attention was devoted to improving the bioavailability of therapeutic agents in the brain. It is probably true that the molecules with increased serum bioavailability would also be better preserved in brain interstitium and ECS. However, it is not clear whether a delivery system that improves peripheral bioavailability of therapeutics also remains intact after crossing the BBB. Justin Hanes's laboratory has recently reported that densely coated PEG nanoparticles over $100 \mathrm{~nm}$ can diffuse in brain parenchyma ECS [120]. This suggests at least a theoretical possibility of designing a nanoscale size delivery system that after crossing the BBB can continue its journey through ECS to the target cell within the brain.

\subsection{Inctracerebroventricular infusion}

The administration of proteins through i.c.v infusion allows these proteins to bypass the $\mathrm{BBB}$, directly enter the lateral ventricles and circulate within the ventricular and extraventricular CSF. However, the clinical trials of i.c.v protein therapeutics have been rather disappointing. For example, in one trial the NGF was given i.c.v. to $3 \mathrm{AD}$ patients [62]. Three months after this treatment a significant increase in nicotine binding in several brain areas in the first 2 patients and in the hippocampus in the third patient were observed. However, a clear cognitive amelioration could not be demonstrated. Moreover, the treatment resulted in significant adverse effects such as back pain and body weight loss, which strongly diminished enthusiasm about the potential of this treatment $[62,121]$. In another clinical trial the GDNF was administered i.c.v. to PD patients [88]. This treatment did not result in any positive response, although no significant side effects were observed either. Subsequent trials of GDNF in PD patients also produced contradictory results. For example, a multicenter, randomized, double blind, placebo-controlled study on 16 subjects concluded that GDNF administered by i.c.v. injection was biologically active as evidenced by the spectrum of adverse effects encountered in this study [63]. However, GDNF did not improve parkinsonism, possibly because the protein did not reach the target tissue - substantia nigra pars compacta. Likewise, a clinical trial of i.c.v enzyme replacement therapy for central 
lysosome storage disease in Tay-Sachs patients also failed [58]. No improvement was observed in patients receiving i.c.v. $\beta$-hexaminidase, an enzyme that depletes lysosome storage of GM2 ganglioside [58].

From the delivery standpoint a key challenge for the i.c.v. route is the ependymal lining, which albeit is less restrictive than the BBB still acts as a significant barrier at the ventricle surface hindering the diffusion of substances from CSF into brain parenchyma [122]. Indeed, the brain section of animals receiving i.c.v infusion of basic FGF (bFGF) and BDNF both confirmed that the compounds were distributed only at the ventricle surface with minimal amounts detected in deep brain parenchyma [123-125]. The limited brain uptake following i.c.v. administration could be further compounded by a rapid turnover of therapeutic agents from CSF to systemic circulation, their degradation in ECS, their slow diffusion within brain interstitial fluid and their sequestration by brain tissues (e.g. ependymal, pial and glial cells) [125]. Based on the experience with i.c.v. administration of native forms of proteins one could suggest that incorporating proteins and other therapeutic molecules in suitable delivery systems is perhaps a necessity for future development of drugs using this route. An optimal delivery system would need to display permeability at the ependymal layer, efficient diffusion in brain interstitial fluid and improve bioavailability of the delivered agent within the CSF.

\subsection{Intraparenchymal injection and implantation}

Proteins can be directly administered into brain parenchyma via intraparenchymal injection or implantation. This invasive central route allows bypassing both the BBB and the ependyma lining barrier at the ventricular surface. However, due to limited diffusion in brain interstitial fluid biotherapeutic molecules often locally spread in an area not more than about $2 \mathrm{~mm}$ from the site of intraparenchymal injection [123, 126]. The majority of injected substance was then eliminated from the CNS interstitial fluid [127]. For more than a decade, convection-enhanced delivery (CED) has been used to improve the locoregional concentration of substances within brain interstitium by stereotactically placing catheters to deliver a bulk flow upon gradient pressure. The detailed evolution of this technology and the main issues that need be addressed for its further successful development are reviewed elsewhere [128-130]. Although initial animal studies showed that CED of transferrin in brain white matter produced a homogenous penetration in gray matter after $24 \mathrm{hr}$. infusion [128], CED of protein therapeutics in clinical trials has not been encouraging in most cases. CED of recombinant human GDNF failed to confer clinical benefit to a trial involving 34 PD patients [64]. In this trial GDNF (called "liatermin") was continuously infused directly in the putamen (ipu). The failure of this trial, as suggested by studies of CED of GDNF in primates, might have been related to the extremely high concentration of GDNF around the catheter tip and limited diffusion into surrounding brain parenchyma which resulted in a very limited drug bioavailability $[65,131]$. The inconsistent results of clinical studies had decreased enthusiasm about using GNDF for PD treatment with no new trials being reported for several years. However, recently British scientists developed a brain implant device that allows GDNF be given more reliably in the putamen area of the brain. Recruitment for the clinical trial in PD patients using this delivery strategy for GDNF is currently open (UKCRN ID 12085). An early clinical trial involving CED of antibody against EGFR to 
malignant glioblastoma patients was not completed because of severe inflammatory reaction prior to tumor debulking [132]. Interestingly, CED of enzyme replacement therapy showed some consistency between preclinical study and clinical trial and appeared to be more successful. Thus CED of glucocerebrosidase to rat and primate brains showed wide enzyme distribution in various brain regions [133]. The CED of this enzyme to neuronopathic Gaucher's patient followed by i.v. enzyme therapy prevented the deterioration in seizures and cranial nerve deficits while showing no clinical signs of toxicity [133]. The variations in the outcomes of CED clinical trials seem to suggest that the slow diffusion still might be a barrier for certain molecules. Moreover, one should carefully examine the surgery or drug associated toxicity arising from this invasive regimen. Nevertheless, radiolabeled antibody ${ }^{124} \mathrm{I}-8 \mathrm{H} 9$ is currently undergoing clinical trials for treatment of brain cancers using CED $[68,69]$. This is the first time that CED of therapeutic protein targets into the tumor of brain stem aiming to treat patients with diffuse intrinsic pontine glioma. In parallel, there has been a major effort in developing polymer-based nanoparticles and matrices (e.g. liposome, dendrimer, polystyrene nanospheres, maghemite nanoparticles and other lipid nanoparticles) that can be used as implants to produce a sustained release of a substance in localized areas within the brain interstitium [134]. Most of these studies, however, focus on development of small molecule drugs in preclinical or clinical study for treatment or diagnosis of brain tumors.

\subsection{Intranasal administration}

Different from traditional nasal spray that is administered in the vicinity of the turbinates and thus distributes through the systemic circulation, administration at the level of nasal cribriform plate allows substances to bypass the BBB and directly enter the brain with minimum serum exposure. This administration procedure, known as intranasal-to-brain (INB), is more patient friendly compared to other approaches and importantly allows to avoid the BBB, serum clearance and peripheral metabolism. The INB administered proteins have reduced systemic side effects and display rapid central action onset. The olfactory nerve originates in the olfactory mucosa in the anterosuperior nasal cavity and then travels down the olfactory tract until it reaches the olfactory bulb, where the fascicles of the olfactory nerve pass through the cribriform plate, a perforated bone in the base of the skull, into the highest reaches of the nasal cavity. Three known pathways conduct substances across the cribriform plate into the CNS [135]: i) diffusion through the CSF and brain interstitial fluid; ii) retrograde transmission via the olfactory nerves to the olfactory bulb; and iii) retrograde transmission via the trigeminal nerve to the trigeminal nuclei. Growing preclinical evidence suggests that various protein molecules including neurotrophic factors, hormones, antibody fragments, and peptides can reach the brain via INB route in adequate amounts to be effective in the animal models [136-139]. Moreover, several intranasal therapeutics tested in clinical trials (e.g., cholecystokinin [140], corticotrophin-releasing hormone [141] and insulin [142]) elicited measurable central responses. For example, nasal insulin has profoundly improved memory in AD patients [56]. Small peptides, such as antidiuretic hormone arginine-vasopressin $(1.1 \mathrm{kDa})$ and neurohypophysial hormone oxytocin (1 kDa) have shown significant promise as nasal spray products [143-149]. Further, intranasal arginine-vasopressin was detected in human lumbar CSF and shown to increase brain electrical response to various stimuli $[150,151]$. 
At the same time, there are conflicting reports about the advantage of INB route over traditional routes (i.v., s.c. and i.m.) in efficiency of delivering polypeptides to the brain. Clinical trial of intranasal peptide $\mathrm{YY}_{3-36}$ (PYY) dosed at $600 \mu \mathrm{g}$ for 12 weeks failed to induce weight loss in obese patients and furthermore, significant nausea and vomiting were observed in some cases [57]. In animal studies comparable and low levels of brain accumulation were reported after INB and i.v. administration of an agonist of the glucagonlike peptide 1 (GLP-1) receptor, exendin-4 [152]. Therefore, to attain brain concentrations within the therapeutic window, multiple i.n. dosing of therapeutic peptides is required. For example, daily intranasal administration over 10 days of a $16-\mathrm{kDa}$ adipose-derived hormone, leptin reduced the body weight of diet-induced obese mice [153]. It should be also noted that the brain region distribution patterns after i.n. administration vary from substance to substance, suggesting that there might be different mechanisms and pathways involved in the delivery of these substances. In some cases, the INB administered drug is taken up in a brain region irrelevant to the biological target of this drug. For example, interferon $\beta$ - $1 \mathrm{~b}$ after intranasal administration in rats accumulated in both in CNS as well cervical lymph nodes [154]. Accordingly, there is a need to focus on brain regional distribution of INBadministered therapeutic agents and analyzing their pharmacodynamic responses. In some cases, there might be a possibility to control the brain regional distribution of peptides after their INB delivery. For example, pituitary adenylate cyclase activating polypeptide (PACAP) after i.n. administration in mice exhibited the highest uptake in the striatum and occipital cortex, but combining this polypeptide with $\beta$-cyclodextrin increased its uptake in hypothalamus by 8 -fold and hippocampus by 2 -fold [155].

The unique factors hindering the brain bioavailability of substances administered via the INB route are likely to include the presence of the nasal epithelium barrier, fast clearance of solutes in CSF, and limited penetration at the neuronal pathways. Overcoming the barriers behind nasal epithelium and targeting the delivery-relevant brain regions is of great importance for developing nasal protein therapeutics. Currently most therapeutic agents administered via INB route are formulated with excipients that act either as permeation enhancers at the olfactory epithelium or mucoadhesives to extend residence time in the nasal cavity. In some cases, vasoconstrictors are also co-administrated to limit the absorption of the therapeutics by non-olfactory epithelium into the systemic circulation. However, the use of drug delivery systems to improve CNS delivery of proteins after INB administration is relatively poorly explored. Nevertheless, some studies have shown that delivery systems could play significant role in this route. For example, the intranasal delivery of albumin to brain was shown to increase after albumin encapsulation in liposomes [156]. Another example is HRP, a hydrophilic and BBB impermeable enzyme, that most likely crosses the cribriform plate by leaking through the intercellular space of nasal epithelium and then distributes within the brain by diffusion through CSF [116]. Modification of HRP by wheat germ agglutinin has increased the HRP adsorptive endocytosis at both nasal epithelium and olfactory neurons and therefore the trafficking of modified HRP to brain regions is likely to involve the olfactory and trigeminal nerve pathways $[157,158]$. Our unpublished data also showed that modification of leptin with amphiphilic block copolymers increased overall brain uptake of intranasal leptin and importantly improved leptin targeting to hypothalamus, the site where leptin controls appetite. Overall, there is a potential of improving CNS 
delivery of INB administered protein therapeutics by using drug delivery strategies including these discussed below. The unmet need to treat CNS related disorders hopefully will push forward the studies in this direction.

\subsection{Intrathecal administration}

Therapeutic agents can be injected into the subarachnoid space of the spinal cord allowing them to bypass the BBB and access the brain. This approach known as i.t. administration goes back to the pioneering work of J. Corning who injected cocaine in the lower lumbar vertebrae for the purpose of local spinal anesthesia [159]. Subsequently, it was established as a clinical procedure for administration of drugs with main indications for anesthesia and pain management. Its least invasive and clinically feasible modes include 1) injecting a substance at the lumbar region through lumbar puncture to evoke an acute postoperative response or 2) using a slow infusion device for maintenance of a sustained effect required for chronic management. I.t. administration of protein therapeutics for treatment of CNS related disorders was also explored both in pre-clinical studies and clinical studies. For instance, an antibody against Fas ligand was administered i.t. to treat the acute phase of multiple sclerosis in a mouse model of experimental autoimmune encephalomyelitis (EAE). Notably, this antibody was more potent in blocking Fas-mediated tissue injury and suppressing EAE progression after i.t. administration ( $20 \mu \mathrm{g} / \mathrm{day}$ for 3 days) than when it was given i.p. (200 $\mu \mathrm{g} / \mathrm{day}$ for 3 days) [160]. Another study, however, reported a negligible effect of i.t. infusion of NGF (125 ng/h for 7 days) in a rat model of neuropathic pain [161]. According to a more recent report a $20 \mathrm{kDa}$ glycoprotein, sonic hedgehog (Shh) exhibited neuroprotective effect after i.t. administration in a rat model of ischemic stroke at a dose of $150 \mu \mathrm{g}$ [162]. More recently, using position emission tomography (PET) five more proteins were shown to rapidly distribute to brain parenchyma after i.t. administration in animal models $[61,163]$. Clinical studies reported include BDNF given i.t. to amyotrophic lateral sclerosis patients at five different dose levels starting from $25 \mu \mathrm{g} /$ day for 12 weeks [164]. Although no efficacy was proven in this study, a notable amount of BDNF was detected in the CSF of patients between day 11 and week 24 of treatment even at the lowest dose applied [164].

As of today, perhaps the most successful example of i.t. application of protein therapeutics for CNS related disorders involves ERT for lysosome storage diseases [61, 165-168]. For example, a-L-iduronidase (rhIDU), an enzyme deficient in mucopolysaccharidosis I (MPS I) was i.t. administered in MPS I model in dogs [168]. The deep penetration of the enzyme into brain regions was shown. Moreover, four weekly i.t. doses of $\sim 1 \mathrm{mg}$ rhIDU produced profound amelioration of the MPS I symptoms. Another study further supported the use of i.t. route over i.c.v. or i.v. routes using I2S, an enzyme deficient in MPS II lysosome storage disease [61]. Intralumbar injection of I2S in monkeys produced nearly same levels of the enzyme in the brain gray matter $4 \mathrm{hr}$. after treatment as did the i.c.v. injection and over 100time higher levels than those observed after i.v. administration of this enzyme [61]. Moreover, i.t. I2S treatment has effectively reversed the brain pathology after 3 injections at a dose of $250 \mu \mathrm{g}$ in a mouse model of MPS II [61]. These efforts have provided momentum towards the clinical use of i.t. I2S in the treatment of MPS II disorder [60]. 
The physiology and mechanisms underlying the i.t. delivery of macromolecules to the CNS have been discussed elsewhere [169]. Briefly, the transport of solutes from the site of i.t. injection to the brain parenchyma includes 1) initial spread and diffusion in the CSF that is likely driven by pulsatile remixing; 2) clearance through drainage of the CSF; 3) active and pulsation-assisted translocation of remaining substance into the perivascular space; and 4) transfer to brain parenchyma. The latter may involve various mechanisms including penetration at the glia limitans and pial cells, convective transport ("bulk flow"), and anterograde axonal transport. Current data suggest that the location and volume of the administered bolus are the most important factors in the initial spread of therapeutic substance in the CSF after i.t. administration. The subsequent processes, however, are less understood. Although very little is known about immunogenicity of i.t. proteins, one study reported a dose-dependent immune response and a meningeal lymphocytic infiltrate in the dogs that received i.t. administration of rhIDU [168].

Little work was done using drug delivery systems to improve the outcomes of the i.t. administration of therapeutic agents. However, one can expect that nanomedicine strategies can address some common problems of protein therapeutics delivery using this route, such as poor stability of proteins in the CSF and perivascular space, limited permeability of proteins from the perivascular space into the brain and protein immunogenicity. For example, PEGylation of IL-10 increased the CSF concentration of this protein as well as the level and duration of the therapeutic response after i.t. administration of this protein in an animal model of neuropathic pain [170]. Additionally, a use of delivery systems might be worth exploring to improve permeation of i.t. administered proteins.

Overall, the choice of the administration routes for the CNS therapeutics is most challenging due to the restricted anatomical access to the CNS, and the complicated CNS environment. There is no doubt that this choice must account for the efficacy, safety, disease stage (chronic and acute) and patient concerns (convenience and cost). Therefore, during development of new CNS therapeutics, in particular, protein therapeutics, selecting the optimal administration route and the delivery strategy specific for this route is essential and accounts for the success, perhaps, no less than identifying the proper therapeutic target.

\section{Chemical modification of proteins for CNS delivery}

To date some of the most extensive studies to increase protein permeability at the BBB have involved protein chemical modification with various strategies such as a) cationization, b) fusion with cell-penetrating peptides (CPPs), c) fatty acid acylation, d) conjugation with brain targeting ligands, and e) modification with polymers (Figure 3). Notably, the protein modification points, linkers, modification degree and the conjugation chemistry are all important design considerations having a dramatic impact on the properties of resulting conjugates and their in vivo performance. Generally, lysine residues of a protein serve as common modification points. Other site-specific chemistries involve protein $\mathrm{N}$ - and Cterminus modifications and disulfide bridge insertion [171-180]. Modification of a protein with CPPs and brain targeting ligands can be also accomplished by genetic engineering. The linker in such fusion proteins need be designed in such a way that it allows the independent folding of each protein and also enables release of the two separate proteins if needed. 
However, detailed consideration of these design factors is outside of the scope of this review. Below we present the different chemical modification strategies and assess their state of development and promise for future pharmaceutical use. The representative examples of these strategies and some principal observations are presented in Table 2.

\subsection{Cationization}

A simplest way to cationize a protein is to chemically modify its carboxylic acid groups with synthetic (e.g. hexamethylenediamine) or natural amines (e.g. putrescine, spermidine and spermine). In an early study Pardridge and co-workers modified native albumin (pI 4) with hexamethylenediamine and produced a cationized albumin ( $\mathrm{pI}>8$ ). They demonstrated that $\beta$-endorphin, a BBB impermeable peptide, after conjugation with such cationized albumin was rapidly taken up by isolated brain capillaries in vitro in a temperature dependent manner. Moreover, the autoradiography data showed that the conjugate crossed the capillaries and distributed in the brain parenchyma following intracarotid injection in rats [181, 182]. An increase in the brain uptake was also observed for cationized IgG (an increase in $\mathrm{pI}$ from 5-6 to >10) in both in vitro and in vivo [183]. Both studies reported that the uptake of cationized proteins in the brain was saturable. Even though the assessment of BBB function was not a part of this study, authors claimed that the increase in brain uptake was not related to the breakdown of the BBB [183]. Subsequently, Poduslo and colleagues demonstrated ability of several cationized proteins (e.g. superoxide dismutase (SOD), insulin, albumin, $\operatorname{IgG}$ and neurotrophic factors) to cross the BBB without disrupting its integrity $[184,185]$. In these studies the permeability of the cationized proteins at the BBB after i.v. administration was assessed by calculating the permeability coefficient times surface area (PS), a reliable PK measure of brain entry. Moreover, the lack of the BBB leakiness was unequivocally proven by little or no change in the volume distribution of a native protein co-injected with the cationized protein [184, 185].

Some therapeutic or disease relevant effects of cationized proteins in animal models were also reported. For example, systemic administration of a putrescine-modified SOD resulted in neuroprotective effects in rats with global cerebral ischemia [186]. The diamine- and gadolinium-derivative of human $\mathrm{A} \beta$ peptide was shown to have enhanced in vitro binding to $\mathrm{AD}$ amyloid plaques and increased in vivo permeability at the $\mathrm{BBB}$ of normal adult mice. Specific targeting of the modified $\mathrm{A} \beta$ peptide to amyloid plaques in the brain was also demonstrated in a transgenic mouse model of AD [187].

It was suggested that cationization increases permeability at the BBB by promoting interaction and transcytosis of the protein across the BMECs. However, the exact mechanisms remained unclear since permeability did not directly correlate with the number of positive charges of the polyamines in the cationized protein [184, 188]. Along with an increased BBB permeability cationization also resulted in undesirable consequences such as an increase in the serum clearance of the protein. For example, when was modified by polyamine, its plasma half-life time dramatically decreased from $3 \mathrm{~min}$ to about $0.6 \mathrm{~min}$ [184]. Similar effects were observed for cationized IgG, albumin and insulin [184]. The decreased half-life could offset improved BBB permeability of the cationized proteins and decrease their net brain accumulation especially for proteins having intrinsically rapid blood 
clearance. Moreover, despite that cationization was not reported to disrupt BBB in these studies, concerns about dose-limited toxicity of cationic substances persist. In particular, although low doses of cationized IgG used in PK studies ware safe for peripheral organs and brain capillaries [183], considerable toxicities (immune complex formation, membranous nephropathy) were observed after injecting therapeutically relevant doses to rabbits [189, 190]. Likewise, administration of high dose of protamine alone also resulted in an increased cerebral and peripheral vascular permeability [191-194]. Thus potential toxicity of cationized proteins and the resulting limitations to the therapeutic window of possible therapeutic agents are the main factors that have limited the development of this technology for the clinical use.

\subsection{Protein fusion with CPPs}

Modification with CPPs is yet another approach to improve brain delivery. Examples of CPPs derived from natural proteins are trans-activating transcriptional activator (TAT), penetratin, and the Syn-B vectors. Other CPPs homoarginine vectors, the model amphipathic peptide, transportan and chimeric peptides (sequence signal-based peptide and fusion sequence-based peptide) are engineered artificially. Heterogeneous in size (10-27 amino acids) and sequence, all CPPs are comprised of basic amino acids and are cationic. Translocation of CPPs through cell membrane may occur by passive diffusion. Alternatively, CPPs can destabilize the phospholipid bilayer and form inverted micelles that enable entry of CPP and its attachment, e.g. proteins into cells without leaving an aqueous environment [195-198]. More detailed description of the CPP internalization mechanisms, and other properties such as stability, toxicity and immunogenicity were reviewed elsewhere [199]. Here we focus on use of CPPs for delivery of proteins to CNS.

Schwarze and colleagues published a seminal work demonstrating ability of CPP to deliver proteins across $\mathrm{BBB}$ [200]. In their study the $\mathrm{NH}_{2}$-terminal TAT (47-57)-galactosidase fusion protein $(120 \mathrm{kDa})$ injected i.p. in mice was detected by immunochemical staining initially at $2 \mathrm{hr}$ in brain microvessels and then at $4-8 \mathrm{hr}$ in brain parenchyma. No PK studies were performed. Nevertheless galactosidase activity was visualized in sagittal and coronal brain sections as well as in liver, kidney, lung and heart (myocardium) and spleen. TAT did not appear to disrupt BBB as the Evan's blue albumin complexes co-injected with TAT were excluded from the brain tissues. Subsequently, TAT peptide was fused with GDNF and injected i.p. in a mouse model of PD. The fusion protein crossed the BBB and reached substantia nigra as was shown by immunohistochemical staining. However, the treatment did not prevent the loss of dopaminergic neurons in PD mice, possibly because the amount of the fusion protein delivered to the target site was not sufficient [201]. A TAT-based system was also used to deliver Bcl-xL protein, a well-characterized death-suppression molecule, to the CNS for treatment of stroke. Intraperitoneal injection of TAT and Bcl-xL fusion protein resulted in a robust protein transduction in neurons, and a dose-dependent decrease of cerebral infarction in a mouse middle cerebral artery occlusion (MCAO) model of ischemic stroke [202]. Similarly, a reduced infarct volume and neurological deficits were observed after i.v. injection of TAT-Bcl-xL fusion protein $1 \mathrm{hr}$. before or immediately after the ischemia induced in a rat MCAO model [203]. A recent study reported that TAT-leptin fusion protein was i.v. injected to mice fed with high-fat diet. Immunohistochemical staining 
suggested increase in leptin accumulation in hypothalamus in the TAT-leptin treated mice, compared to the unmodified leptin or saline-treated animals. Importantly, TAT-leptin also prevented body-weight gain more efficiently compared to leptin [204]. Cai et al. recently described positive effects of TAT-mediated delivery of neuroglobin $(\mathrm{Ngb})$ on focal cerebral ischemia outcome in mice [205]. After i.v. injection the TAT-Ngb fusion protein was detected in mice brain tissues by immunohistochemistry and western blotting. The group treated with TAT-Ngb $2 \mathrm{hr}$. before MCAO showed smaller brain infarct volume and improved neurologic outcomes compared to the control groups. Moreover, the group treated with TAT-Ngb after MCAO and reperfusion showed significantly increased neuronal survival in the striatum, compared to the controls [205].

Besides TAT some other CPPs, such as Syn-B vectors and Rabies virus glycoproteinderived peptide (RDP), were also shown to deliver small molecules and proteins across BBB [206, 207]. For example, Xiang et al reported efficient hippocampus targeting by a $\beta$ galactosidase-RDP fusion protein [206]. Interestingly, a simple mixing of a protein with $\mathrm{CPP}$ also improved delivery of multiple proteins such as $\beta$-galactosidase, human IgG and IgM to mouse brain [208].

However, CPP have displayed various toxicities including neurotoxicity, endothelial cell apoptosis and inflammation [199], which decreased likelihood of their translation to clinic use. Another obstacle to future product development is a non-specific penetration of CPPmodified proteins into peripheral tissues. Thus a case-by-case preclinical toxicology study accounting for stability, efficacy and safety must be performed to evaluate further possibilities of using this technology for specific CNS therapeutic application.

\subsection{Fatty acid acylation}

Early work by Chekhonin and Kabanov described protein modification with fatty acids for brain delivery [209]. For example, a neuroleptic drug (trifluoperazine) was attached to Fabfragments of antibodies against gliofibrillar acid protein (GFAP) or brain specific a2glycoprotein (a2-GP). The drug-Fab conjugates were then modified with stearate in reverse micelle system formed by a surfactant, sodium bis-(2-ethylhexyl)sulfosucciate (Aerosol OT) in octane. Stearoylated Fab fragments of brain-specific antibody exhibited brain accumulation and a drastic increase in neuroleptic activity of trifluoperazine following intracoratid injection into rats. In contrast, fatty acylated Fab fragments of nonspecific antibodies accumulated in the liver rather in the brain [209]. Subsequent studies using BMECs as an in vitro BBB model demonstrated that stearoylation of ribonuclease A increased the transport of this enzyme across the BBB by almost 9-fold [210]. In another study Slepnev and colleagues used a membrane-impermeable enzyme, HRP as a model protein to examine effects of stearoylation of the protein on its interaction with cells [211]. This work demonstrated that stearoylation increased binding and internalization of HRP in mammalian cells, albeit the internalized protein accumulated in endocytic vesicles but not in the cytoplasm [211]. Notably, the stearoylated HRP displayed much greater binding with a hepatic cell line than with epithelial cells, which could be due to the presence of the fatty acid binding receptor in hepatocytes. Subsequent PK study from Kabanov and Banks' laboratory demonstrated that after i.v. injection stearoylated HRP was able to cross mouse 
BBB at a higher influx rate than the native HRP [212]. This work also reported about 13\% increases in brain uptake of stearoylated HRP over $200 \mathrm{~min}$ as compared to native HRP. The volume of distribution of fatty acylated HRP also increased due to its non-specific distribution in liver and other organs [212]. Shen and colleagues reported that palmitoyl residue conjugation through a disulfide linker to interferon a enhanced its circulation and liver accumulation; the effect of palmitoylation on brain uptake of interferon a was not reported [213].

Overall fatty acylation is likely to result in the increased binding of proteins to brain microvessel endothelial cell membranes through hydrophobic interactions of the attached lipid anchor with the membrane bilayer [212]. In addition many other factors can contribute to delivery of proteins following lipidization. Cellular binding might be further increased when the modified protein itself contains a polybasic motif which in addition to lipid carrier serves an anchor for interaction with cell membrane [214]. A transporter-mediated mechanism might come in play when proteins are modified with essential fatty acids, such as linoleic acid, which is naturally transferred to the brain by transporters [215, 216]. Other factors including plasma protein binding, intracellular sequestration, non-target organ uptake can contribute to plasma PK and biodistribution and should be taken into account when developing CNS targeted therapeutics using this approach.

As of today perhaps the most advanced application of fatty acylated proteins is the development of long-acting anti-obese hormones that originate from the gut-intestine tissue and act partially or exclusively within the CNS to control appetite and energy consumption. Interestingly, fatty acylation of gut-brain hormones is a naturally occurring phenomenon. In fact, the octanoic acid acylated ghrelin acts as an important cognate ligand to stimulate growth hormone release and regulate energy hemostasis [217]. Post-translational O-noctanoylation of ghrelin at the serine 3 position is indispensible to the hormone binding to and activation of the growth-hormone secretagogue receptor [218, 219]. The brain PK study did show that octanoylation of ghrelin has a dramatic effect on its transport characteristics across the BBB [220]. Another example is liraglutide, a GLP-1 analog modified with a C16 fatty acid chain that is currently being tested in Phase III clinical trial as an anti-obesity drug [221-224]. This modified peptide analog displays notable improvement in its PK profile (longer circulation, smaller volume of distribution), and can be used once a day to replace exenatide (a native form of GLP-1) given twice daily. Interestingly, GLP-1 as well as many other gut-brain hormones control appetite and thermogenesis at two sites: peripherally by signaling the vagus nerve surrounding gut-intestine and centrally acting at the receptor in the brain. However, in spite of improvement in the hormone's peripheral circulation, no brain PK data were reported to support the role of fatty acylation to increase GLP-1 brain uptake. Further discussion of the application of the fatty acylation for development of gut-brain hormone therapeutics can be found elsewhere [225].

\subsection{Conjugation with brain-targeting ligands}

To maintain homeostatic environment of CNS brain endothelial cells express a variety of receptors and transporters that mediate blood-to-brain transcytosis of hormones, transport proteins and other essential substances including insulin, growth factors, low-density 
lipoprotein (LDL), amino acids, and glucose. Low molecular mass drugs or polypeptides can be designed to closely resemble endogenous ligands of these receptors. Conjugation of such artificial ligands to polypeptides (as well as other biomacromolecules) can improve delivery of these molecules to the brain [226-228]. Such brain delivery strategy is frequently referred to as "Trojan horse". This strategy has a few well-known caveats. First, the ligand-modified molecules compete with the endogenous ligands, which can potentially lead to 1) ineffective brain targeting; or 2) side effects induced by endogenous ligand deficiency in the brain. Second, chemical conjugation can affect binding affinity of the ligand to its receptor and/or the biological activity of molecule to be delivered. The linkers used for conjugation can significantly alter the PK profile of the conjugate and affect the release and stability of delivered molecules. Below we consider several such Trojan horse approaches using various targeting ligands such as antibodies against transferrin receptor (Ab-TfR), antibodies against insulin receptor (Ab-InsR), ligands of LDL receptor-related proteins 1 and 2 (LRP1 and LRP2), melanotransferrin (MTf), receptor associated protein (RAP) and angiopep.

Ab-TfR-TfR is responsible for iron transport to the brain. Both transferrin and Ab-TfR bind with TfR in brain endothelium albeit they use different binding sites. However, transferrin is not a good candidate for the Trojan horse strategy because its TfR binding site is already saturated by endogenous transferrin. Pardridge and colleagues reported that AbTfR (OX26), a mouse IgG2a monoclonal antibody against rat TfR accumulated in the brain to a greater extent than in liver or other organs [229] and can serve as vehicle for delivery of various proteins to the brain [230]. Thus, basic bFGF conjugated to OX26 through biotinstreptavidin reaction accumulated in rat brain at $0.05 \%$ injected dose/g brain tissue, which was 5-fold higher than non-conjugated bFGF [231]. A single i.v. injection of a bFGF-OX26 conjugate produced nearly $80 \%$ reduction in infarct volume in a rat model of transient ischemic stroke [232]. In another study conjugation of OX26 to EGF resulted in increased the brain uptake and accumulation of EGF in brain tumors after i.v. administration [233]. Other proteins such as vasoactive intestinal peptide (VIP), BDNF as well as nucleic acids were also conjugated with OX26 for brain delivery [234, 235]. An alternative to OX26, a chimeric monoclonal antibody against mouse TfR (CTfRMAb) was also used in production of fusion proteins for brain delivery of erythropoietin (EPO), a-L-iduronidase (IDUA), anti$\mathrm{A} \beta$ amyloid antibody, $\mathrm{A} \beta_{1-40}$ peptide, GDNF, tumor necrosis factor decoy receptor (TNFR) and others [236-246]. Therapeutic effects of the fusion proteins in relevant CNS disease models were also demonstrated. For example, Boado et al. reported that IDUA-CTfRMAb fusion protein reduced brain intracellular lysosomal inclusion bodies in a mouse model of MPS I [239]. Studies were also reported using antibody against human TfR. These antibodies may have greater potential for clinical translation than OX26 and CTfRMAb, which are specific to mouse and rat, respectively. For example, Xu et al. used scFv fragment of antibody against human TfR to target cationic immunolipoplex to breast tumor [247]. Another study demonstrated brain accumulation of the scFv fragment against human TfR in mice [248].

The transcellular permeability at the BBB is governed by the internalization of the molecules at the luminal side of the brain endothelium, the intracellular sorting of the molecules in the endothelial cells and the release of these molecules from the abluminal side 
of the endothelium. In spite of the aforementioned reports showing that Ab-TfR improved the brain delivery of various cargo the use of this strategy for the delivery proteins across the BBB to brain parenchyma was a matter of discussion for over a decade. In early days Moos and Gosk have shown that most of brain-associated OX26 accumulated in brain capillary endothelium and not in brain parenchyma [249, 250]. It was not until recently when thorough studies by scientists from Genentech, Inc have provided an insightful understanding of this issue $[117,251,252]$. They confirmed by microautoradiography and confocal microscopy that the majority of i.v. Ab-TfR was indeed entrapped in the brain endothelium due to lysosomal sorting. To improve BBB penetration a lower affinity antibody was developed and evidenced by less degradation within the brain endothelium and maintains the capability to bind with TfR and internalize at the brain endothelial luminal side but also is easily released at the abluminal side of the BBB. They showed that at therapeutically relevant concentrations in mouse, this lower affinity antibody was released from the BBB and broadly distributed in brain parenchyma. The brain delivery of this low affinity Ab-TfR was then significantly improved after i.v. administration [117]. This example underscores the importance of in-depth understanding of intracellular trafficking (e.g. lysosome escape, early endosome targeting) and sorting of the delivered materials within the brain endothelium, a field that has been insufficiently explored.

There is also a possibility to avoid covalent conjugation of Ab-TfR and the transported molecules, which can facilitate pharmaceutical development of the respective delivery systems. Taking advantage of the inherent $\mathrm{Y}$-shape structure of antibodies, Genentech scientists also made substantial progress by engineering a bi-specific antibody with one Fab fragment (arm) derived from low affinity Ab-TfR and another Fab fragment (arm) containing an antibody against $\beta$-secretase (Ab-BACE1) [117, 252]. Without additional changes in its molecular weight, size and overall structure, this bi-specific antibody embedded therapeutic function of Ab-BACE1 for the treatment of AD and transcytosis capability at the BBB arising from the low affinity Ab-TfR. Indeed, the bi-specific antibody accumulated in the brain in a greater amount than Ab-BACE1 and significantly reduced the brain $\mathrm{A} \beta$ levels in a mouse model of $\mathrm{AD}[117,252]$. Unfortunately, targeting the transferrin receptor at the $\mathrm{BBB}$ apparently also increases the peripheral exposure of the bi-specific antibodies, which raises some safety concerns. It was shown that Ab-TfR after i.v. injection in mice at doses starting from $1 \mathrm{mg} / \mathrm{kg}$ caused acute clinical signs and decreased reticulocyte count [252]. Therefore, prospects of the clinical use of Ab-TfR containing bi-specific antibodies remain uncertain.

Ab-InsR-A high affinity insulin receptor (InsR) in brain endothelium binds insulin and enables its transport across the BBB. Insulin cannot be used as a carrier protein in vivo due to a risk of hyperglycemia. However, Pardridge and colleagues have successfully used AbInsR to deliver proteins to the brain [253]. In particular, a conjugate of GDNF with fully humanized antibody against human InsR (HInsR) exhibited neuroprotective effect in a rat model of transient ischemic stroke $[254,255]$. This conjugate was also shown to accumulate in a rhesus monkey brain. The fusion constructs comprising monoclonal antibody against HInsR with EPO, TNFR and anti-A $\beta$ amyloid ScFv were also evaluated as potential therapeutic agents [256-259]. However, concerns about possible interference of such 
constructs with insulin receptor and adverse effects on glucose metabolism decrease enthusiasm about their possible clinical use.

LRP1 and LRP2 Ligand-LRP1 (CD91) and LRP2 (gp330) are type I transmembrane proteins that belong LDL receptor superfamily. LRP1 and LRP2 both contain intracellular and transmembrane domain along with an extracellular domain characteristic of LDL receptor family [260, 261]. Both proteins interact with a wide range of ligands and facilitate their endocytosis. LRP1 also plays a major role in regulation of signaling pathways. The dysfunction of LRP1 has been associated with a number of CNS related disorders, including AD, stroke and multiple sclerosis [262-264]. A large number of ligands are shared between LRP1 and LRP2, such as lipoprotein lipase, a2-macroglobulin, receptor associated protein (RAP), lactoferrin, tissue- and urokinase-type plasminogen activator (tPA/uPA), etc. However, some ligands (e.g. melanotransferrin (or P97), A $\beta$ precursor protein, complement C3, apolipoprotein E, and HIV-1 Tat protein) exhibit relatively higher specificity to LRP1, whereas others (e.g., apolipoprotein $\mathrm{J}, \mathrm{A} \beta$ bound to apolipoprotein $\mathrm{J}$ and apolipoprotein $\mathrm{E}$, very-low-density lipoprotein (VLDL)) are more specific to LRP2 [265-271]. Some of these ligands, such as angiopep, MTf and RAP, have shown capability for LRP mediated transport across the BBB and were used for delivery of proteins to the brain.

Angiopep-Angiopep is a family of 19 amino acid sequences derived from aprotinin, a 6.5 $\mathrm{kDa}$ pancreatic trypsin inhibitor that by itself is rapidly transported across the BBB through LRP mediated pathway [272]. One member of this family, angiopep-2, displays the highest transcytosis rate at the BBB and best accumulation in brain parenchyma among all identified angiopep peptides [272, 273]. It is now clearly shown that angiopep- 2 is transported through LRP1 mediated pathway [274, 275]. Currently the most successful application of Angiopep in CNS delivery is ANG1005 (Angichem, Inc), a paclitaxel-angiopep-2 conjugate that contains three paclitaxel molecules attached to two lysine residues and $\mathrm{N}$-terminus of angiopep-2. ANG1005 was shown to bypass Pgp and exhibit greater brain uptake than free paclitaxel in in situ mouse brain perfusion study [276]. ANG1005 has shown some antitumor effects in intracerebral glioblastoma in mice, although no direct comparison with paclitaxel was made [276]. Nevertheless the drug was evaluated in the phase I clinical trial in the patients with recurrent malignant gliomas and brain metastases and was fairly well tolerated showing a toxicity profile similar to that of Taxol. Importantly, the concentration of paclitaxel in tumors removed from some ANG1005 treated patients exceeded that previously reported for patients treated with Taxol [277, 278]. This might suggest that the drug penetration at the BBB using ANG1005 was improved compared to regular Taxol chemotherapy. Two other angiopep-2-based conjugates, ANG1007 (angiopep-2doxorubicin) and ANG1009 (angiopep-2-dimethylglycine etoposide), also demonstrate improvement in brain accumulation and brain tumor inhibition in animal studies [279]. The use of angiopep-2 for the brain delivery of various macromolecular species was also reported. Examples include polyamidoamine dendrimers-PEG/DNA nanoparticles [280], PEG-polylactic acid (PLA) polymeric micelles [281], poly(ethyleneimine)-PEG (PEI-PEG) based polymeric micelles loaded with amphotericin B [282], and a few others [283-286]. Angiochem also reported conjugation of angiopep-2 to anti-HER2 antibody (ANG4043) and anti-EGFR antibody [287, 288]. In both cases, modification was reported to increase the 
antibody transport rate across BBB as shown using in situ brain perfusion and fluorescent imaging in a mouse [287, 288]. In another study, angiopep- 2 conjugation to a short sequence analgesic peptide, neurotensin (1.6 kDa) (ANG2002) appeared to be successful in targeting thins peptide to the brain for the treatment of chronic pain [289]. At least 10 times increase in the neurotensin transport across the BBB and a significant improvement in the analgesic effect for pain control in three rat models of pain were reported. However, along with these promising reports there were some discouraging results obtained using the angiopep-2 strategy for the brain delivery of a lysosome enzyme, arylsulfatase A (ASA) [290].

MTf-MTf, an iron-binding homolog of transferrin was initially recognized as a melanomaspecific marker (also called melanoma tumor antigen P97) [291]. It was later detected in other tissues including brain, where it is expressed by endothelial cells and activated microglia in AD patients. Despite structural similarity to transferrin, MTf exists mainly in membrane-bound form having a C-terminal glycosyl phosphatidylinositol anchor (25 residues) and two homologous extracellular domains (342 and 352 amino-acid residues). A soluble form of MTf (sMTf) was detected in the blood at very low concentration. Interestingly, i.v. injected sMTf accumulated in the brain although to a lesser extent than transferrin [292]. Beliveau's group and others demonstrated that recombinant human MTf passed into the brain across BBB at a high rate via LRP1 receptor-mediated pathway [267, 293]. Owing to a very low level in the blood and fast rate of transcytosis across the BBB, MTf could be used as a carrier for drug delivery to the brain. Indeed, Tang and colleagues engineered a fusion protein of sMTf and cell surface coxsackie-adenovirus receptor (sCAR), which binds as adaptor protein to both adenovirus serotype 5 (Ad5) and brain endothelium receptor and promotes internalization of the $\mathrm{Ad} 5$ vector. Using an in vitro $\mathrm{BBB}$ model, these authors demonstrated that sMTf-sCAR fusion protein redirects the cell trafficking of the Ad5 vector and facilitates its transport across the brain endothelial cells [294]. Moreover, sMTf was able to successfully deliver conjugated doxorubicin molecule to brain tumors in vivo [295]. Similarly, sMTf-adriamycin conjugates crossed BBB and prolonged survival of animals bearing intracranial gliomas or peripheral mammary tumors, compared to the animals treated with the same cumulative dose of free-adriamycin [296]. BioMarin Pharmaceuticals Inc. is currently developing sMTf as delivery modality for enzyme replacement therapy in the brain [297].

RAP-RAP is a $39 \mathrm{kDa}$ protein located mainly in endoplasmic reticulum where it plays crucial role in assisting folding and trafficking of the LDL receptor family including LRP1 and LRP2. Upon i.v. administration RAP binds LDL receptor family and therefore inhibits clearance of other ligands such as tPA [298, 299]. Pan and colleagues reported that RAP crossed BBB and reached brain parenchyma via LRP2-mediated pathway at a higher rate than transferrin and MTf [300]. Moreover, Prince showed that conjugation of RAP to lysosome enzyme, IDUA and acid a-glucosidase enhanced enzymes intracellular accumulation and substrate depletion within fibroblasts thus suggesting the possibility of RAP use as a drug carrier [301]. However, therapeutic potential of RAP conjugates for treatment of brain-related lysosome storage disease remains untested. 


\subsection{Protein modification with hydrophilic and amphiphilic polymers}

Perhaps the most successful approach to improvement of bioavailability of proteins is PEGylation - covalent attachment of PEG polymer chains to protein molecules. Frank Davis and Abraham Abuchowski reported the very first studies on protein PEGylation in 1970s. Using catalase and albumin as model proteins, they discovered that attachment of PEG (1.9 or $5.0 \mathrm{kDa}$ ) improved protein circulation and serum stability and reduced immunogenicity $[302,303]$. Since then, PEGylation has been widely used to modify proteins and helped to advance development of protein therapeutics tremendously [304]. Various aspects of PEGylation, such as chemistry of PEGylation, analytic and bioanalytic characterization, the PK and pharmacologic properties and the clinical applications are extensively discussed in literature [180, 305-312]. PEGylation of proteins can prolong their blood circulation, increase their serum stability, and reduce their immunogenicity [305, 310, 311, 313]. Peptide agonists of the GLP-1 receptor are rapidly gaining attention as antidiabetic agents, since in addition to increasing glucose-dependent insulin secretion, they also cause weight loss. For example, oxyntomodulin (OXM), a natural peptide with sequence homology to both glucagon and GLP-1, was recently modified with PEG to increase this peptide's half-life and decrease its degradation by dipeptidyl peptidase IV (DPP-IV) [314]. The PEGylated OXM exerted an anti-hyperglycemic effect in diet-induced obese (DIO) mice in a glucosedependent manner, and thus has shown potential as novel once-weekly GLP-1 mimetic with both glucose-lowering activity and weight loss efficacy. However, albeit PEGylation of leptin increased this hormone's half-life in circulation it did not improve its brain uptake in animals. Moreover, PEGylated leptin failed to induce weight loss in obese patients.[315317] Therefore it appears that PEGylation is not successful as a brain targeting strategy. This may be explained by increased molecular weight and hydrophilicity of PEGylated proteins, both unfavorable for transport of proteins across cellular barriers. Therefore, albeit PEGylation improves serum bioavailability of a protein and thus increases its exposure to the brain capillaries these effects are offset by reduced permeability of PEGylated proteins across the BBB $[318,319]$. In addition to PEG some other hydrophilic polymers, such as natural polysialic acid (PSA) [119], dextrin [320-323], and hyaluronic acid [324] as well as synthetic N-(2-hydroxypropyl)-methacrylamide (HPMA) [325] were also used for protein modification. Most of these protein-polymer conjugates have extended circulation time and improved stability in serum as compared to native proteins. However, modification of proteins with these hydrophilic polymers, like in the case of PEGylation, improves the PK profile of proteins but not their ability to cross the physiological barriers.

The protein serum bioavailability and ability to penetrate across brain endothelium can be improved by modification of proteins with amphiphilc block copolymers [225]. For example, Pluronic block copolymers (also termed "poloxamers") consist of hydrophilic poly(ethylene oxide) (PEO or PEG) and hydrophobic poly(propylene oxide) (PPO or polypropylene glycol (PPG)) segments arranged in a basic A-B-A structure: PEO-PPO-PEO (PEG-PPG-PEG). By changing the lengths of the PEO and PPO segments one can vary the hydrophilic-lipophilic balance of these polymers and alter their ability to interact with each other and lipid membranes. A characteristic of Pluronics is the ability to self-assemble into micelles in aqueous solutions above the critical micelle concentration (CMC). Already a quarter of century ago Pluronic micelles conjugated with antibodies to brain specific 
antigens (e.g. a2-GP) were shown to deliver solubilized compounds to the CNS after i.v. administration in mice [326]. Interestingly, selected Pluronics are potent inhibitors of Pgp and increase entry of Pgp-substrates into the brain across BBB [327-329]. These copolymers were shown to cross membranes of BMECs and enter brain tissues in mouse models [330, 331]. Moreover, some copolymers, such as Pluronic P85 were shown to internalize in primary neurons [332]. These copolymers follow cell trafficking itinerary similar that of cholera toxin B, including binding with cholesterol-rich domains in cell membrane and then internalization via caveolae-mediated or caveolae- and clathrinindependent endocytosis $[333,334]$. Based on these observations Pluronics were used to modify proteins to deliver them across the BBB. Initially, HRP modified with relatively hydrophobic Pluronic block copolymers (P85, L81 and L121) was shown to cross in vitro BBB model and following i.v. administration in mice, HRP-P85 exhibit higher permeability at the BBB than HPR alone and accumulated in brain parenchyma [212, 335]. Subsequently, SOD1 modified with Pluronic P85 or L81 was shown to internalize into neuronal cells, while retaining enzymatic activity and acting as a scavenger of intracellular superoxide induced by angiotensin II [336]. Moreover, after intracarotid administration in rabbits this conjugate also induced a central physiological response by inhibiting angiotensin II-induced increase in the arterial pressure, not observed after native SOD1 injection [337].

Protein modification with Pluronics was used recently for development of an anti-obese drug on the base of leptin [78, 338, 339]. Leptin, a candidate for the treatment of epidemic obesity, has failed in part because of impairment in its transport across the BBB that develops with obesity [340-342]. It was suggested that modification of leptin with Pluronic P85 might permit this protein to penetrate the BBB independently of its transporter, thereby overcoming peripheral leptin resistance. PK studies demonstrated that Pluronic conjugate was transported across BBB at an influx rate similar to native leptin, but via non-saturable mechanism independent of leptin transporter [338]. Importantly, the conjugate reduced food intake following i.c.v. or i.v. administration in healthy mice and in mouse models of obesity (ob/ob, and diet-induced obese mouse) [338, 339]. We further generated two new leptin-P85 conjugates: one, Lep(ss)-P85(L), containing one P85 chain and another, Lep(ss)-P85(H), containing multiple P85 chains. Lep(ss)-P85(L) crosses the BBB using the leptin transporter, and exhibits improved peripheral PK along with increased accumulation in the brain compared to unmodified leptin. Lep(ss)-P85(H) also has improved peripheral PK but in a striking difference to the first conjugate penetrates the BBB independently of the leptin transporter via a non-saturable mechanism. The results demonstrate that leptin analogs can be developed through chemical modification of the native leptin with Pluronic P85 to overcome leptin resistance at the level of the BBB, thus improving the potential for the treatment of obesity [339].

Although the use of Pluronics for brain delivery of proteins is still under investigation, the translation of this technology to a clinic is promising. One advantage of using Pluronics for brain delivery is their relatively low toxicity. Pluronic copolymers are FDA-approved excipients and are widely used in a variety of clinical applications. No CNS related toxicity was reported in Phase I and II clinical trials of doxorubicin formulated with Pluronics ("SP1049C") [343, 344]. Studies show that Pluronics at concentrations substantially 
exceeding those used in protein-Pluronic conjugates have little if any toxic effect on brain endothelial cells in vitro and in vivo and do not alter paracellular permeability of BBB [327, $328,345]$.

Another technology showing potential is protein modification with amphiphilc poly(2oxazoline)s (POx) block copolymers [346]. POx polymers have been explored in various drug delivery and other biomedical applications [347-357]. Their advantages compared to PEG and Pluronics include greater stability, greater synthetic versatility allowing introduction of various functionalities both the polymer repeating units and terminal groups. This makes them promising candidates for protein brain delivery. Hydrophilic POx homopolymers such as poly(2-methyl-2-oxazoline) (PMeOx) and poly(2-ethyl-2-oxazoline) (PEtOx) are considered as alternatives to PEG in applications similar to PEGylation [358, 359]. The amphiphilic POx block copolymers exhibit relatively low cytotoxicity and can transport into cells similarly to Pluronics [356, 357]. We have reported recently that HRP modified with amphiphilic block copolymers of $\mathrm{PMeOx}$ and 2-butyl-2-oxazoline ( $\mathrm{P}(\mathrm{MeOx}-$ $b$-BuOx), or PEtOx and 2-butyl-2-oxazoline ( $\mathrm{P}(\mathrm{EtOx}-b-\mathrm{BuOx})$ transported into intracellular compartments in both MDCK and Caco-2 cells [360]. Next, we modified SOD1 with two aforementioned POx block copolymers [361]. Similar to SOD1-Pluronic conjugates, SOD1POx conjugates retained high stability and catalytic activity after modification. Moreover, SOD1-P(EtOx- $b$-BuOx) conjugate showed high uptake level in CATH.a neurons and efficiently scavenged intracellular superoxide induced by Ang II stimulation. This conjugate utilized caveolae-mediated and/or clathrin and caveolae-independent endocytosis for cell entry. After i.v. administration in mice radiolabeled SOD1-P(EtOx- $b$-BuOx) displayed longer blood half-life compared to native SOD1, crossed BBB by non-saturable mechanism, and reached brain parenchyma [361]. Even though this new technology has already shown potential in enhancing delivery of proteins to the brain, a clear understanding of POx and protein-POx interactions with brain endothelium is needed to take the full advantage of the structural versatility of this type of polymer.

\section{Particle-based carriers for CNS delivery of proteins}

Numerous studies have shown that encapsulation of therapeutic proteins in nano- or micron size particles decreases protein immunogenicity and improves protein stability and circulation time (Figure 4). Liposomes and PLGA nanoparticles are possibly the most extensively investigated types of carriers for protein delivery. Other systems investigated in the context of CNS delivery include poly(butylcyanoacrylate) (PBCA) nanoparticles, and more recently, polyion complexes. Some other materials such as PEG-silica, bolaamphiphilies, chitosan, PEG-polylactide (PLA), PEG-poly( $\varepsilon$-caprolactone) (PCL) and PLA-D-a-Tocopheryl polyethylene glycol succinate (TPGS) were also evaluated for brain delivery [283, 371-377]. Unfortunately, such particle-based carriers generally do not cross BBB. Surface modification with specific brain targeting moieties may provide opportunities to enhance brain the delivery of particles but the effectiveness remains questionable [378380]. Nevertheless interest in particle-based systems for delivery of therapeutic agents to CNS persists due to ongoing efforts in application of these systems with drugs having a peripheral mode of action. Notably, majority of such studies using particle-based carriers involve delivery of low molecular mass therapeutics to the CNS [381, 382], with only 
relatively few examples reporting CNS delivery of proteins [383]. Because most carrierbased technologies were originally developed for delivery of low molecular mass drugs, in some cases there is an additional challenge in modifying the carrier technology to facilitate protein formulation, ensure high protein loading and stability. Below we consider some of these carries and their applications for protein delivery to the brain.

\subsection{Liposomal carriers}

Liposomes have been extensively investigated as carriers for delivery of small drugs, proteins, DNA, siRNA and imaging agents [384-387]. Few of these studies involved delivery of proteins to the brain. For example, over 30-years ago it was reported that encapsulation of proteins ( $\beta$-galactosidase, thyrotrophin-releasing hormone (TRH)) in neutral (phosphatidylcholine (PC), cholesterol (Chol)) or anionic (PC, Chol, dicetylphosphate or phosphatidylserine (PS)) liposomes can increase brain accumulation of these proteins after i.v. administration [388, 389]. Interestingly, TRH loaded in neutral liposomes showed greater brain uptake and physiological effect (rise in body temperature) than TRH in anionic liposomes. Incorporation of TRH in cationic liposomes (PC, Chol and stearylamine) also increased the protein brain uptake. However, stearylamine caused epileptic seizures and cerebral tissue necrosis this and therefore, due to toxicity this formulation was not pursued [389]. Nevertheless, cationic liposomes were further used to deliver SOD1. Several studies demonstrated that SOD1 formulated in cationic liposomes administered i.v. can reduce cerebral infarct volume size in ischemic stroke and brain trauma animal models [390-393]. Though reasons for the improved brain delivery of the liposomeincorporated proteins remained unknown, it was speculated that liposome could crosslipophilic membranes of brain endothelial cells [389]. To the best of our knowledge no evidence of that has been provided so far to support this mechanism. It was also suggested that cationic liposomes can produce a transient pathologic opening of the BBB during experimental stroke, which can explain at least some of the effects observed [394, 395]. Overall, the translation of cationic liposomes to practical use has been hindered due to their low stability and potential toxicity in vivo [396, 397].

Some of the early work using liposomes of different sizes $(40-80 \mathrm{~nm},<1 \mu \mathrm{m},>5 \mu \mathrm{m}$, and up to $40 \mu \mathrm{m}$ ) and compositions (Chol/PC, mouse brain homogenates lipids, PC/PS; dioleoyl phosphatidylethanolamine (DOPE) and N-succinyldioleoylphosphatidylethanolamine (SOPE)) failed to show liposomes uptake into the brain in healthy mice or mice with experimental brain metastases $[398,399]$. The larger $\mu \mathrm{m}$-sized liposomes were retained at the BBB possibly fusing with the membranes of endothelial cells and causing embolism and high pressure within the brain, especially in animals with experimental tumors [398, 399]. Interestingly, one of these studies implied that circulating blood monocytes could phagocytose liposomes and deliver them to the brain since these cells were shown to invade experimental metastases even in animals with an intact BBB [398].

It is well known that many liposomes are rapidly cleared from circulation by the reticuloendothelial system, which could decrease the exposure of such liposomes to the BBB after parenteral administration. The immunogenicity of liposomes has also been a concern. Incorporation of PS or phosphatidylinositol in the lipid bilayer in protein-containing 
liposomes can stabilize liposomal formulations, prevent the premature protein release in serum and reduce the immunogenicity [400-402]. Decreasing the liposome particle size $(<$ $100 \mathrm{~nm}$ ) and PEGylation of the liposome surface can also extended the liposomes circulation time. However, such modifications also can reduce liposome interactions with the brain endothelium and neuronal cells thereby hindering delivery of liposomal drugs to the brain. To increase delivery of PEGylated liposomes to the brain, one can modify liposomes with brain-specific ligands that can be internalized and transcytosed across the brain endothelium. For example, modification of the surface of the PEGylated liposomes with transferrin enhanced cellular uptake of the liposomes and delivery of the liposomeencapsulated protein (HRP) in the brain capillary endothelial cells [378]. In an animal study PEGylated liposomes functionalized with brain-targeting ligand, RMP-7 were shown to carry NGF to the brain [379]. Another example of targeted liposomes is so-called "procationic liposomes" modified with a cationic ligand lactoferrin (LF), which targets receptors in brain endothelium [403]. Such modified liposomes were shown to enter the primary rat brain endothelial cells through a combination of adsorptive and receptor-mediated endocytosis. After i.v. administration these liposomes can deliver an encapsulated anticancer agent, doxorubicin to a glioma in a mouse model [404]. In spite of all these findings, the ability of brain targeting moieties to improve liposome delivery to the brain might be questionable. Most of these studies provided evidence using in vitro brain endothelial cells. Moreover, most of the animal studies available have not reported brain PK parameters (influx rate, serum half-life etc.) that are essential for evaluation of protein brain delivery outcomes. As a result the interpretation of the effects of some brain targeting moieties can be challenging. For example, one study reported that several brain specific moieties such as angiopep-2, COG133 and CRM197, did not show any improvement in targeting liposomes to the brain in vitro and in in vivo [380]. Nevertheless, targeting via nutrient transporters expressed at the BBB has been also used to increase brain uptake of liposomes. For example, liposomes modified with reduced glutathione (GSH) have been used as a targeted carrier for delivery of low molecular mass drugs like ribavirin [405], methylprednisolone [406], doxorubicin [407] and an opioid peptide [408]. GSH-liposomes showed higher brain uptake upon i.v. injection in normal rats and in rat model of MS compared to non-targeted liposomes and free drug/peptide, respectively [406, 409]. The i.v. injection of methylprednisolone in GSH-liposomes decreased the clinical score of neurological aberrations in a rat model of MS [406]. GSH-liposomes encapsulating an opioid peptide showed an improved PK profile compared to the free drug in a rat microdialysis study [408]. GSH-PEG modified Doxil@ liposomes showed a small but significant increase (compared to non-targeted Doxil ${ }^{\circledR}$ liposomes) in plasma drug concentrations 4 days after i.v. injection in mice; however, drug concentration in the brain was not significantly improved.

Nevertheless, these targeted liposomes showed a safety profile similar to Doxil®, decreased brain tumor volume and resulted in a marginal but significant increase in survival time compared to saline and non-targeted Doxil ${ }^{\circledR}$ liposomes in a mouse model of gliablastoma multiforme. Brain delivery of GSH-liposomes was also evidenced using tracer dye carboxyfluorescein as a cargo [410]. The cellular uptake of the dye in rat brain endothelial cells was increased when incorporating to GSH-liposomes compared to that of non-targeted liposomes. Moreover, rat brain microdialysis studies after i.v, injection of GSH-liposomes showed a small but statistically significant increase in the dye concentrations in the brain 
extracellular fluid 6 hrs post-injection compared the non-targeted liposomes. However, to the best of our knowledge the GSH-liposomes have not been used for protein delivery to CNS so far.

In addition to a traditional parenteral delivery route liposomes were also administered intranasally. For example, Migliore and colleagues developed cationic liposomal formulation loaded with a model protein, ovalbumin for intranasal delivery [411]. This formulation resulted in elevated brain delivery of encapsulated ovalbumin concentrations in brain compared to delivery of the free protein [411].

Overall, studies on liposomal carriers for protein therapeutics for neurologic diseases have presented conflicting evidence of brain delivery and safety and faced many challenges associated with encapsulation procedures, loading capacity, and preserving protein activity.

\subsection{PLGA particles}

PLGA and its derivatives are used to make perhaps the most widely studied nano/micro-size particles for encapsulation of therapeutic proteins. Advantages of these polymers include their biocompatibility and biodegradability as well as suitability for design of sustainedrelease protein formulations. The release rates of encapsulated proteins can be tuned by varying the lactic acid to glycolic acid molar ratio and the polymer molecular mass [412]. On the flip side, disadvantages of PLGA carriers include initial "burst" release, irreversible adsorption of proteins to the polymer matrix, as well as inactivation of proteins during preparation, storage and application including effects of products of PLGA degradation, lactic and glycolic acids, on protein stability [413]. Blending with other polymers or excipients, stabilizing proteins during encapsulation by adding zinc or antacid excipients and other means may improve protein stability, loading and release profile [414].

In spite of its extensive use for protein delivery, no direct brain PK data is available showing that PLGA particles improve uptake of encapsulated proteins in the brain. However, a sustained release of proteins from PLGA carriers could benefit the treatment of chronic brain diseases. Indeed, subcutaneous injection of PLGA microspheres containing insulinlike growth factor I (IGF-I) restored the motor function and increased the survival in mice with inherited Purkinje cell degeneration disease [415]. IGF-I was continuously released from the microspheres, which likely increased the brain levels of IGF-I over a period of time and resulted in therapeutic effects similar to a continuous subcutaneous infusion of IGF-I $[415,416]$. Another study reported a sustained release for up to 60 days of a therapeutic protein, BDNF from PLGA-poly( L-lysine)-PEG microspheres [417]. Although in vivo test was not reported, the bioactivity of the released BDNF was confirmed by cell proliferation and neurite outgrowth in pheochromocytoma PC12 cells stably expressing BDNF cognate receptor TrkB [417].

Interestingly, intracarotid (i.c.) injection of SOD1 encapsulated in PLGA nanoparticles significantly reduced brain infarct volume and prevented neuronal cell death in a rat model of transient ischemic stroke [396]. This study compared 3 different administration routes: i.c., i.v. (via the tail and jugular veins) and demonstrated that i.c. route resulted in a 13-fold greater brain uptake of the enzyme compared to the i.v. routes. The observed 
neuroprotection could be a result of a sustained release of active SOD1 from nanoparticles, which accumulate in the brain due to the BBB impairment typical of ischemia-reperfusion model.

Like in the case of other carriers, the PLGA nanoparticles can be decorated with brain targeting moieties. For instance, PLGA nanoparticles modified with similopioid peptide were shown to deliver their payload to the brain after i.v. administration in rats $[418,419]$. Notably, the nanoparticles modified with a scrambled peptide did not accumulate in the brain, suggesting involvement of a similopioid peptide-related brain uptake mechanism [420]. The targeted nanoparticles loaded with a low molecular mass drug, loperamide produced central antinociceptive effect in rats, comparable to the effects of this drug, administered i.c.v.. Another study used PLGA nanoparticles decorated with similopioid peptide and sialic acid residues, which target sialic acid receptor in brain parenchyma [421]. However, this modification in addition to increased accumulation of the nanoparticles in the brain also appeared to increase their accumulation in peripheral tissues.

Targeting strategies is commonly combined with PEGylation of the nanoparticle surface in an attempt to increase the nanoparticle circulation time and decrease interactions with nontargeted cells. Thus, PEGylated PLGA nanoparticles decorated with tetanus toxin fragment $\mathrm{C}$ (a neuron-binding motif) were selectively taken up by neuroblastoma cells but not in hepatocellular carcinoma and BMECs, however, no in vivo studies were reported [422]. The PEGylated PLGA nanoparticles conjugated with cationized BSA delivered and released their cargo, 6-coumarin in the brain after caudal vein administration in mice [423]. As is evident from this discussion, most of these studies reported the use of the targeted nanoparticles for the delivery of low molecular mass solutes. However, there are some examples of targeted nanoparticles for the brain delivery of oligo- and polypeptides. For example, PEGylated PLGA nanoparticles decorated with lactoferrin were shown to deliver neuroprotective peptides including S14G-humanin and urocortin to the brain and induce neuroprotective effects in animal models of AD and PD [424, 425]. Overall, although these observations appear encouraging, numerous questions including PK and evidence of brain delivery and release of proteins, as well treatment associated toxicities, in particular immunogenicity of the ligand coated particles, would need to be thoroughly addressed in most cases before a possibility of clinical translation of these systems could be discussed.

\subsection{PBCA nanoparticles}

Kreuter and colleagues evaluated PBCA nanoparticles coated with non-ionic surfactants (polysorbate 80, Pluronic F68) for CNS delivery of a variety of low molecular mass drugs such as doxorubicin, loperamide, tubocurarine, NMDA receptor antagonist MRZ 2/576, and peptides such as dalargin and kytorphin [426]. Later on these nanoparticles were also used to deliver proteins. For example, one study suggested increased brain uptake of NGF and reduced PD symptoms after i.v. administration of NGF-loaded polysorbate 80-coated PBCA nanoparticles in a mouse model of PD [383]. Similarly, Lin and colleagues reported that polysorbate 80-coated PBCA nanoparticles loaded with HRP or enhanced green fluorescent protein (EGFP) can deliver these proteins to the brain in a rat model of TBI [427]. Another study evaluated dextran and polysorbate 80-coated PBCA nanoparticles carrying covalently 
immobilized SOD1 and anti-glutamate N-methyl D-aspartate receptor 1 antibody [428]. These protein-PBCA conjugates were shown to prevent neuronal cell death mediated by superoxide radicals $\mathrm{O}_{2}{ }^{-}$toxicity in the rat cerebellar cells. No animal study was reported in this work.

The enhanced brain delivery was also observed in PEGylated cyanoacrylate nanoparticles coated with polysorbate 80 [429]. However, not all nanoparticles with polysorbate 80 coating showed enhanced brain delivery. For example, polystyrene nanoparticles coated with polysortabe 80 did not deliver any dalargin cargo into the brain [430]. Instead of brain accumulation, polysorbate 80 -coated poly(methylmethacrylate) nanoparticles mainly accumulated in the liver [431]. Olivier and colleagues reported a fast cargo release from PBCA nanoparticles in serum likely caused by polysorbate 80 , serum protein competition and rapid nanoparticle degradation in the blood [430, 432].

The brain entry mechanism of PBCA nanoparticles after their i.v. administration is still unclear. It is hypothesized that surfactant-coated PBCA nanoparticles adsorb apolipoprotein E (ApoE) or apolipoprotein B (ApoB) from the bloodstream and cross BBB by LRPmediated transcytosis [433]. ApoE is a $35 \mathrm{kDa}$ glycoprotein lipoproteins component that plays a major role in the transport of plasma cholesterol in the bloodstream and CNS [434]. Its non-lipid related functions including immune response and inflammation, oxidation and smooth muscle proliferation and migration [435]. Published reports indicate that some nanoparticles such as human albumin nanoparticles with covalently-bound ApoE [436] and liposomes coated with polysorbate 80 and ApoE [437] can take advantage of ApoE-induced transcytosis. Although no studies provided direct evidence that ApoE or ApoB are responsible for brain uptake of the PBCA nanoparticles, the precoating of these nanoparticles with ApoB or ApoE enhanced the central effect of the nanoparticle encapsulated drugs [426, 433]. Moreover, these effects were attenuated in ApoE-deficient mice [426, 433]. Another possible mechanism of transport of surfactant-coated PBCA nanoparticles to the brain is their toxic effect on the BBB resulting in tight junction opening [430]. Therefore, in addition to uncertainty regarding brain transport mechanism of PBCA nanoparticle, cyanocarylate polymers are not FDA-approved excipients and have not been parenterally administered to humans.

\subsection{Block ionomer complexes (BIC)}

BIC (also called "polyion complex micelles") are a promising class of carriers for the delivery of charged molecules developed independently by Kabanov's and Kataoka's groups $[438,439]$. They are formed as a result of the polyion complexation of double hydrophilic block copolymers containing ionic and non-ionic blocks with macromolecules of opposite charge including oligonucleotides, plasmid DNA and proteins [438, 440-443] or surfactants of opposite charge [444-449]. Kataoka's group demonstrated that model proteins such as trypsin or lysozyme (that are positively charged under physiological conditions) can form BICs upon reacting with an anionic block copolymer, PEG-poly ( $\alpha, \beta$-aspartic acid) (PEGPAA) [440, 443]. Our initial work in this field used negatively charged enzymes, such as SOD1 and catalase, which we incorporated these into a polyion complexes with cationic copolymers such as, PEG-poly( ethyleneimine) (PEG-PEI) or PEG-poly(L-lysine) (PEG- 
PLL). Such complex forms core-shell nanoparticles with a polyion complex core of neutralized polyions and proteins and a shell of PEG, and are similar to polyplexes for the delivery of DNA. Advantages of incorporation of proteins in BICs include 1) high loading efficiency (nearly 100\% of protein), a distinct advantage compared to cationic liposomes ( $\sim 32 \%$ for SOD1 and $\sim 21 \%$ for catalase [450]; 2 ) simplicity of the BIC preparation procedure by simple physical mixing of the components; 3 ) preservation of nearly $100 \%$ of the enzyme activity, a significant advantage compared to PLGA particles. The proteins incorporated in BIC display extended circulation time, increased uptake in brain endothelial cells and neurons demonstrated in cell culture and increased stability in cells [451]. Our laboratory has demonstrated that BIC-incorporated butyrylcholinesterase (BChE) can be delivered to the brain in $\mathrm{BChE}-/-$ mice. Interestingly, the delivery of $\mathrm{BChE}$ appeared to be more efficient when the BIC was administered i.m. compared to the i.v. administration [452]. We speculate that BIC administered i.m. could be delivered to the brain via neuromuscular junctions by retrograde transport. In addition, we also developed and characterized several generations of BIC formulations ("nanozymes") of two antioxidant enzymes, SOD1 and catalase and evaluated them in several animal models [451, 453, 454]. For example, a covalently stabilized, cross-linked $(c l)$ nanozyme formed by SOD1 and PEGPLL exhibited improved stability in blood and brain and increased uptake in both brain capillaries and parenchyma, as compared to non- $c l$ nanozymes and native protein [453]. The single dose of this nanozyme after i.v. administration resulted in a decreased infarct volume and improved sensorimotor outcomes compared to untreated (saline-injected) and native SOD1 groups in a rat model of transient cerebral ischemia-reperfusion injury. One should expect further developments in evaluation of this new technology for the delivery of proteins to the CNS.

\subsection{Cell-mediated delivery of nanoparticles}

A relatively new approach to CNS protein delivery involves loading of protein-incorporated BIC in immune response cells that respond to pathological inflammation and migrate to the brain tissue thereby serving as conduits for protein delivery [455] (Figure 5). Batrakova and colleagues have investigated this paradigm as a potential strategy for the delivery of therapeutic antioxidant enzymes to treat PD in a series of studies [456-462]. To protect enzymes from degradation in the carrier cells they incorporated these enzymes in the BIC. For example, they loaded catalase-PEI-PEG nanozymes (60-100 nm in diameter) into bonemarrow derived macrophages (BMM) and administered these macrophages i.v. in a mouse model of PD. Nearly $0.5 \%$ of protein delivered this way with the BMM accumulated in the brain tissue, which was several fold improvement in brain delivery compared to the nanozymes directly injected in the mouse [462]. The attenuation of PD manifestations (microglial activation and astrocytosis) in animals treated with nanozyme-loaded BMM was also reported, which was not much different from animals injected with the nanozyme alone [462]. The nanozyme-loaded BMM also increased survival of dopaminergic neurons and rescued the loss in the $\mathrm{N}$-acetyl aspartate (used a measure to determine neuroprotection), which suggested the neuroprotective effects. The optimization of the nanozyme formulation for this delivery strategy was also reported [463]. The PK and biodistribution studies demonstrated that nanozyme-loaded BMM had increased area under the curve (AUC), halflife and mean residence time in blood circulation, and greater bioavailability, compared to 
nanozyme alone. Enhanced brain delivery of nanozyme loaded in BMM was also demonstrated [464]. However, AUC was also increased (ranging from 1.8 to 4.6-fold) in the non-target organs such as liver, spleen and kidney in addition to the brain tissue. A brain influx rate of $0.026 \mu \mathrm{L} / \mathrm{g}$.min was determined for nanozyme-loaded BMM, which was 1.9fold higher than for nanozyme alone. Recent study also suggested that BMM facilitated transport of nanozyme form to brain endothelial, glial and neuronal cells through multiple endocytosis-independent pathways such as transient intercellular connections, macrophage bridging conduits and exosomes $[465,466]$. Altogether these studies may open new avenues for cell-mediated protein delivery to the brain. Interested readers are referred to a recent review for a comprehensive overview [467].

\section{Conclusion}

Developing protein therapeutics for treatment of CNS disorders is an unmet need. A variety of delivery strategies discussed in this review have shown promise to delivery proteins to the brain. The most advanced in clinic are the strategies involving direct delivery of proteins to the CNS using the central administration routes, i.c.v. and intraparenchymal, as well as i.t. administration. Recently intranasal administration in the vicinity of nasal cribriform plate, which allows substances to bypass the BBB and enter the brain directly with minimum serum exposure, has gained increasing attention. There appears to be a significant room for advancement of these strategies by combining them with the protein delivery approaches, which were previously explored mainly in the context of the parenteral administration. Modification of proteins with cationic moieties, CPP, fatty acid residues, brain-targeting moieties and amphiphilic block copolymers can result in alteration of protein peripheral PK and increase in the permeability of these proteins at the BBB. Numerous studies demonstrate increased protein uptake in the brain and in some cases increased therapeutic efficacy in relevant CNS disease models. However, the mechanisms of transport of the modified proteins across the BBB in most cases are not well understood. Moreover, there are safety issues associated with most delivery approaches especially the use of cationic moieties and CPP. In contrast, modification of proteins with fatty acids and amphiphilic block copolymers, appear to be promising and in particular, fatty acylation has already reached a clinical stage, although toxicology profiles should be carefully evaluated in each case. Much insight on the mechanism of CNS delivery has been obtained in studies of the PK, pharmacodynamics and toxicity of low affinity antibodies against TfR. In contrast, CNS delivery of proteins using particle-based carriers, in particular, liposomes or PLGA particles appears to be less advanced and less effective. Decorating the particle surface with appropriate molecules that can target receptors at the brain endothelium is one way to address this problem but the available results are still contradictory. Nevertheless, investigating novel nanoparticles to deliver protein to the brain certainly represents a future direction especially in the context of nontraditional delivery approaches avoiding the BBB, intranasal administration and delivery using cells as carriers.

\section{Acknowledgments}

We would like to acknowledge the support of the National Institutes of Health RO1 NS051334, the Center of Biomedical Research Excellence (CoBRE) Nebraska Center for Nanomedicine P20 GM103480 (P20 RR021937) and the Russian Ministry of Science and Education Megagrant award (Contracts 11.G34.31.0004) as well as the 
Carolina Partnership, a strategic partnership between the UNC Eshelman School of Pharmacy and the University Cancer Research Fund through the Lineberger Comprehensive Cancer Center. We also thank Dr. Daria Alakova, Zhijian He and Dr. Zagit Gaymalov for assistance with figures preparation and Dr. Jing Tong for assistance with manuscript preparation. Last but not the least Dr. William A. Banks at Veterans Affairs Puget Sound Health Care System, Seattle, WA has continuously supported and inspired our work, which we are pleased to gratefully acknowledge.

\section{Abbreviations}

$\mathbf{A} \beta$

Ab-InsR

Ab-TfR

AD

Aerosol OT

ALS

ApoB

ApoE

ASA

AUC

a2-GP

Ab-BACE1

BBB

BDNF

BIC

BChE

bFGF

BMECs

BMM

CED

Chol

CMC

CNS

CPPs

CSF

DIO

DOPE

DPP-IV amyloid $\beta$

antibodies against insulin receptor

antibodies against transferrin receptor

Alzheimer's disease

bis-(2-ethylhexyl) sulfosucciate

amyotrophic lateral sclerosis

apolipoprotein B

apolipoprotein E

arylsulfatase A

area under the curve

a2-glycoprotein

antibodies against $\beta$-secretase

blood-brain barrier

brain-derived neurotrophic factor

block ionomer complexes

butyrylcholinesterase

basic fibroblast growth factor

brain microvessel endothelial cells

bone-marrow derived macrophages

convection-enhanced delivery

cholesterol

critical micelle concentration

central nervous system

cell-penetrating peptides

cerebrospinal fluid

diet-induced obese

dioleoyl phosphatidylethanolamine

dipeptidyl peptidase IV 


\begin{tabular}{|c|c|}
\hline EPO & erythropoietin \\
\hline GDNF & glial cell-derived neurotrophic factor \\
\hline GFAP & gliofibrillar acid protein \\
\hline GLP-1 & glucagon-like peptide 1 \\
\hline GSH & reduced glutathione \\
\hline EAE & experimental autoimmune encephalomyelitis \\
\hline ECS & extracellular space \\
\hline EGF & epidermal growth factor \\
\hline EGFR & EGF receptor \\
\hline ERT & enzyme replacement therapy \\
\hline FDA & Food and Drug Administration \\
\hline FGF & fibroblast growth factor \\
\hline HAD & HIV-1-associated dementia \\
\hline HIV-1 & human immunodeficiency virus 1 \\
\hline HRP & horseradish peroxidase \\
\hline HPMA & N-(2-hydroxypropyl)-methacrylamide \\
\hline I2S & iduronate-2-sulfatase \\
\hline INB & intranasal-to-brain \\
\hline i.c.v. & intracerebroventricular \\
\hline IGF-I & insulin-like growth factor I \\
\hline i.m. & intramuscular \\
\hline i.n. & intranasal \\
\hline i.t. & intrathecal \\
\hline InsR & insulin receptor \\
\hline i.v. & intravenous \\
\hline KLH & keyhole limpet hemocyanin \\
\hline LDL & low-density lipoprotein \\
\hline LRP1 & ligand of LDL receptor-related protein 1 \\
\hline LRP2, LRP1 & ligand of LDL receptor-related protein 2 \\
\hline LSDs & lysosomal storage disorders \\
\hline M6P & mannose 6-phosphate \\
\hline MCAO & middle cerebral artery occlusion model \\
\hline
\end{tabular}




\begin{tabular}{|c|c|}
\hline MPS I & mucopolysaccharidosis I \\
\hline MPS II & mucopolysaccharidosis II \\
\hline MS & multiple sclerosis \\
\hline NGF & nerve growth factor \\
\hline $\mathbf{N T}-\mathbf{3}$ & neurotrophin-3 \\
\hline MTf & melanotransferrin \\
\hline NVU & neurovascular unit \\
\hline OXM & oxyntomodulin \\
\hline PACAP & pituitary adenylate cyclase activating polypeptide \\
\hline PBCA & poly(butylcyanoacrylate) \\
\hline PBuOx & 2-butyl-2-oxazoline \\
\hline PC & phosphatidylcholine \\
\hline PCL & $\operatorname{poly}(\varepsilon$-caprolactone $)$ \\
\hline PEG & poly(ethylene glycol) \\
\hline PEI & poly(ethyleneimine) \\
\hline PEO & poly(ethylene oxide) \\
\hline PET & position emission tomography \\
\hline PEtOx & poly(2-ethyl-2-oxazoline) \\
\hline PD & Parkinson's disease \\
\hline Pgp & P-glycoprotein \\
\hline PK & pharmacokinetics \\
\hline PLA & polylactic acid \\
\hline PLGA & poly(D,L-lactic-co-glycolide) \\
\hline PMeOx & poly(2-methyl-2-oxazoline) \\
\hline POx & poly(2-oxazoline)s \\
\hline PS & phosphatidylserine \\
\hline PPG & polypropylene glycol \\
\hline PPO & poly(propylene oxide) \\
\hline $\mathbf{R A P}$ & receptor associated protein \\
\hline RDP & Rabies virus glycoprotein-derived peptide \\
\hline rhIDU & a-L-iduronidase \\
\hline sCAR & cell surface coxsackie-adenovirus receptor \\
\hline
\end{tabular}




$\begin{array}{ll}\text { S.c. } & \text { subcutaneous } \\ \text { Shh } & \text { sonic hedgehog } \\ \text { SMTf } & \text { soluble melanotransferrin } \\ \text { SOD } & \text { superoxide dismutase } \\ \text { SOPE } & \text { N-succinyldioleoylphosphatidyl-ethanolamine } \\ \text { TAT } & \text { trans-activating transcriptional activator } \\ \text { TBI } & \text { traumatic brain injury } \\ \text { TJ } & \text { tight junctions } \\ \text { TfR } & \text { transferrin receptor } \\ \text { TNFR } & \text { tumor necrosis factor decoy receptor } \\ \text { TPGS } & \text { a-tocopheryl polyethylene glycol succinate } \\ \text { VLDL } & \text { very-low-density lipoprotein }\end{array}$

\section{References}

1. Tof, I. Recombinant DNA technology in the synthesis of human insulin. Little Tree Publishing; 1994.

2. Leader B, Baca QJ, Golan DE. Protein therapeutics: a summary and pharmacological classification. Nature reviews. 2008; 7:21-39.

3. Veronese FM, Harris JM. Introduction and overview of peptide and protein pegylation. Advanced drug delivery reviews. 2002; 54:453-456. [PubMed: 12052707]

4. Danhier F, Ansorena E, Silva JM, Coco R, Le Breton A, Preat V. PLGA-based nanoparticles: an overview of biomedical applications. J Control Release. 2012; 161:505-522. [PubMed: 22353619]

5. Kulasa KM. The Current Status of Exenatide Once Weekly. Clinical Medicine Insights: Therapeutics. 2011; 3:221-232.

6. Willis CL, Brooks TA, Davis TP. Chronic inflammatory pain and the neurovascular unit: a central role for glia in maintaining BBB integrity? Current pharmaceutical design. 2008; 14:1625-1643. [PubMed: 18673205]

7. Pan W, Kastin AJ. Cytokine transport across the injured blood-spinal cord barrier. Current pharmaceutical design. 2008; 14:1620-1624. [PubMed: 18673204]

8. Kastin AJ, Pan W. Blood-brain barrier and feeding: regulatory roles of saturable transport systems for ingestive peptides. Current pharmaceutical design. 2008; 14:1615-1619. [PubMed: 18673203]

9. Banks WA. The blood-brain barrier as a cause of obesity. Current pharmaceutical design. 2008; 14:1606-1614. [PubMed: 18673202]

10. Deane R, Sagare A, Zlokovic BV. The role of the cell surface LRP and soluble LRP in blood-brain barrier Abeta clearance in Alzheimer's disease. Current pharmaceutical design. 2008; 14:16011605. [PubMed: 18673201]

11. Huber JD. Diabetes, cognitive function, and the blood-brain barrier. Current pharmaceutical design. 2008; 14:1594-1600. [PubMed: 18673200]

12. Dore-Duffy P. Pericytes: pluripotent cells of the blood brain barrier. Current pharmaceutical design. 2008; 14:1581-1593. [PubMed: 18673199]

13. Begley DJ, Pontikis CC, Scarpa M. Lysosomal storage diseases and the blood-brain barrier. Current pharmaceutical design. 2008; 14:1566-1580. [PubMed: 18673198] 
14. Engelhardt B. The blood-central nervous system barriers actively control immune cell entry into the central nervous system. Current pharmaceutical design. 2008; 14:1555-1565. [PubMed: 18673197]

15. Banks WA. The blood-brain barrier as a cause of disease. Current pharmaceutical design. 2008; 14:1553-1554. [PubMed: 18673196]

16. Paul, E. Das Sauerstoff-Bedurfnis des Organismus: Eine Farbenanalytische Studie. Berlin: Hirschwald; 1885.

17. Goldmann EE. Vitalfarbung am Zentralnervensystem. Abh. Preuss. Akad. Wiss. Phys. Math. K1. $1913 ; 1: 1-60$.

18. Reese TS, Karnovsky MJ. Fine structural localization of a blood-brain barrier to exogenous peroxidase. The Journal of cell biology. 1967; 34:207-217. [PubMed: 6033532]

19. Karnovsky MJ. The ultrastructural basis of capillary permeability studied with peroxidase as a tracer. The Journal of cell biology. 1967; 35:213-236. [PubMed: 6061717]

20. Rubin LL, Staddon JM. The cell biology of the blood-brain barrier. Annual review of neuroscience. 1999; 22:11-28.

21. Ramsauer, M. Pericytes and Their Conctribution to the Blood-Brain Barrier. In: Rolf Dermietzel, DCSaMN., editor. Blood-Brain Barriers, from Ontogeny to Artificial Interfaces. WILEY-VCH; 2006. p. 29

22. Frederic Mercier, SM.; Hatton, Glenn I. Brain Microphages: Enigmas and Conundrums. In: Rolf Dermietzel, DCSaMN., editor. Blood-Brain Barriers, from Ontogeny to Artificial Interfaces. WILEY-VCH; 2006. p. 37

23. Hawkins BT, Davis TP. The blood-brain barrier/neurovascular unit in health and disease. Pharmacological reviews. 2005; 57:173-185. [PubMed: 15914466]

24. Banks WA. Drug delivery to the brain in Alzheimer's disease: consideration of the blood-brain barrier. Advanced drug delivery reviews. 2012; 64:629-639. [PubMed: 22202501]

25. Ogunshola OO, Al-Ahmad A. HIF-1 at the blood-brain barrier: a mediator of permeability? High altitude medicine \& biology. 2012; 13:153-161. [PubMed: 22994514]

26. Kaur C, Ling EA. Blood brain barrier in hypoxic-ischemic conditions. Current neurovascular research. 2008; 5:71-81. [PubMed: 18289024]

27. Fiala M, Zhang L, Gan X, Sherry B, Taub D, Graves MC, Hama S, Way D, Weinand M, Witte M, Lorton D, Kuo YM, Roher AE. Amyloid-beta induces chemokine secretion and monocyte migration across a human blood--brain barrier model. Mol Med. 1998; 4:480-489. [PubMed: 9713826]

28. Rosell A, Cuadrado E, Ortega-Aznar A, Hernandez-Guillamon M, Lo EH, Montaner J. MMP-9positive neutrophil infiltration is associated to blood-brain barrier breakdown and basal lamina type IV collagen degradation during hemorrhagic transformation after human ischemic stroke. Stroke; a journal of cerebral circulation. 2008; 39:1121-1126.

29. Scholler K, Trinkl A, Klopotowski M, Thal SC, Plesnila N, Trabold R, Hamann GF, SchmidElsaesser R, Zausinger S. Characterization of microvascular basal lamina damage and blood-brain barrier dysfunction following subarachnoid hemorrhage in rats. Brain research. 2007; 1142:237246. [PubMed: 17303089]

30. Nicaise C, Mitrecic D, Demetter P, De Decker R, Authelet M, Boom A, Pochet R. Impaired bloodbrain and blood-spinal cord barriers in mutant SOD1-linked ALS rat. Brain research. 2009; 1301:152-162. [PubMed: 19748495]

31. Claudio L. Ultrastructural features of the blood-brain barrier in biopsy tissue from Alzheimer's disease patients. Acta neuropathologica. 1996; 91:6-14. [PubMed: 8773140]

32. Williams DW, Eugenin EA, Calderon TM, Berman JW. Monocyte maturation, HIV susceptibility, and transmigration across the blood brain barrier are critical in HIV neuropathogenesis. Journal of leukocyte biology. 2012; 91:401-415. [PubMed: 22227964]

33. Kondo A, Suzuki K. The blood brain barrier in human leukodystrophies and allied diseases. Ultrastructural and morphometric studies on the capillaries in brain biopsies. Clinical neuropathology. 1993; 12:169-174. [PubMed: 8324966] 
34. Tsurita G, Nagawa H, Ueno S, Watanabe S, Taki M. Biological and morphological effects on the brain after exposure of rats to a $1439 \mathrm{MHz}$ TDMA field. Bioelectromagnetics. 2000; 21:364-371. [PubMed: 10899772]

35. Miller DS, Bauer B, Hartz AM. Modulation of P-glycoprotein at the blood-brain barrier: opportunities to improve central nervous system pharmacotherapy. Pharmacological reviews. 2008; 60:196-209. [PubMed: 18560012]

36. Banks WA, Kastin AJ, Huang W, Jaspan JB, Maness LM. Leptin enters the brain by a saturable system independent of insulin. Peptides. 1996; 17:305-311. [PubMed: 8801538]

37. Banks WA, DiPalma CR, Farrell CL. Impaired transport of leptin across the bloodbrain barrier in obesity. Peptides. 1999; 20:1341-1345. [PubMed: 10612449]

38. Banks WA, Farrell CL. Impaired transport of leptin across the blood-brain barrier in obesity is acquired and reversible. American journal of physiology. Endocrinology and metabolism. 2003; 285:E10-E15. [PubMed: 12618361]

39. Kastin AJ, Pan W, Maness LM, Koletsky RJ, Ernsberger P. Decreased transport of leptin across the blood-brain barrier in rats lacking the short form of the leptin receptor. Peptides. 1999; 20:1449-1453. [PubMed: 10698121]

40. Hileman SM, Pierroz DD, Masuzaki H, Bjorbaek C, El-Haschimi K, Banks WA, Flier JS. Characterizaton of short isoforms of the leptin receptor in rat cerebral microvessels and of brain uptake of leptin in mouse models of obesity. Endocrinology. 2002; 143:775-783. [PubMed: 11861497]

41. Ravenstijn PG, Drenth HJ, O'Neill MJ, Danhof M, de Lange EC. Evaluation of bloodbrain barrier transport and CNS drug metabolism in diseased and control brain after intravenous L-DOPA in a unilateral rat model of Parkinson's disease. Fluids and barriers of the CNS. 2012; 9:4. [PubMed: 22316420]

42. Marsala, M.; Vanicky, I.; Tokumine, J.; Kakinohana, O.; Marsala, J. Blood-Brain Barrier Changes in Global And Focal Cerebral Ischemia. In: Westman, HSSaJ, editor. Blood-spinal cord and brain barriers in health and disease. Elsiver Academic Press; 2004. p. 385-386.

43. Preston E, Webster J. Differential passage of [14C]sucrose and [3H]inulin across rat blood-brain barrier after cerebral ischemia. Acta neuropathologica. 2002; 103:237-242. [PubMed: 11907803]

44. Nagaraja TN, Keenan KA, Fenstermacher JD, Knight RA. Acute leakage patterns of fluorescent plasma flow markers after transient focal cerebral ischemia suggest large openings in blood-brain barrier. Microcirculation. 2008; 15:1-14. [PubMed: 17934962]

45. Nagaraja TN, Ewing JR, Karki K, Jacobs PE, Divine GW, Fenstermacher JD, Patlak CS, Knight RA. MRI and quantitative autoradiographic studies following bolus injections of unlabeled and (14)C-labeled gadolinium-diethylenetriaminepentaacetic acid in a rat model of stroke yield similar distribution volumes and blood-to-brain influx rate constants. NMR in biomedicine. 2011; 24:547558. [PubMed: 21674656]

46. Jullienne A, Badaut J. Molecular contributions to neurovascular unit dysfunctions after brain injuries: lessons for target-specific drug development. Future neurology. 2013; 8:677-689. [PubMed: 24489483]

47. Kuntz M, Mysiorek C, Petrault O, Petrault M, Uzbekov R, Bordet R, Fenart L, Cecchelli R, Berezowski V. Stroke-induced brain parenchymal injury drives blood-brain barrier early leakage kinetics: a combined in vivo/in vitro study. J Cereb Blood Flow Metab. 2014; 34:95-107. [PubMed: 24084699]

48. Jullienne A, Badaut J. Molecular contributions to neurovascular unit dysfunctions after brain injuries: lessons for target-specific drug development. Future neurology. 2013; 8 677+.

49. Saenger AK, Christenson RH. Stroke biomarkers: progress and challenges for diagnosis, prognosis, differentiation, and treatment. Clinical chemistry. 2010; 56:21-33. [PubMed: 19926776]

50. Lee SW, Kim WJ, Park JA, Choi YK, Kwon YW, Kim KW. Blood-brain barrier interfaces and brain tumors. Archives of pharmacal research. 2006; 29:265-275. [PubMed: 16681030]

51. Feng S, Cen J, Huang Y, Shen H, Yao L, Wang Y, Chen Z. Matrix metalloproteinase-2 and -9 secreted by leukemic cells increase the permeability of blood-brain barrier by disrupting tight junction proteins. PloS one. 2011; 6:e20599. [PubMed: 21857898] 
52. Wisniewski HM, Pluta R, Lossinsky AS, Mossakowski MJ. Ultrastructural studies of cerebral vascular spasm after cardiac arrest-related global cerebral ischemia in rats. Acta neuropathologica. 1995; 90:432-440. [PubMed: 8560974]

53. Cipolla MJ, Crete R, Vitullo L, Rix RD. Transcellular transport as a mechanism of blood-brain barrier disruption during stroke. Frontiers in bioscience : a journal and virtual library. 2004; 9:777-785. [PubMed: 14766407]

54. Craft S, Baker LD, Montine TJ, Minoshima S, Watson GS, Claxton A, Arbuckle M, Callaghan M, Tsai E, Plymate SR, Green PS, Leverenz J, Cross D, Gerton B. Intranasal insulin therapy for Alzheimer disease and amnestic mild cognitive impairment: a pilot clinical trial. Archives of neurology. 2012; 69:29-38. [PubMed: 21911655]

55. Craft S, Cholerton B, Baker LD. Insulin and Alzheimer's Disease: Untangling the Web. Journal of Alzheimer's disease : JAD,. 2012

56. Freiherr J, Hallschmid M, Frey WH 2nd, Brunner YF, Chapman CD, Holscher C, Craft S, De Felice FG, Benedict C. Intranasal insulin as a treatment for Alzheimer's disease: a review of basic research and clinical evidence. CNS drugs. 2013; 27:505-514. [PubMed: 23719722]

57. Gantz I, Erondu N, Mallick M, Musser B, Krishna R, Tanaka WK, Snyder K, Stevens C, Stroh MA, Zhu H, Wagner JA, Macneil DJ, Heymsfield SB, Amatruda JM. Efficacy and safety of intranasal peptide YY3-36 for weight reduction in obese adults. The Journal of clinical endocrinology and metabolism. 2007; 92:1754-1757. [PubMed: 17341568]

58. Rattazzi MC, Dobrenis K. Treatment of GM2 gangliosidosis: past experiences, implications, and future prospects. Advances in genetics. 2001; 44:317-339. [PubMed: 11596993]

59. von Specht BU, Geiger B, Arnon R, Passwell J, Keren G, Goldman B, Padeh B. Enzyme replacement in Tay?Sachs disease. Neurology. 1979; 29:848. [PubMed: 572006]

60. Shire. Study of Intrathecal Idursulfase-IT Administered in Conjunction With Elaprase®. Pediatric Patients With Hunter Syndrome and Early Cognitive Impairment (AIM-IT). ClinicalTrials.gov. 2014.

61. Calias P, Papisov M, Pan J, Savioli N, Belov V, Huang Y, Lotterhand J, Alessandrini M, Liu N, Fischman AJ, Powell JL, Heartlein MW. CNS penetration of intrathecal-lumbar idursulfase in the monkey, dog and mouse: implications for neurological outcomes of lysosomal storage disorder. PloS one. 2012; 7:e30341. [PubMed: 22279584]

62. Eriksdotter Jonhagen M, Nordberg A, Amberla K, Backman L, Ebendal T, Meyerson B, Olson L, Seiger, Shigeta M, Theodorsson E, Viitanen M, Winblad B, Wahlund LO. Intracerebroventricular infusion of nerve growth factor in three patients with Alzheimer's disease. Dementia and geriatric cognitive disorders. 1998; 9:246-257. [PubMed: 9701676]

63. Nutt JG, Burchiel KJ, Comella CL, Jankovic J, Lang AE, Laws ER Jr, Lozano AM, Penn RD, Simpson RK Jr, Stacy M, Wooten GF. Randomized, double-blind trial of glial cell line-derived neurotrophic factor (GDNF) in PD. Neurology. 2003; 60:69-73. [PubMed: 12525720]

64. Lang AE, Gill S, Patel NK, Lozano A, Nutt JG, Penn R, Brooks DJ, Hotton G, Moro E, Heywood P, Brodsky MA, Burchiel K, Kelly P, Dalvi A, Scott B, Stacy M, Turner D, Wooten VG, Elias WJ, Laws ER, Dhawan V, Stoessl AJ, Matcham J, Coffey RJ, Traub M. Randomized controlled trial of intraputamenal glial cell line-derived neurotrophic factor infusion in Parkinson disease. Annals of neurology. 2006; 59:459-466. [PubMed: 16429411]

65. Salvatore MF, Ai Y, Fischer B, Zhang AM, Grondin RC, Zhang Z, Gerhardt GA, Gash DM. Point source concentration of GDNF may explain failure of phase II clinical trial. Experimental neurology. 2006; 202:497-505. [PubMed: 16962582]

66. Kalra S, Genge A, Arnold DL. A prospective, randomized, placebo-controlled evaluation of corticoneuronal response to intrathecal BDNF therapy in ALS using magnetic resonance spectroscopy: feasibility and results, Amyotrophic lateral sclerosis and other motor neuron disorders : official publication of the World Federation of Neurology. Research Group on Motor Neuron Diseases. 2003; 4:22-26.

67. Beck M, Flachenecker P, Magnus T, Giess R, Reiners K, Toyka KV, Naumann M. Autonomic dysfunction in ALS: a preliminary study on the effects of intrathecal BDNF, Amyotrophic lateral sclerosis and other motor neuron disorders : official publication of the World Federation of Neurology. Research Group on Motor Neuron Diseases. 2005; 6:100-103. 
68. Boswell CA, Brechbiel MW. Development of radioimmunotherapeutic and diagnostic antibodies: an inside-out view. Nuclear medicine and biology. 2007; 34:757-778. [PubMed: 17921028]

69. Convection-Enhanced Delivery of 124I-8H9 for Patients With Non-Progressive Diffuse Pontine Gliomas Previously Treated With External Beam Radiation Therapy. 2014

70. DDAVP Nasal Spray, in, RxList Inc. 2014 http://www.rxlist.com/ddavp-nasal-spray-drug/ indications-dosage.htm.

71. De Berardis D, Marini S, Iasevoli F, Tomasetti C, de Bartolomeis A, Mazza M, Valchera A, Fornaro M, Cavuto M, Srinivasan V, Sepede G, Martinotti G, Di Giannantonio M. The role of intranasal oxytocin in the treatment of patients with schizophrenia: a systematic review. CNS \& neurological disorders drug targets. 2013; 12:252-264. [PubMed: 23469841]

72. Davis MC, Lee J, Horan WP, Clarke AD, McGee MR, Green MF, Marder SR. Effects of single dose intranasal oxytocin on social cognition in schizophrenia. Schizophrenia research. 2013; 147:393-397. [PubMed: 23676253]

73. Lee MR, Wehring HJ, McMahon RP, Linthicum J, Cascella N, Liu F, Bellack A, Buchanan RW, Strauss GP, Contoreggi C, Kelly DL. Effects of adjunctive intranasal oxytocin on olfactory identification and clinical symptoms in schizophrenia: results from a randomized double blind placebo controlled pilot study. Schizophrenia research. 2013; 145:110-115. [PubMed: 23415472]

74. Bakermans-Kranenburg MJ, van IJMH. Sniffing around oxytocin: review and metaanalyses of trials in healthy and clinical groups with implications for pharmacotherapy. Translational psychiatry. 2013; 3:e258. [PubMed: 23695233]

75. Preti A, Melis M, Siddi S, Vellante M, Doneddu G, Fadda R. Oxytocin and autism: a systematic review of randomized controlled trials. Journal of child and adolescent psychopharmacology. 2014; 24:54-68. [PubMed: 24679173]

76. Sanger GJ, Lee K. Hormones of the gut-brain axis as targets for the treatment of upper gastrointestinal disorders. Nature reviews. 2008; 7:241-254.

77. Banks WA, Farr SA, Morley JE. The effects of high fat diets on the blood-brain barrier transport of leptin: failure or adaptation? Physiology \& behavior. 2006; 88:244-248. [PubMed: 16781741]

78. Banks WA, Gertler A, Solomon G, Niv-Spector L, Shpilman M, Yi X, Batrakova E, Vinogradov S, Kabanov AV. Principles of strategic drug delivery to the brain (SDDB): development of anorectic and orexigenic analogs of leptin. Physiology \& behavior. 2011; 105:145-149. [PubMed: 21669216]

79. Ratko, TA.; Marbella, A.; Godfrey, S.; Aronson, N. Enzyme-Replacement Therapies for Lysosomal Storage Diseases. Rockville MD; 2013.

80. Hawkes C, Kar S. The insulin-like growth factor-II/mannose-6-phosphate receptor: structure, distribution and function in the central nervous system. Brain research. Brain research reviews. 2004; 44:117-140. [PubMed: 15003389]

81. Urayama A, Grubb JH, Sly WS, Banks WA. Mannose 6-phosphate receptor-mediated transport of sulfamidase across the blood-brain barrier in the newborn mouse. Molecular therapy : the journal of the American Society of Gene Therapy. 2008; 16:1261-1266. [PubMed: 18443601]

82. Urayama A, Grubb JH, Banks WA, Sly WS. Epinephrine enhances lysosomal enzyme delivery across the blood brain barrier by up-regulation of the mannose 6-phosphate receptor. Proceedings of the National Academy of Sciences of the United States of America. 2007; 104:12873-12878. [PubMed: 17646643]

83. Urayama A, Grubb JH, Sly WS, Banks WA. Developmentally regulated mannose 6- phosphate receptor-mediated transport of a lysosomal enzyme across the blood-brain barrier. Proceedings of the National Academy of Sciences of the United States of America. 2004; 101:12658-12663. [PubMed: 15314220]

84. Schlesinger PH, Rodman JS, Doebber TW, Stahl PD, Lee YC, Stowell CP, Kuhlenschmidt TB. The role of extra-hepatic tissues in the receptor-mediated plasma clearance of glycoproteins terminated by mannose or N-acetylglucosamine. The Biochemical journal. 1980; 192:597-606. [PubMed: 7236228]

85. Thorne RG, Frey WH 2nd. Delivery of neurotrophic factors to the central nervous system: pharmacokinetic considerations. Clinical pharmacokinetics. 2001; 40:907-946. [PubMed: 11735609] 
86. Pan W, Banks WA, Kastin AJ. Permeability of the blood-brain barrier to neurotrophins. Brain research. 1998; 788:87-94. [PubMed: 9554964]

87. Pan W, Banks WA, Fasold MB, Bluth J, Kastin AJ. Transport of brain-derived neurotrophic factor across the blood-brain barrier. Neuropharmacology. 1998; 37:1553-1561. [PubMed: 9886678]

88. Kordower JH, Palfi S, Chen EY, Ma SY, Sendera T, Cochran EJ, Cochran EJ, Mufson EJ, Penn R, Goetz CG, Comella CD. Clinicopathological findings following intraventricular glial-derived neurotrophic factor treatment in a patient with Parkinson's disease. Annals of neurology. 1999; 46:419-424. [PubMed: 10482276]

89. Kim YH, Nagai H, Ozasa H, Sakamori Y, Mishima M. Therapeutic strategy for nonsmall- cell lung cancer patients with brain metastases (Review). Biomedical reports. 2013; 1:691-696. [PubMed: 24649011]

90. Kuittinen O, Siniluoto T, Isokangas M, Turpeenniemi-Hujanen T, Peltonen J, Alahuhta S, Sonkajarvi E. [Chemotherapy in conjunction with blood brain barrier disruption in the treatment of primary central nervous system lymphoma]. Duodecim; laaketieteellinen aikakauskirja. 2013; 129:1563-1570.

91. Hernandez-Pedro NY, Rangel-Lopez E, Vargas Felix G, Pineda B, Sotelo J. An update in the use of antibodies to treat glioblastoma multiforme. Autoimmune diseases. 2013; 2013:716813. [PubMed: 24294521]

92. Winblad B, Graf A, Riviere ME, Andreasen N, Ryan JM. Active immunotherapy options for Alzheimer's disease. Alzheimer's research \& therapy. 2014; 6:7.

93. Lannfelt L, Relkin NR, Siemers ER. Amyloid-ss-directed immunotherapy for Alzheimer's disease. Journal of internal medicine. 2014; 275:284-295. [PubMed: 24605809]

94. Poduslo JF, Ramakrishnan M, Holasek SS, Ramirez-Alvarado M, Kandimalla KK, Gilles EJ, Curran GL, Wengenack TM. In vivo targeting of antibody fragments to the nervous system for Alzheimer's disease immunotherapy and molecular imaging of amyloid plaques. Journal of neurochemistry. 2007; 102:420-433. [PubMed: 17596213]

95. Witt KA, Gillespie TJ, Huber JD, Egleton RD, Davis TP. Peptide drug modifications to enhance bioavailability and blood-brain barrier permeability. Peptides. 2001; 22:2329-2343. [PubMed: 11786210]

96. Chen C, Pollack GM. Altered disposition and antinociception of [D-penicillamine(2,5)] enkephalin in mdrla-gene-deficient mice. The Journal of pharmacology and experimental therapeutics. 1998; 287:545-552. [PubMed: 9808679]

97. Del Vecchio CA, Li G, Wong AJ. Targeting EGF receptor variant III: tumor-specific peptide vaccination for malignant gliomas. Expert review of vaccines. 2012; 11:133-144. [PubMed: 22309662]

98. Del Vecchio CA, Li G, Wong AJ. Targeting EGF receptor variant III: tumor-specific peptide vaccination for malignant gliomas.

99. Ha D, Stone DK, Mosley RL, Gendelman HE. Immunization strategies for Parkinson's disease. Parkinsonism \& related disorders. 2012; 18(Suppl 1):S218-S221. [PubMed: 22166440]

100. Schneeberger A, Mandler M, Mattner F, Schmidt W. Vaccination for Parkinson's disease. Parkinsonism \& related disorders. 2012; 18(Suppl 1):S11-S13. [PubMed: 22166404]

101. Agu RU, Ugwoke MI, Armand M, Kinget R, Verbeke N. The lung as a route for systemic delivery of therapeutic proteins and peptides. Respiratory research. 2001; 2:198-209. [PubMed: 11686885]

102. Scheuch G, Kohlhaeufl MJ, Brand P, Siekmeier R. Clinical perspectives on pulmonary systemic and macromolecular delivery. Advanced drug delivery reviews. 2006; 58:996-1008. [PubMed: 16996638]

103. Selam JL. Inhaled insulin for the treatment of diabetes: projects and devices. Expert opinion on pharmacotherapy. 2003; 4:1373-1377. [PubMed: 12877644]

104. Park K, Kwon IC, Park K. Oral protein delivery: Current status and future prospect. Reactive and Functional Polymers. 2011; 71:280-287.

105. Singh R, Singh S, Lillard JW Jr. Past, present, and future technologies for oral delivery of therapeutic proteins. Journal of pharmaceutical sciences. 2008; 97:2497-2523. [PubMed: 17918721] 
106. Jung T, Kamm W, Breitenbach A, Kaiserling E, Xiao JX, Kissel T. Biodegradable nanoparticles for oral delivery of peptides: is there a role for polymers to affect mucosal uptake? Eur J Pharm Biopharm. 2000; 50:147-160. [PubMed: 10840198]

107. Das D, Lin S. Double-coated poly (butylcynanoacrylate) nanoparticulate delivery systems for brain targeting of dalargin via oral administration. Journal of pharmaceutical sciences. 2005; 94:1343-1353. [PubMed: 15858853]

108. Zhou S, Deng X, He S, Li X, Jia W, Wei D, Zhang Z, Ma J. Study on biodegradable microspheres containing recombinant interferon-alpha-2a. The Journal of pharmacy and pharmacology. 2002; 54:1287-1292. [PubMed: 12356284]

109. Banks WA. Are the extracellular [correction of extracelluar] pathways a conduit for the delivery of therapeutics to the brain? Current pharmaceutical design. 2004; 10:1365-1370. [PubMed: 15134487]

110. Banks WA, Terrell B, Farr SA, Robinson SM, Nonaka N, Morley JE. Passage of amyloid beta protein antibody across the blood-brain barrier in a mouse model of Alzheimer's disease. Peptides. 2002; 23:2223-2226. [PubMed: 12535702]

111. Bard F, Cannon C, Barbour R, Burke RL, Games D, Grajeda H, Guido T, Hu K, Huang J, Johnson-Wood K, Khan K, Kholodenko D, Lee M, Lieberburg I, Motter R, Nguyen M, Soriano F, Vasquez N, Weiss K, Welch B, Seubert P, Schenk D, Yednock T. Peripherally administered antibodies against amyloid beta-peptide enter the central nervous system and reduce pathology in a mouse model of Alzheimer disease. Nature medicine. 2000; 6:916-919.

112. Morgan D, Diamond DM, Gottschall PE, Ugen KE, Dickey C, Hardy J, Duff K, Jantzen P, DiCarlo G, Wilcock D, Connor K, Hatcher J, Hope C, Gordon M, Arendash GW. A beta peptide vaccination prevents memory loss in an animal model of Alzheimer's disease. Nature. 2000; 408:982-985. [PubMed: 11140686]

113. Banks WA, Jumbe NL, Farrell CL, Niehoff ML, Heatherington AC. Passage of erythropoietic agents across the blood-brain barrier: a comparison of human and murine erythropoietin and the analog darbepoetin alfa. European journal of pharmacology. 2004; 505:93-101. [PubMed: 15556141]

114. Ehrenreich H, Hasselblatt M, Dembowski C, Cepek L, Lewczuk P, Stiefel M, Rustenbeck HH, Breiter N, Jacob S, Knerlich F, Bohn M, Poser W, Ruther E, Kochen M, Gefeller O, Gleiter C, Wessel TC, De Ryck M, Itri L, Prange H, Cerami A, Brines M, Siren AL. Erythropoietin therapy for acute stroke is both safe and beneficial. Mol Med. 2002; 8:495-505. [PubMed: 12435860]

115. Broadwell RD, Sofroniew MV. Serum proteins bypass the blood-brain fluid barriers for extracellular entry to the central nervous system. Experimental neurology. 1993; 120:245-263. [PubMed: 8491281]

116. Balin BJ, Broadwell RD, Salcman M, el-Kalliny M. Avenues for entry of peripherally administered protein to the central nervous system in mouse, rat, and squirrel monkey. The Journal of comparative neurology. 1986; 251:260-280. [PubMed: 3782501]

117. Yu YJ, Zhang Y, Kenrick M, Hoyte K, Luk W, Lu Y, Atwal J, Elliott JM, Prabhu S, Watts RJ, Dennis MS. Boosting brain uptake of a therapeutic antibody by reducing its affinity for a transcytosis target. Science translational medicine. 2011; 3:84ra44.

118. Vogler C, Levy B, Grubb JH, Galvin N, Tan Y, Kakkis E, Pavloff N, Sly WS. Overcoming the blood-brain barrier with high-dose enzyme replacement therapy in murine mucopolysaccharidosis VII. Proceedings of the National Academy of Sciences of the United States of America. 2005; 102:14777-14782. [PubMed: 16162667]

119. Pisal DS, Kosloski MP, Balu-Iyer SV. Delivery of therapeutic proteins. Journal of pharmaceutical sciences. 2010; 99:2557-2575. [PubMed: 20049941]

120. Nance EA, Woodworth GF, Sailor KA, Shih TY, Xu Q, Swaminathan G, Xiang D, Eberhart C, Hanes J. A dense poly(ethylene glycol) coating improves penetration of large polymeric nanoparticles within brain tissue. Science translational medicine. 2012; 4:149ra1 19.

121. Jonhagen ME. Nerve growth factor treatment in dementia. Alzheimer disease and associated disorders. 2000; 14(Suppl 1):S31-S38. [PubMed: 10850728] 
122. Blasberg RG, Patlak C, Fenstermacher JD. Intrathecal chemotherapy: brain tissue profiles after ventriculocisternal perfusion. The Journal of pharmacology and experimental therapeutics. 1975; 195:73-83. [PubMed: 810575]

123. Mufson EJ, Kroin JS, Liu YT, Sobreviela T, Penn RD, Miller JA, Kordower JH. Intrastriatal and intraventricular infusion of brain-derived neurotrophic factor in the cynomologous monkey: distribution, retrograde transport and co-localization with substantia nigra dopamine-containing neurons. Neuroscience. 1996; 71:179-191. [PubMed: 8834401]

124. Yan Q, Matheson C, Sun J, Radeke MJ, Feinstein SC, Miller JA. Distribution of intracerebral ventricularly administered neurotrophins in rat brain and its correlation with trk receptor expression. Experimental neurology. 1994; 127:23-36. [PubMed: 8200435]

125. Ferguson IA, Schweitzer JB, Bartlett PF, Johnson EM Jr. Receptor-mediated retrograde transport in CNS neurons after intraventricular administration of NGF and growth factors. The Journal of comparative neurology. 1991; 313:680-692. [PubMed: 1664436]

126. Jain RK. Delivery of novel therapeutic agents in tumors: physiological barriers and strategies. Journal of the National Cancer Institute. 1989; 81:570-576. [PubMed: 2649688]

127. Saltzman WM, Mak MW, Mahoney MJ, Duenas ET, Cleland JL. Intracranial delivery of recombinant nerve growth factor: release kinetics and protein distribution for three delivery systems. Pharmaceutical research. 1999; 16:232-240. [PubMed: 10100308]

128. Bobo RH, Laske DW, Akbasak A, Morrison PF, Dedrick RL, Oldfield EH. Convection-enhanced delivery of macromolecules in the brain. Proceedings of the National Academy of Sciences of the United States of America. 1994; 91:2076-2080. [PubMed: 8134351]

129. Debinski W, Tatter SB. Convection-enhanced delivery for the treatment of brain tumors. Expert review of neurotherapeutics. 2009; 9:1519-1527. [PubMed: 19831841]

130. Barua NU, Gill SS, Love S. Convection-Enhanced Drug Delivery to the Brain: Therapeutic Potential and Neuropathological Considerations. Brain Pathol. 2013

131. Pardridge WM. Biopharmaceutical drug targeting to the brain. Journal of drug targeting. 2010; 18:157-167. [PubMed: 20064077]

132. Wersall P, Ohlsson I, Biberfeld P, Collins VP, von Krusenstjerna S, Larsson S, Mellstedt H, Boethius J. Intratumoral infusion of the monoclonal antibody, mAb 425, against the epidermalgrowth-factor receptor in patients with advanced malignant glioma. Cancer Immunol Immunother. 1997; 44:157-164. [PubMed: 9191875]

133. Lonser RR, Schiffman R, Robison RA, Butman JA, Quezado Z, Walker ML, Morrison PF, Walbridge S, Murray GJ, Park DM, Brady RO, Oldfield EH. Image-guided, direct convective delivery of glucocerebrosidase for neuronopathic Gaucher disease. Neurology. 2007; 68:254261. [PubMed: 17065591]

134. Allard E, Passirani C, Benoit JP. Convection-enhanced delivery of nanocarriers for the treatment of brain tumors. Biomaterials. 2009; 30:2302-2318. [PubMed: 19168213]

135. Lochhead JJ, Thorne RG. Intranasal delivery of biologics to the central nervous system. Advanced drug delivery reviews. 2012; 64:614-628. [PubMed: 22119441]

136. Chen XQ, Fawcett JR, Rahman YE, Ala TA, Frey IW. Delivery of Nerve Growth Factor to the Brain via the Olfactory Pathway. Journal of Alzheimer's disease : JAD. 1998; 1:35-44.

137. Thorne RG, Pronk GJ, Padmanabhan V, Frey WH 2nd. Delivery of insulin-like growth factor-I to the rat brain and spinal cord along olfactory and trigeminal pathways following intranasal administration. Neuroscience. 2004; 127:481-496. [PubMed: 15262337]

138. Renner DB, Frey WH 2nd, Hanson LR. Intranasal delivery of siRNA to the olfactory bulbs of mice via the olfactory nerve pathway. Neuroscience letters. 2012; 513:193-197. [PubMed: 22387067]

139. Renner DB, Svitak AL, Gallus NJ, Ericson ME, Frey WH 2nd, Hanson LR. Intranasal delivery of insulin via the olfactory nerve pathway. The Journal of pharmacy and pharmacology. 2012; 64:1709-1714. [PubMed: 23146033]

140. Pietrowsky R, Thiemann A, Kern W, Fehm HL, Born J. A nose-brain pathway for psychotropic peptides: evidence from a brain evoked potential study with cholecystokinin. Psychoneuroendocrinology. 1996; 21:559-572. [PubMed: 8983091] 
141. Kern W, Schiefer B, Schwarzenburg J, Stange EF, Born J, Fehm HL. Evidence for central nervous effects of corticotropin-releasing hormone on gastric acid secretion in humans. Neuroendocrinology. 1997; 65:291-298. [PubMed: 9143001]

142. Kern W, Born J, Schreiber H, Fehm HL. Central nervous system effects of intranasally administered insulin during euglycemia in men. Diabetes. 1999; 48:557-563. [PubMed: 10078556]

143. Guastella AJ, MacLeod C. A critical review of the influence of oxytocin nasal spray on social cognition in humans: evidence and future directions. Hormones and behavior. 2012; 61:410-418. [PubMed: 22265852]

144. Evans SL, Dal Monte O, Noble P, Averbeck BB. Intranasal oxytocin effects on social cognition: A critique. Brain research. 2013

145. Lopes T, Dias JS, Marcelino J, Varela J, Ribeiro S, Dias J. An assessment of the clinical efficacy of intranasal desmopressin spray in the treatment of renal colic. BJU international. 2001; 87:322325. [PubMed: 11251523]

146. http://www.drugs.com/pro/desmopressin-nasal-spray.html, in.

147. Theodoridou A, Penton-Voak IS, Rowe AC. A direct examination of the effect of intranasal administration of oxytocin on approach-avoidance motor responses to emotional stimuli. PloS one. 2013; 8:e58113. [PubMed: 23469148]

148. Kim YR, Kim CH, Cardi V, Eom JS, Seong Y, Treasure J. Intranasal oxytocin attenuates attentional bias for eating and fat shape stimuli in patients with anorexia nervosa. Psychoneuroendocrinology. 2014

149. Prehn K, Kazzer P, Lischke A, Heinrichs M, Herpertz SC, Domes G. Effects of intranasal oxytocin on pupil dilation indicate increased salience of socioaffective stimuli. Psychophysiology. 2013; 50:528-537. [PubMed: 23551070]

150. Riekkinen P, Legros JJ, Sennef C, Jolkkonen J, Smitz S, Soininen H. Penetration of DGAVP (Org 5667) across the blood-brain barrier in human subjects. Peptides. 1987; 8:261-265. [PubMed: 3588346]

151. Pietrowsky R, Struben C, Molle M, Fehm HL, Born J. Brain potential changes after intranasal vs. intravenous administration of vasopressin: evidence for a direct nose-brain pathway for peptide effects in humans. Biological psychiatry. 1996; 39:332-340. [PubMed: 8704064]

152. Banks WA, During MJ, Niehoff ML. Brain uptake of the glucagon-like peptide-1 antagonist exendin(9-39) after intranasal administration. The Journal of pharmacology and experimental therapeutics. 2004; 309:469-475. [PubMed: 14724226]

153. Kovalszky I, Surmacz E, Scolaro L, Cassone M, Ferla R, Sztodola A, Olah J, Hatfield MP, Lovas S, Otvos L Jr. Leptin-based glycopeptide induces weight loss and simultaneously restores fertility in animal models. Diabetes, obesity \& metabolism. 2010; 12:393-402.

154. Ross TM, Martinez PM, Renner JC, Thorne RG, Hanson LR, Frey WH 2nd. Intranasal administration of interferon beta bypasses the blood-brain barrier to target the central nervous system and cervical lymph nodes: a non-invasive treatment strategy for multiple sclerosis. Journal of neuroimmunology. 2004; 151:66-77. [PubMed: 15145605]

155. Nonaka N, Farr SA, Nakamachi T, Morley JE, Nakamura M, Shioda S, Banks WA. Intranasal administration of PACAP: uptake by brain and regional brain targeting with cyclodextrins. Peptides. 2012; 36:168-175. [PubMed: 22687366]

156. Migliore MM, Vyas TK, Campbell RB, Amiji MM, Waszczak BL. Brain delivery of proteins by the intranasal route of administration: a comparison of cationic liposomes versus aqueous solution formulations. Journal of pharmaceutical sciences. 2010; 99:1745-1761. [PubMed: 19774660]

157. Broadwell RD, Balin BJ. Endocytic and exocytic pathways of the neuronal secretory process and trans-synaptic transfer of wheat germ agglutinin-horseradish peroxidase in vivo. The Journal of comparative neurology. 1985; 242:632-650. [PubMed: 2418083]

158. Baker H, Spencer RF. Transneuronal transport of peroxidase-conjugated wheat germ agglutinin (WGA-HRP) from the olfactory epithelium to the brain of the adult rat. Experimental brain research. Experimentelle Hirnforschung. 1986; 63:461-473. 
159. Corning J. Spinal anaesthesia and local medication of the cord. New York Medical Journal. 1885; 42:3.

160. Okuda Y, Sakoda S, Fujimura H, Nagata S, Yanagihara T, Bernard CC. Intrathecal administration of neutralizing antibody against Fas ligand suppresses the progression of experimental autoimmune encephalomyelitis. Biochemical and biophysical research communications. 2000; 275:164-168. [PubMed: 10944459]

161. Cahill CM, Dray A, Coderre TJ. Intrathecal nerve growth factor restores opioid effectiveness in an animal model of neuropathic pain. Neuropharmacology. 2003; 45:543-552. [PubMed: 12907315]

162. Bambakidis NC, Petrullis M, Kui X, Rothstein B, Karampelas I, Kuang Y, Selman WR, LaManna JC, Miller RH. Improvement of neurological recovery and stimulation of neural progenitor cell proliferation by intrathecal administration of Sonic hedgehog. Journal of neurosurgery. 2012; 116:1114-1120. [PubMed: 22324418]

163. MB Papisov V, Fischman AJ, Belova E, Titus J, Gagne C MG. Delivery of proteins to CNS as seen and measured by Positron Emission Tomography. Drug Delivery Transl. Res. 2012; 2:9.

164. Ochs G, Penn RD, York M, Giess R, Beck M, Tonn J, Haigh J, Malta E, Traub M, Sendtner M, Toyka KV. A phase I/II trial of recombinant methionyl human brain derived neurotrophic factor administered by intrathecal infusion to patients with amyotrophic lateral sclerosis, Amyotrophic lateral sclerosis and other motor neuron disorders : official publication of the World Federation of Neurology. Research Group on Motor Neuron Diseases. 2000; 1:201-206.

165. Dierenfeld AD, McEntee MF, Vogler CA, Vite CH, Chen AH, Passage M, Le S, Shah S, Jens JK, Snella EM, Kline KL, Parkes JD, Ware WA, Moran LE, Fales-Williams AJ, Wengert JA, Whitley RD, Betts DM, Boal AM, Riedesel EA, Gross W, Ellinwood NM, Dickson PI. Replacing the enzyme alpha-L-iduronidase at birth ameliorates symptoms in the brain and periphery of dogs with mucopolysaccharidosis type I. Science translational medicine. 2010; 2:60ra89.

166. Vuillemenot BR, Katz ML, Coates JR, Kennedy D, Tiger P, Kanazono S, Lobel P, Sohar I, Xu S, Cahayag R, Keve S, Koren E, Bunting S, Tsuruda LS, O'Neill CA. Intrathecal tripeptidylpeptidase 1 reduces lysosomal storage in a canine model of late infantile neuronal ceroid lipofuscinosis. Molecular genetics and metabolism. 2011; 104:325-337. [PubMed: 21784683]

167. Sohn YB, Lee J, Cho SY, Kim SJ, Ko AR, Nam MH, Jin DK. Improvement of CNS defects via continuous intrathecal enzyme replacement by osmotic pump in mucopolysaccharidosis type II mice. American journal of medical genetics. Part A. 2013; 161A:1036-1043. [PubMed: 23529876]

168. Kakkis E, McEntee M, Vogler C, Le S, Levy B, Belichenko P, Mobley W, Dickson P, Hanson S, Passage M. Intrathecal enzyme replacement therapy reduces lysosomal storage in the brain and meninges of the canine model of MPS I. Molecular genetics and metabolism. 2004; 83:163-174. [PubMed: 15464431]

169. Papisov MI, Belov VV, Gannon KS. Physiology of the intrathecal bolus: the leptomeningeal route for macromolecule and particle delivery to CNS. Molecular pharmaceutics. 2013; 10:1522-1532. [PubMed: 23316936]

170. Soderquist RG, Milligan ED, Harrison JA, Chavez RA, Johnson KW, Watkins LR, Mahoney MJ. PEGylation of interleukin-10 for the mitigation of enhanced pain states. Journal of biomedical materials research. Part A. 2010; 93:1169-1179. [PubMed: 19768789]

171. Lee BK, Kwon JS, Kim HJ, Yamamoto S, Lee EK. Solid-phase PEGylation of recombinant interferon alpha-2a for site-specific modification: process performance, characterization, and in vitro bioactivity. Bioconjug Chem. 2007; 18:1728-1734. [PubMed: 17941681]

172. Balan S, Choi JW, Godwin A, Teo I, Laborde CM, Heidelberger S, Zloh M, Shaunak S, Brocchini S. Site-specific PEGylation of protein disulfide bonds using a threecarbon bridge. Bioconjug Chem. 2007; 18:61-76. [PubMed: 17226958]

173. Brocchini S, Balan S, Godwin A, Choi JW, Zloh M, Shaunak S. PEGylation of native disulfide bonds in proteins. Nature protocols. 2006; 1:2241-2252.

174. Brocchini S, Godwin A, Balan S, Choi JW, Zloh M, Shaunak S. Disulfide bridge based PEGylation of proteins. Advanced drug delivery reviews. 2008; 60:3-12. [PubMed: 17920720] 
175. Shaunak S, Godwin A, Choi JW, Balan S, Pedone E, Vijayarangam D, Heidelberger S, Teo I, Zloh M, Brocchini S. Site-specific PEGylation of native disulfide bonds in therapeutic proteins. Nature chemical biology. 2006; 2:312-313.

176. Zloh M, Shaunak S, Balan S, Brocchini S. Identification and insertion of 3-carbon bridges in protein disulfide bonds: a computational approach. Nature protocols. $2007 ; 2: 1070-1083$.

177. Geoghegan KF, Stroh JG. Site-directed conjugation of nonpeptide groups to peptides and proteins via periodate oxidation of a 2-amino alcohol. Application to modification at Nterminal serine. Bioconjug Chem. 1992; 3:138-146. [PubMed: 1325188]

178. Salmaso S, Bersani S, Scomparin A, Mastrotto F, Scherpfer R, Tonon G, Caliceti P. Tailored PEG for rh-G-CSF analogue site-specific conjugation. Bioconjug Chem. 2009; 20:1179-1185. [PubMed: 19469471]

179. Zhang X, Li F, Lu XW, Liu CF. Protein C-terminal modification through thioacid/azide amidation. Bioconjug Chem. 2009; 20:197-200. [PubMed: 19140742]

180. Kinstler O, Molineux G, Treuheit M, Ladd D, Gegg C. Mono-N-terminal poly(ethylene glycol)protein conjugates. Advanced drug delivery reviews. 2002; 54:477-485. [PubMed: 12052710]

181. Kumagai AK, Eisenberg JB, Pardridge WM. Absorptive-mediated endocytosis of cationized albumin and a beta-endorphin-cationized albumin chimeric peptide by isolated brain capillaries. Model system of blood-brain barrier transport. The Journal of biological chemistry. 1987; 262:15214-15219. [PubMed: 2959663]

182. Pardridge WM, Kumagai AK, Eisenberg JB. Chimeric peptides as a vehicle for peptide pharmaceutical delivery through the blood-brain barrier. Biochemical and biophysical research communications. 1987; 146:307-313. [PubMed: 2955786]

183. Triguero D, Buciak JB, Yang J, Pardridge WM. Blood-brain barrier transport of cationized immunoglobulin G: enhanced delivery compared to native protein. Proceedings of the National Academy of Sciences of the United States of America. 1989; 86:4761-4765. [PubMed: 2734318]

184. Poduslo JF, Curran GL. Polyamine modification increases the permeability of proteins at the blood-nerve and blood-brain barriers. Journal of neurochemistry. 1996; 66:1599-1609. [PubMed: 8627316]

185. Poduslo JF, Curran GL. Permeability at the blood-brain and blood-nerve barriers of the neurotrophic factors: NGF, CNTF, NT-3, BDNF. Brain research. 1996; 36:280-286. [PubMed: 8965648]

186. Wengenack TM, Curran GL, Poduslo JF. Postischemic, systemic administration of polyaminemodified superoxide dismutase reduces hippocampal CA1 neurodegeneration in rat global cerebral ischemia. Brain research. 1997; 754:46-54. [PubMed: 9134958]

187. Poduslo JF, Curran GL, Peterson JA, McCormick DJ, Fauq AH, Khan MA, Wengenack TM. Design and chemical synthesis of a magnetic resonance contrast agent with enhanced in vitro binding, high blood-brain barrier permeability, and in vivo targeting to Alzheimer's disease amyloid plaques. Biochemistry. 2004; 43:6064-6075. [PubMed: 15147190]

188. Poduslo JF, Curran GL. Increased permeability of superoxide dismutase at the blood-nerve and blood-brain barriers with retained enzymatic activity after covalent modification with the naturally occurring polyamine, putrescine. Journal of neurochemistry. 1996; 67:734-741. [PubMed: 8764602]

189. Adler SG, Wang H, Ward HJ, Cohen AH, Border WA. Electrical charge. Its role in the pathogenesis and prevention of experimental membranous nephropathy in the rabbit. The Journal of clinical investigation. 1983; 71:487-499. [PubMed: 6826719]

190. Huang JT, Mannik M, Gleisner J. In situ formation of immune complexes in the choroid plexus of rats by sequential injection of a cationized antigen and unaltered antibodies. Journal of neuropathology and experimental neurology. 1984; 43:489-499. [PubMed: 6470747]

191. Ward HJ, Cohen AH, Border WA. In situ formation of subepithelial immune complexes in the rabbit glomerulus: requirement of a cationic antigen. Nephron. 1984; 36:257-264. [PubMed: 6369163]

192. Hardebo JE, Kahrstrom J. Endothelial negative surface charge areas and blood-brain barrier function. Acta physiologica Scandinavica. 1985; 125:495-499. [PubMed: 4083048] 
193. Nagy Z, Peters H, Huttner I. Charge-related alterations of the cerebral endothelium. Laboratory investigation; a journal of technical methods and pathology. 1983; 49:662-671.

194. Vehaskari VM, Chang CT, Stevens JK, Robson AM. The effects of polycations on vascular permeability in the rat. A proposed role for charge sites. The Journal of clinical investigation. 1984; 73:1053-1061. [PubMed: 6200500]

195. Vives E, Brodin P, Lebleu B. A truncated HIV-1 Tat protein basic domain rapidly translocates through the plasma membrane and accumulates in the cell nucleus. The Journal of biological chemistry. 1997; 272:16010-16017. [PubMed: 9188504]

196. Drin G, Mazel M, Clair P, Mathieu D, Kaczorek M, Temsamani J. Physico-chemical requirements for cellular uptake of pAntp peptide. Role of lipid-binding affinity. European journal of biochemistry / FEBS. 2001; 268:1304-1314. [PubMed: 11231282]

197. Wender PA, Mitchell DJ, Pattabiraman K, Pelkey ET, Steinman L, Rothbard JB. The design, synthesis, and evaluation of molecules that enable or enhance cellular uptake: peptoid molecular transporters. Proceedings of the National Academy of Sciences of the United States of America. 2000; 97:13003-13008. [PubMed: 11087855]

198. Lindgren M, Hallbrink M, Prochiantz A, Langel U. Cell-penetrating peptides. Trends in pharmacological sciences. 2000; 21:99-103. [PubMed: 10689363]

199. Herve F, Ghinea N, Scherrmann JM. CNS delivery via adsorptive transcytosis. The AAPS journal. 2008; 10:455-472. [PubMed: 18726697]

200. Schwarze SR, Ho A, Vocero-Akbani A, Dowdy SF. In vivo protein transduction: delivery of a biologically active protein into the mouse. Science. 1999; 285:1569-1572. [PubMed: 10477521]

201. Dietz GP, Valbuena PC, Dietz B, Meuer K, Mueller P, Weishaupt JH, Bahr M. Application of a blood-brain-barrier-penetrating form of GDNF in a mouse model for Parkinson's disease. Brain research. 2006; 1082:61-66. [PubMed: 16703672]

202. Cao G, Pei W, Ge H, Liang Q, Luo Y, Sharp FR, Lu A, Ran R, Graham SH, Chen J. In Vivo Delivery of a Bcl-xL Fusion Protein Containing the TAT Protein Transduction Domain Protects against Ischemic Brain Injury and Neuronal Apoptosis. J Neurosci. 2002; 22:5423-5431. [PubMed: 12097494]

203. Kilic E, Dietz GP, Hermann DM, Bahr M. Intravenous TAT-Bcl-Xl is protective after middle cerebral artery occlusion in mice. Annals of neurology. 2002; 52:617-622. [PubMed: 12402259]

204. Zhang C, Su Z, Zhao B, Qu Q, Tan Y, Cai L, Li X. Tat-modified leptin is more accessible to hypothalamus through brain-blood barrier with a significant inhibition of body-weight gain in high-fat-diet fed mice. Exp Clin Endocrinol Diabetes. 118:31-37. [PubMed: 19472101]

205. Cai B, Lin Y, Xue XH, Fang L, Wang N, Wu ZY. TAT-mediated delivery of neuroglobin protects against focal cerebral ischemia in mice. Exp Neurol. 227:224-231. [PubMed: 21093435]

206. Xiang L, Zhou R, Fu A, Xu X, Huang Y, Hu C. Targeted delivery of large fusion protein into hippocampal neurons by systemic administration. Journal of drug targeting. 19:632-636. [PubMed: 20932231]

207. Fu A, Wang Y, Zhan L, Zhou R. Targeted delivery of proteins into the central nervous system mediated by rabies virus glycoprotein-derived peptide. Pharm Res. 29:1562-1569. [PubMed: 22231987]

208. Sarkar G, Curran GL, Mahlum E, Decklever T, Wengenack TM, Blahnik A, Hoesley B, Lowe VJ, Poduslo JF, Jenkins RB. A carrier for non-covalent delivery of functional beta-galactosidase and antibodies against amyloid plaques and IgM to the brain. PLoS ONE. 6:e28881. [PubMed: 22216132]

209. Chekhonin VP, Kabanov AV, Zhirkov YA, Morozov GV. Fatty acid acylated Fabfragments of antibodies to neurospecific proteins as carriers for neuroleptic targeted delivery in brain. FEBS letters. 1991; 287:149-152. [PubMed: 1715283]

210. Chopineau J, Robert S, Fenart L, Cecchelli R, Lagoutte B, Paitier S, Dehouck MP, Domurado D. Monoacylation of ribonuclease A enables its transport across an in vitro model of the blood-brain barrier. J Control Release. 1998; 56:231-237. [PubMed: 9801446]

211. Slepnev VI, Phalente L, Labrousse H, Melik-Nubarov NS, Mayau V, Goud B, Buttin G, Kabanov AV. Fatty acid acylated peroxidase as a model for the study of interactions of hydrophobically- 
modified proteins with mammalian cells. Bioconjug Chem. 1995; 6:608-615. [PubMed: 8974461]

212. Batrakova EV, Vinogradov SV, Robinson SM, Niehoff ML, Banks WA, Kabanov AV. Polypeptide point modifications with fatty acid and amphiphilic block copolymers for enhanced brain delivery. Bioconjug Chem. 2005; 16:793-802. [PubMed: 16029020]

213. Yuan L, Wang J, Shen WC. Lipidization of human interferon-alpha: a new approach toward improving the delivery of protein drugs. J Control Release. 2008; 129:11-17. [PubMed: 18448186]

214. Resh MD. Trafficking and signaling by fatty-acylated and prenylated proteins. Nature chemical biology. 2006; 2:584-590.

215. Edmond J. Essential polyunsaturated fatty acids and the barrier to the brain: the components of a model for transport. J Mol Neurosci. 2001; 16:181-193. discussion 215-121. [PubMed: 11478373]

216. Edmond J, Higa TA, Korsak RA, Bergner EA, Lee WN. Fatty acid transport and utilization for the developing brain. Journal of neurochemistry. 1998; 70:1227-1234. [PubMed: 9489745]

217. Chen CY, Fujimiya M, Asakawa A, Chang FY, Cheng JT, Lee SD, Inui A. At the cutting edge: ghrelin gene products in food intake and gut motility. Neuroendocrinology. 2009; 89:9-17. [PubMed: 18931475]

218. Kojima M, Hosoda H, Date Y, Nakazato M, Matsuo H, Kangawa K. Ghrelin is a growthhormone-releasing acylated peptide from stomach. Nature. 1999; 402:656-660. [PubMed: 10604470]

219. Bednarek MA, Feighner SD, Pong SS, McKee KK, Hreniuk DL, Silva MV, Warren VA, Howard AD, Van Der Ploeg LH, Heck JV. Structure-function studies on the new growth hormonereleasing peptide, ghrelin: minimal sequence of ghrelin necessary for activation of growth hormone secretagogue receptor 1a. Journal of medicinal chemistry. 2000; 43:4370-4376. [PubMed: 11087562]

220. Banks WA, Tschop M, Robinson SM, Heiman ML. Extent and direction of ghrelin transport across the blood-brain barrier is determined by its unique primary structure. The Journal of pharmacology and experimental therapeutics. 2002; 302:822-827. [PubMed: 12130749]

221. Holst JJ. The physiology of glucagon-like peptide 1. Physiological reviews. 2007; 87:1409-1439. [PubMed: 17928588]

222. Garber A, Henry RR, Ratner R, Hale P, Chang CT, Bode B. Liraglutide, a once-daily human glucagon-like peptide 1 analogue, provides sustained improvements in glycaemic control and weight for 2 years as monotherapy compared with glimepiride in patients with type 2 diabetes. Diabetes, obesity \& metabolism. 2011; 13:348-356.

223. Kanoski SE, Rupprecht LE, Fortin SM, De Jonghe BC, Hayes MR. The role of nausea in food intake and body weight suppression by peripheral GLP-1 receptor agonists, exendin-4 and liraglutide. Neuropharmacology. 2012; 62:1916-1927. [PubMed: 22227019]

224. Jespersen MJ, Knop FK, Christensen M. GLP-1 agonists for type 2 diabetes: pharmacokinetic and toxicological considerations. Expert opinion on drug metabolism \& toxicology. 2013; 9:17-29. [PubMed: 23094590]

225. Yi X, Kabanov AV. Brain delivery of proteins via their fatty acid and block copolymer modifications. Journal of drug targeting. 2013; 21:940-955. [PubMed: 24160902]

226. Tsuji A. Small molecular drug transfer across the blood-brain barrier via carriermediated transport systems. NeuroRx. 2005; 2:54-62. [PubMed: 15717057]

227. Brasnjevic I, Steinbusch HW, Schmitz C, Martinez-Martinez P. Delivery of peptide and protein drugs over the blood-brain barrier. Progress in neurobiology. 2009; 87:212-251. [PubMed: 19395337]

228. van Rooy I, Cakir-Tascioglu S, Couraud PO, Romero IA, Weksler B, Storm G, Hennink WE, Schiffelers RM, Mastrobattista E. Identification of peptide ligands for targeting to the bloodbrain barrier. Pharm Res. 27:673-682. [PubMed: 20162339]

229. Pardridge WM, Buciak JL, Friden PM. Selective transport of an anti-transferrin receptor antibody through the blood-brain barrier in vivo. The Journal of pharmacology and experimental therapeutics. 1991; 259:66-70. [PubMed: 1920136] 
230. Pardridge WM. Drug and gene targeting to the brain via blood-brain barrier receptor-mediated transport systems. Int.Cong.Series. 2005; 1277:49-59.

231. Wu D, Song BW, Vinters HV, Pardridge WM. Pharmacokinetics and brain uptake of biotinylated basic fibroblast growth factor conjugated to a blood-brain barrier drug delivery system. Journal of drug targeting. 2002; 10:239-245. [PubMed: 12075825]

232. Song BW, Vinters HV, Wu D, Pardridge WM. Enhanced neuroprotective effects of basic fibroblast growth factor in regional brain ischemia after conjugation to a blood-brain barrier delivery vector. The Journal of pharmacology and experimental therapeutics. 2002; 301:605610. [PubMed: 11961063]

233. Kurihara A, Deguchi Y, Pardridge WM. Epidermal growth factor radiopharmaceuticals: 111In chelation, conjugation to a blood-brain barrier delivery vector via a biotin-polyethylene linker, pharmacokinetics, and in vivo imaging of experimental brain tumors. Bioconjug Chem. 1999; 10:502-511. [PubMed: 10346884]

234. Pardridge WM, Kang YS, Buciak JL. Transport of human recombinant brainderived neurotrophic factor (BDNF) through the rat blood-brain barrier in vivo using vector-mediated peptide drug delivery. Pharmaceutical research. 1994; 11:738-746. [PubMed: 8058646]

235. Bickel U, Yoshikawa T, Landaw EM, Faull KF, Pardridge WM. Pharmacologic effects in vivo in brain by vector-mediated peptide drug delivery. Proceedings of the National Academy of Sciences of the United States of America. 1993; 90:2618-2622. [PubMed: 8385339]

236. Zhou QH, Boado RJ, Lu JZ, Hui EK, Pardridge WM. Re-engineering erythropoietin as an IgG fusion protein that penetrates the blood-brain barrier in the mouse. Molecular pharmaceutics. 7:2148-2155. [PubMed: 20860349]

237. Fu A, Hui EK, Lu JZ, Boado RJ, Pardridge WM. Neuroprotection in stroke in the mouse with intravenous erythropoietin-Trojan horse fusion protein. Brain Res. 1369:203-207. [PubMed: 21047502]

238. Zhou QH, Hui EK, Lu JZ, Boado RJ, Pardridge WM. Brain penetrating IgGerythropoietin fusion protein is neuroprotective following intravenous treatment in Parkinson's disease in the mouse. Brain Res. 1382:315-320. [PubMed: 21276430]

239. Boado RJ, Hui EK, Lu JZ, Zhou QH, Pardridge WM. Reversal of lysosomal storage in brain of adult MPS-I mice with intravenous Trojan horse-iduronidase fusion protein. Molecular pharmaceutics. 8:1342-1350. [PubMed: 21667973]

240. Zhou QH, Fu A, Boado RJ, Hui EK, Lu JZ, Pardridge WM. Receptor-mediated abeta amyloid antibody targeting to Alzheimer's disease mouse brain. Molecular pharmaceutics. 8:280-285. [PubMed: 21141969]

241. Zhou QH, Lu JZ, Hui EK, Boado RJ, Pardridge WM. Delivery of a peptide radiopharmaceutical to brain with an IgG-avidin fusion protein. Bioconjug Chem. 22:1611-1618. [PubMed: 21707084]

242. Zhou QH, Boado RJ, Lu JZ, Hui EK, Pardridge WM. Monoclonal antibody-glialderived neurotrophic factor fusion protein penetrates the blood-brain barrier in the mouse. Drug Metab Dispos. 38:566-572. [PubMed: 20075191]

243. Fu A, Zhou QH, Hui EK, Lu JZ, Boado RJ, Pardridge WM. Intravenous treatment of experimental Parkinson's disease in the mouse with an IgG-GDNF fusion protein that penetrates the blood-brain barrier. Brain Res. 1352:208-213. [PubMed: 20599807]

244. Zhou QH, Boado RJ, Hui EK, Lu JZ, Pardridge WM. Chronic dosing of mice with a transferrin receptor monoclonal antibody-glial-derived neurotrophic factor fusion protein. Drug Metab Dispos. 39:1149-1154. [PubMed: 21502195]

245. Zhou QH, Boado RJ, Hui EK, Lu JZ, Pardridge WM. Brain-penetrating tumor necrosis factor decoy receptor in the mouse. Drug Metab Dispos. 39:71-76. [PubMed: 20884844]

246. Boado RJ, Zhou QH, Lu JZ, Hui EK, Pardridge WM. Pharmacokinetics and brain uptake of a genetically engineered bifunctional fusion antibody targeting the mouse transferrin receptor. Molecular pharmaceutics. 7:237-244. [PubMed: 19921848]

247. Xu L, Tang WH, Huang CC, Alexander W, Xiang LM, Pirollo KF, Rait A, Chang EH. Systemic p53 gene therapy of cancer with immunolipoplexes targeted by anti-transferrin receptor scFv. Mol Med. 2001; 7:723-734. [PubMed: 11713371] 
248. Zhao LX, Yan B, Xu L, Jiang SW, Zhang YY, Yang ZX, Zhou XW, Huang PT. [Expression, purification and activity analysis of anti-human transferrin receptor $\mathrm{scFv}]$. Sheng wu gong cheng xue bao = Chinese journal of biotechnology. 2006; 22:488-491. [PubMed: 16755932]

249. Moos T, Morgan EH. Restricted transport of anti-transferrin receptor antibody (OX26) through the blood-brain barrier in the rat. Journal of neurochemistry. 2001; 79:119-129. [PubMed: 11595764]

250. Gosk S, Vermehren C, Storm G, Moos T. Targeting anti-transferrin receptor antibody (OX26) and OX26-conjugated liposomes to brain capillary endothelial cells using in situ perfusion. $\mathbf{J}$ Cereb Blood Flow Metab. 2004; 24:1193-1204. [PubMed: 15545912]

251. Bien-Ly N, Yu YJ, Bumbaca D, Elstrott J, Boswell CA, Zhang Y, Luk W, Lu Y, Dennis MS, Weimer RM, Chung I, Watts RJ. Transferrin receptor (TfR) trafficking determines brain uptake of TfR antibody affinity variants. The Journal of experimental medicine. 2014; 211:233-244. [PubMed: 24470444]

252. Couch JA, Yu YJ, Zhang Y, Tarrant JM, Fuji RN, Meilandt WJ, Solanoy H, Tong RK, Hoyte K, Luk W, Lu Y, Gadkar K, Prabhu S, Ordonia BA, Nguyen Q, Lin Y, Lin Z, Balazs M, ScearceLevie K, Ernst JA, Dennis MS, Watts RJ. Addressing safety liabilities of TfR bispecific antibodies that cross the blood-brain barrier. Science translational medicine. 2013; 5:183ra157, $181-112$.

253. Coloma MJ, Lee HJ, Kurihara A, Landaw EM, Boado RJ, Morrison SL, Pardridge WM. Transport across the primate blood-brain barrier of a genetically engineered chimeric monoclonal antibody to the human insulin receptor. Pharmaceutical research. 2000; 17:266-274. [PubMed: 10801214]

254. Boado RJ, Zhang Y, Zhang Y, Wang Y, Pardridge WM. GDNF fusion protein for targeted-drug delivery across the human blood-brain barrier. Biotechnology and bioengineering. 2008; 100:387-396. [PubMed: 18080333]

255. Boado RJ, Pardridge WM. Comparison of blood-brain barrier transport of glialderived neurotrophic factor (GDNF) and an IgG-GDNF fusion protein in the rhesus monkey. Drug metabolism and disposition: the biological fate of chemicals. 2009; 37:2299-2304. [PubMed: 19741036]

256. Boado RJ, Hui EK, Lu JZ, Pardridge WM. Drug targeting of erythropoietin across the primate blood-brain barrier with an IgG molecular Trojan horse. The Journal of pharmacology and experimental therapeutics. 333:961-969. [PubMed: 20233799]

257. Fu A, Hui EK, Lu JZ, Boado RJ, Pardridge WM. Neuroprotection in experimental stroke in the rat with an IgG-erythropoietin fusion protein. Brain Res. 1360:193-197. [PubMed: 20833153]

258. Boado RJ, Hui EK, Lu JZ, Zhou QH, Pardridge WM. Selective targeting of a TNFR decoy receptor pharmaceutical to the primate brain as a receptor-specific IgG fusion protein. J Biotechnol. 146:84-91. [PubMed: 20100527]

259. Boado RJ, Lu JZ, Hui EK, Pardridge WM. IgG-single chain Fv fusion protein therapeutic for Alzheimer's disease: Expression in CHO cells and pharmacokinetics and brain delivery in the rhesus monkey. Biotechnology and bioengineering. 105:627-635. [PubMed: 19816967]

260. May P, Woldt E, Matz RL, Boucher P. The LDL receptor-related protein (LRP) family: an old family of proteins with new physiological functions. Annals of medicine. 2007; 39:219-228. [PubMed: 17457719]

261. Saito A, Pietromonaco S, Loo AK, Farquhar MG. Complete cloning and sequencing of rat gp330/"megalin," a distinctive member of the low density lipoprotein receptor gene family. Proceedings of the National Academy of Sciences of the United States of America. 1994; 91:9725-9729. [PubMed: 7937880]

262. Gaultier A, Wu X, Le Moan N, Takimoto S, Mukandala G, Akassoglou K, Campana WM, Gonias SL. Low-density lipoprotein receptor-related protein 1 is an essential receptor for myelin phagocytosis. Journal of cell science. 2009; 122:1155-1162. [PubMed: 19299462]

263. Deane R, Bell RD, Sagare A, Zlokovic BV. Clearance of amyloid-beta peptide across the bloodbrain barrier: implication for therapies in Alzheimer's disease. CNS \& neurological disorders drug targets. 2009; 8:16-30. [PubMed: 19275634] 
264. Zhang C, An J, Strickland DK, Yepes M. The low-density lipoprotein receptorrelated protein 1 mediates tissue-type plasminogen activator-induced microglial activation in the ischemic brain. The American journal of pathology. 2009; 174:586-594. [PubMed: 19147818]

265. Zlokovic BV, Martel CL, Matsubara E, McComb JG, Zheng G, McCluskey RT, Frangione B, Ghiso J. Glycoprotein 330/megalin: probable role in receptor-mediated transport of apolipoprotein $\mathrm{J}$ alone and in a complex with Alzheimer disease amyloid beta at the blood-brain and blood-cerebrospinal fluid barriers. Proceedings of the National Academy of Sciences of the United States of America. 1996; 93:4229-4234. [PubMed: 8633046]

266. Deane R, Wu Z, Zlokovic BV. RAGE (yin) versus LRP (yang) balance regulates alzheimer amyloid beta-peptide clearance through transport across the blood-brain barrier. Stroke; a journal of cerebral circulation. 2004; 35:2628-2631.

267. Demeule M, Poirier J, Jodoin J, Bertrand Y, Desrosiers RR, Dagenais C, Nguyen T, Lanthier J, Gabathuler R, Kennard M, Jefferies WA, Karkan D, Tsai S, Fenart L, Cecchelli R, Beliveau R. High transcytosis of melanotransferrin (P97) across the blood-brain barrier. Journal of neurochemistry. 2002; 83:924-933. [PubMed: 12421365]

268. Yepes M, Sandkvist M, Moore EG, Bugge TH, Strickland DK, Lawrence DA. Tissuetype plasminogen activator induces opening of the blood-brain barrier via the LDL receptor-related protein. The Journal of clinical investigation. 2003; 112:1533-1540. [PubMed: 14617754]

269. Boucher P, Gotthardt M, Li WP, Anderson RG, Herz J. LRP: role in vascular wall integrity and protection from atherosclerosis. Science. 2003; 300:329-332. [PubMed: 12690199]

270. Herz J. LRP: a bright beacon at the blood-brain barrier. The Journal of clinical investigation. 2003; 112:1483-1485. [PubMed: 14617749]

271. Herz J, Strickland DK. LRP: a multifunctional scavenger and signaling receptor. The Journal of clinical investigation. 2001; 108:779-784. [PubMed: 11560943]

272. Demeule M, Regina A, Che C, Poirier J, Nguyen T, Gabathuler R, Castaigne JP, Beliveau R. Identification and design of peptides as a new drug delivery system for the brain. The Journal of pharmacology and experimental therapeutics. 2008; 324:1064-1072. [PubMed: 18156463]

273. Bertrand Y, Currie JC, Demeule M, Regina A, Che C, Abulrob A, Fatehi D, Sartelet H, Gabathuler R, Castaigne JP, Stanimirovic D, Beliveau R. Transport characteristics of a novel peptide platform for CNS therapeutics. J Cell Mol Med. 14:2827-2839. [PubMed: 19818094]

274. Demeule M, Currie JC, Bertrand Y, Che C, Nguyen T, Regina A, Gabathuler R, Castaigne JP, Beliveau R. Involvement of the low-density lipoprotein receptor-related protein in the transcytosis of the brain delivery vector angiopep-2. Journal of neurochemistry. 2008; 106:15341544. [PubMed: 18489712]

275. Bertrand Y, Currie JC, Demeule M, Regina A, Che C, Abulrob A, Fatehi D, Sartelet H, Gabathuler R, Castaigne JP, Stanimirovic D, Beliveau R. Transport characteristics of a novel peptide platform for CNS therapeutics. Journal of cellular and molecular medicine. 2009

276. Regina A, Demeule M, Che C, Lavallee I, Poirier J, Gabathuler R, Beliveau R, Castaigne JP. Antitumour activity of ANG1005, a conjugate between paclitaxel and the new brain delivery vector Angiopep-2. British journal of pharmacology. 2008; 155:185-197. [PubMed: 18574456]

277. Drappatz J, Brenner A, Wong ET, Eichler A, Schiff D, Groves MD, Mikkelsen T, Rosenfeld S, Sarantopoulos J, Meyers CA, Fielding RM, Elian K, Wang X, Lawrence B, Shing M, Kelsey S, Castaigne JP, Wen PY. Phase I study of GRN1005 in recurrent malignant glioma. Clinical cancer research : an official journal of the American Association for Cancer Research. 2013; 19:15671576. [PubMed: 23349317]

278. Kurzrock R, Gabrail N, Chandhasin C, Moulder S, Smith C, Brenner A, Sankhala K, Mita A, Elian K, Bouchard D, Sarantopoulos J. Safety, pharmacokinetics, and activity of GRN1005, a novel conjugate of angiopep-2, a peptide facilitating brain penetration, and paclitaxel, in patients with advanced solid tumors. Molecular cancer therapeutics. 2012; 11:308-316. [PubMed: 22203732]

279. Che C, Yang G, Thiot C, Lacoste MC, Currie JC, Demeule M, Regina A, Beliveau R, Castaigne JP. New Angiopep-modified doxorubicin (ANG1007) and etoposide (ANG1009) chemotherapeutics with increased brain penetration. Journal of medicinal chemistry. 53:28142824. [PubMed: 20210346] 
280. Ke W, Shao K, Huang R, Han L, Liu Y, Li J, Kuang Y, Ye L, Lou J, Jiang C. Gene delivery targeted to the brain using an Angiopep-conjugated polyethyleneglycol-modified polyamidoamine dendrimer. Biomaterials. 2009; 30:6976-6985. [PubMed: 19765819]

281. Shen J, Zhan C, Xie C, Meng Q, Gu B, Li C, Zhang Y, Lu W. Poly(ethylene glycol)- blockpoly(d,l-lactide acid) micelles anchored with angiopep-2 for brain-targeting delivery. Journal of drug targeting.

282. Shao K, Huang R, Li J, Han L, Ye L, Lou J, Jiang C. Angiopep-2 modified PE-PEG based polymeric micelles for amphotericin B delivery targeted to the brain. J Control Release. 2010

283. Xin H, Jiang X, Gu J, Sha X, Chen L, Law K, Chen Y, Wang X, Jiang Y, Fang X. Angiopepconjugated poly(ethylene glycol)-co-poly(epsilon-caprolactone) nanoparticles as dual-targeting drug delivery system for brain glioma. Biomaterials. 32:4293-4305. [PubMed: 21427009]

284. Shen J, Zhan C, Xie C, Meng Q, Gu B, Li C, Zhang Y, Lu W. Poly(ethylene glycol)- blockpoly(D,L-lactide acid) micelles anchored with angiopep-2 for brain-targeting delivery. J Drug Target. 19:197-203. [PubMed: 20446756]

285. Ren J, Shen S, Wang D, Xi Z, Guo L, Pang Z, Qian Y, Sun X, Jiang X. The targeted delivery of anticancer drugs to brain glioma by PEGylated oxidized multi-walled carbon nanotubes modified with angiopep-2. Biomaterials. 33:3324-3333. [PubMed: 22281423]

286. Sun X, Pang Z, Ye H, Qiu B, Guo L, Li J, Ren J, Qian Y, Zhang Q, Chen J, Jiang X. Codelivery of pEGFP-hTRAIL and paclitaxel to brain glioma mediated by an angiopepconjugated liposome. Biomaterials. 33:916-924. [PubMed: 22048008]

287. Jean E. Lachowicz, MD.; Ché, Christian; Tripathy, Sasmita; Currie, Jean-Christophe; Régina, Anthony; Nguyen, Tran; Lord-Dufour, Simon; Castaigne, Jean-Paul. ANG4043: A new brainpenetrant peptide-mAb conjugate that reduces tumor growth in a HER2-positive orthotopic tumor model. AACR Annual Meeting; April 2013; 2013.

288. Jean E. Lachowicz, MD.; Ché, Christian; Tripathy, Sasmita; Jarvis, Scott; Currie, JeanChristophe; Régina, Anthony; Nguyen, Tran; Castaigne, Jean-Paul. Design of new Angiopep-2anti- EGFR and Angiopep-2-anti-HER2 derivatives with increased blood-brain barrier permeability for treatment of brain tumors. Society of Neuro-Oncology (SNO) Annual Meeting; November 2012; 2012.

289. Demeule M, Beaudet N, Regina A, Besserer-Offroy E, Murza A, Tetreault P, Belleville K, Che C, Larocque A, Thiot C, Beliveau R, Longpre JM, Marsault E, Leduc R, Lachowicz JE, Gonias SL, Castaigne JP, Sarret P. Conjugation of a brain-penetrant peptide with neurotensin provides antinociceptive properties. The Journal of clinical investigation. 2014; 124:1199-1213. [PubMed: 24531547]

290. Bockenhoff A, Cramer S, Wolte P, Knieling S, Wohlenberg C, Gieselmann V, Galla HJ, Matzner U. Comparison of five Peptide vectors for improved brain delivery of the lysosomal enzyme arylsulfatase a. J Neurosci. 2014; 34:3122-3129. [PubMed: 24573272]

291. Brown JP, Nishiyama K, Hellstrom I, Hellstrom KE. Structural characterization of human melanoma-associated antigen p97 with monoclonal antibodies. J Immunol. 1981; 127:539-546. [PubMed: 6166674]

292. Richardson DR, Morgan EH. The transferrin homologue, melanotransferrin (p97), is rapidly catabolized by the liver of the rat and does not effectively donate iron to the brain. Biochim Biophys Acta. 2004; 1690:124-133. [PubMed: 15469901]

293. Moroo I, Ujiie M, Walker BL, Tiong JW, Vitalis TZ, Karkan D, Gabathuler R, Moise AR, Jefferies WA. Identification of a novel route of iron transcytosis across the mammalian bloodbrain barrier. Microcirculation. 2003; 10:457-462. [PubMed: 14745458]

294. Tang Y, Han T, Everts M, Zhu ZB, Gillespie GY, Curiel DT, Wu H. Directing adenovirus across the blood-brain barrier via melanotransferrin (P97) transcytosis pathway in an in vitro model. Gene therapy. 2007; 14:523-532. [PubMed: 17167498]

295. Gabathuler R AG, Kennard M, Chen Q, Tsai S, et al. Development of a potenial vector Neuro Tans to deliver drugs across the blood-brain barrier. Int. Cong. Series. 2005; 1277:171-184.

296. Karkan D, Pfeifer C, Vitalis TZ, Arthur G, Ujiie M, Chen Q, Tsai S, Koliatis G, Gabathuler R, Jefferies WA. A unique carrier for delivery of therapeutic compounds beyond the blood-brain barrier. PloS one. 2008; 3:e2469. [PubMed: 18575595] 
297. de Boer AG, Gaillard PJ. Drug targeting to the brain. Annual review of pharmacology and toxicology. 2007; 47:323-355.

298. Warshawsky I, Bu G, Schwartz AL. Identification of domains on the 39-kDa protein that inhibit the binding of ligands to the low density lipoprotein receptor-related protein. The Journal of biological chemistry. 1993; 268:22046-22054. [PubMed: 7691821]

299. Warshawsky I, Bu G, Schwartz AL. 39-kD protein inhibits tissue-type plasminogen activator clearance in vivo. The Journal of clinical investigation. 1993; 92:937-944. [PubMed: 8349826]

300. Pan W, Kastin AJ, Zankel TC, van Kerkhof P, Terasaki T, Bu G. Efficient transfer of receptorassociated protein (RAP) across the blood-brain barrier. Journal of cell science. 2004; 117:50715078. [PubMed: 15383619]

301. Prince WS, McCormick LM, Wendt DJ, Fitzpatrick PA, Schwartz KL, Aguilera AI, Koppaka V, Christianson TM, Vellard MC, Pavloff N, Lemontt JF, Qin M, Starr CM, Bu G, Zankel TC. Lipoprotein receptor binding, cellular uptake, and lysosomal delivery of fusions between the receptor-associated protein (RAP) and alpha-L-iduronidase or acid alphaglucosidase. The Journal of biological chemistry. 2004; 279:35037-35046. [PubMed: 15170390]

302. Abuchowski A, McCoy JR, Palczuk NC, van Es T, Davis FF. Effect of covalent attachment of polyethylene glycol on immunogenicity and circulating life of bovine liver catalase. The Journal of biological chemistry. 1977; 252:3582-3586. [PubMed: 16907]

303. Abuchowski A, van Es T, Palczuk NC, Davis FF. Alteration of immunological properties of bovine serum albumin by covalent attachment of polyethylene glycol. The Journal of biological chemistry. 1977; 252:3578-3581. [PubMed: 405385]

304. Pisal DS, Kosloski MP, Balu-Iyer SV. Delivery of therapeutic proteins. Journal of pharmaceutical sciences. 99:2557-2575. [PubMed: 20049941]

305. Chapman AP. PEGylated antibodies and antibody fragments for improved therapy: a review. Advanced drug delivery reviews. 2002; 54:531-545. [PubMed: 12052713]

306. Hinds KD, Kim SW. Effects of PEG conjugation on insulin properties. Advanced drug delivery reviews. 2002; 54:505-530. [PubMed: 12052712]

307. Roberts MJ, Bentley MD, Harris JM. Chemistry for peptide and protein PEGylation. Advanced drug delivery reviews. 2002; 54:459-476. [PubMed: 12052709]

308. Sato H. Enzymatic procedure for site-specific pegylation of proteins. Advanced drug delivery reviews. 2002; 54:487-504. [PubMed: 12052711]

309. Torchilin VP. PEG-based micelles as carriers of contrast agents for different imaging modalities. Advanced drug delivery reviews. 2002; 54:235-252. [PubMed: 11897148]

310. Veronese FM, Caliceti P, Schiavon O, Sergi M. Polyethylene glycol-superoxide dismutase, a conjugate in search of exploitation. Advanced drug delivery reviews. 2002; 54:587-606. [PubMed: 12052716]

311. Wang YS, Youngster S, Grace M, Bausch J, Bordens R, Wyss DF. Structural and biological characterization of pegylated recombinant interferon alpha-2b and its therapeutic implications. Advanced drug delivery reviews. 2002; 54:547-570. [PubMed: 12052714]

312. Harris JM, Chess RB. Effect of pegylation on pharmaceuticals. Nature reviews. 2003; 2:214-221.

313. Bailon P, Won CY. PEG-modified biopharmaceuticals. Expert opinion on drug delivery. 2009; 6:1-16. [PubMed: 19236204]

314. Bianchi E, Carrington PE, Ingallinella P, Finotto M, Santoprete A, Petrov A, Eiermann G, Kosinski J, Marsh DJ, Pocai A, SinhaRoy R, Pessi A. A PEGylated analog of the gut hormone oxyntomodulin with long-lasting antihyperglycemic, insulinotropic and anorexigenic activity. Bioorganic \& medicinal chemistry. 2013; 21:7064-7073. [PubMed: 24094437]

315. Lejeune MP, Hukshorn CJ, Saris WH, Westerterp-Plantenga MS. Effect of dietary restraint during and following pegylated recombinant leptin (PEG-OB) treatment of overweight men. International journal of obesity and related metabolic disorders : journal of the International Association for the Study of Obesity. 2003; 27:1494-1499.

316. Hukshorn CJ, van Dielen FM, Buurman WA, Westerterp-Plantenga MS, Campfield LA, Saris WH. The effect of pegylated recombinant human leptin (PEG-OB) on weight loss and inflammatory status in obese subjects. International journal of obesity and related metabolic disorders : journal of the International Association for the Study of Obesity. 2002; 26:504-509. 
317. Lo KM, Zhang J, Sun Y, Morelli B, Lan Y, Lauder S, Brunkhorst B, Webster G, Hallakou-Bozec S, Doare L, Gillies SD. Engineering a pharmacologically superior form of leptin for the treatment of obesity. Protein engineering, design \& selection : PEDS. 2005; 18:1-10.

318. Pardridge WM, Wu D, Sakane T. Combined use of carboxyl-directed protein pegylation and vector-mediated blood-brain barrier drug delivery system optimizes brain uptake of brain-derived neurotrophic factor following intravenous administration. Pharmaceutical research. 1998; 15:576-582. [PubMed: 9587954]

319. Yoshida K, Burton GF, McKinney JS, Young H, Ellis EF. Brain and tissue distribution of polyethylene glycol-conjugated superoxide dismutase in rats. Stroke; a journal of cerebral circulation. 1992; 23:865-869.

320. Hardwicke J, Moseley R, Stephens P, Harding K, Duncan R, Thomas DW. Bioresponsive dextrin-rhEGF conjugates: in vitro evaluation in models relevant to its proposed use as a treatment for chronic wounds. Molecular pharmaceutics. 7:699-707. [PubMed: 20166755]

321. Ferguson EL, Duncan R. Dextrin-phospholipase A2: synthesis and evaluation as a bioresponsive anticancer conjugate. Biomacromolecules. 2009; 10:1358-1364. [PubMed: 19354276]

322. Hardwicke J, Ferguson EL, Moseley R, Stephens P, Thomas DW, Duncan R. Dextrin-rhEGF conjugates as bioresponsive nanomedicines for wound repair. J Control Release. 2008; 130:275283. [PubMed: 18700156]

323. Duncan R, Gilbert HR, Carbajo RJ, Vicent MJ. Polymer masked-unmasked protein therapy. 1. Bioresponsive dextrin-trypsin and -melanocyte stimulating hormone conjugates designed for alpha-amylase activation. Biomacromolecules. 2008; 9:1146-1154. [PubMed: 18348531]

324. Oh EJ PK, Kim KS, Kim J, Yang JA, Kong JH, Lee MY, Hoffman AS, Hahn SK. Target specific and long-acting delivery of protein, peptide, and nucleotide therapeutics using hyaluronic acid derivatives. J Control Release. 2010; 141:2-12. [PubMed: 19758573]

325. Kopecek J, Kopeckova P. HPMA copolymers: origins, early developments, present, and future. Advanced drug delivery reviews. 2009; 62:122-149. [PubMed: 19919846]

326. Kabanov AV, Chekhonin VP, Alakhov V, Batrakova EV, Lebedev AS, Melik-Nubarov NS, Arzhakov SA, Levashov AV, Morozov GV, Severin ES, et al. The neuroleptic activity of haloperidol increases after its solubilization in surfactant micelles. Micelles as microcontainers for drug targeting. FEBS letters. 1989; 258:343-345. [PubMed: 2599097]

327. Batrakova EV, Miller DW, Li S, Alakhov VY, Kabanov AV, Elmquist WF. Pluronic P85 enhances the delivery of digoxin to the brain: in vitro and in vivo studies. The Journal of pharmacology and experimental therapeutics. 2001; 296:551-557. [PubMed: 11160643]

328. Batrakova EV, Han HY, Miller DW, Kabanov AV. Effects of pluronic P85 unimers and micelles on drug permeability in polarized BBMEC and Caco-2 cells. Pharmaceutical research. 1998; 15:1525-1532. [PubMed: 9794493]

329. Batrakova EV, Li S, Miller DW, Kabanov AV. Pluronic P85 increases permeability of a broad spectrum of drugs in polarized BBMEC and Caco-2 cell monolayers. Pharmaceutical research. 1999; 16:1366-1372. [PubMed: 10496651]

330. Nametkin SN, AK LD, Kabanov AV, Levashov AV. [Modulation of membrane activity of an enzyme in reversed micelle system with a change of media $\mathrm{pH}$ (using alkaline phosphatase as an example)]. Bioorganicheskaia khimiia. 1992; 18:777-783. [PubMed: 1384508]

331. Batrakova EV, Li S, Alakhov VY, Miller DW, Kabanov AV. Optimal structure requirements for pluronic block copolymers in modifying P-glycoprotein drug efflux transporter activity in bovine brain microvessel endothelial cells. The Journal of pharmacology and experimental therapeutics. 2003; 304:845-854. [PubMed: 12538842]

332. Sahay G, Gautam V, Luxenhofer R, Kabanov AV. The utilization of pathogen-like cellular trafficking by single chain block copolymer. Biomaterials. 2009; 31:1757-1764. [PubMed: 19963266]

333. Sahay G, Batrakova EV, Kabanov AV. Different internalization pathways of polymeric micelles and unimers and their effects on vesicular transport. Bioconjug Chem. 2008; 19:2023-2029. [PubMed: 18729494]

334. Sahay G, Gautam V, Luxenhofer R, Kabanov AV. The utilization of pathogen-like cellular trafficking by single chain block copolymer. Biomaterials. 31:1757-1764. [PubMed: 19963266] 
335. Yi X, Batrakova E, Banks WA, Vinogradov S, Kabanov AV. Protein conjugation with amphiphilic block copolymers for enhanced cellular delivery. Bioconjug Chem. 2008; 19:10711077. [PubMed: 18447367]

336. Yi X, Zimmerman MC, Yang R, Tong J, Vinogradov S, Kabanov AV. Pluronicmodified superoxide dismutase 1 attenuates angiotensin II-induced increase in intracellular superoxide in neurons. Free radical biology \& medicine. 2010; 49:548-558. [PubMed: 20493251]

337. Yi, X. Protein Modification by Pluronic Block Copolymer for Brain Delivery (Thesis). University of Nebraska Medical Center; 2010.

338. Price TO, Farr SA, Yi X, Vinogradov S, Batrakova E, Banks WA, Kabanov AV. Transport across the blood-brain barrier of pluronic leptin. The Journal of pharmacology and experimental therapeutics. 2010; 333:253-263. [PubMed: 20053933]

339. Xiang, Yi; Yuan, Dongfen; Farr, Susan A.; Banks, William A.; Poon, C-D.; Kabanov, AV. Pluronic Modified Leptin with Increased Systemic Circulation. Brain Uptake and Efficacy for Treatment of Obesity, in: Journal of Controlled Release. 2014 (in publish).

340. Levin BE, Dunn-Meynell AA, Banks WA. Obesity-prone rats have normal bloodbrain barrier transport but defective central leptin signaling before obesity onset. American journal of physiology. 2004; 286:R143-R150. [PubMed: 12958061]

341. Ravussin E, Smith SR, Mitchell JA, Shringarpure R, Shan K, Maier H, Koda JE, Weyer C. Enhanced weight loss with pramlintide/metreleptin: an integrated neurohormonal approach to obesity pharmacotherapy. Obesity (Silver Spring). 2009; 17:1736-1743. [PubMed: 19521351]

342. Van Heek M, Compton DS, France CF, Tedesco RP, Fawzi AB, Graziano MP, Sybertz EJ, Strader CD, Davis HR Jr. Diet-induced obese mice develop peripheral, but not central, resistance to leptin. The Journal of clinical investigation. 1997; 99:385-390. [PubMed: 9022070]

343. Danson S, Ferry D, Alakhov V, Margison J, Kerr D, Jowle D, Brampton M, Halbert G, Ranson M. Phase I dose escalation and pharmacokinetic study of pluronic polymer-bound doxorubicin (SP1049C) in patients with advanced cancer. British journal of cancer. 2004; 90:2085-2091. [PubMed: 15150584]

344. Valle JW, Armstrong A, Newman C, Alakhov V, Pietrzynski G, Brewer J, Campbell S, Corrie P, Rowinsky EK, Ranson M. A phase 2 study of SP1049C, doxorubicin in P-glycoprotein-targeting pluronics, in patients with advanced adenocarcinoma of the esophagus and gastroesophageal junction. Investigational new drugs.

345. Batrakova EV, Zhang Y, Li Y, Li S, Vinogradov SV, Persidsky Y, Alakhov VY, Miller DW, Kabanov AV. Effects of pluronic P85 on GLUT1 and MCT1 transporters in the bloodbrain barrier. Pharmaceutical research. 2004; 21:1993-2000. [PubMed: 15587920]

346. Tong J, Luxenhofer R, Yi X, Jordan R, Kabanov AV. Protein modification with amphiphilic block copoly(2-oxazoline)s as a new platform for enhanced cellular delivery. Molecular pharmaceutics. 2010; 7:984-992. [PubMed: 20550191]

347. Hoogenboom R. Poly(2-oxazoline)s: a polymer class with numerous potential applications. Angew Chem Int Ed Engl. 2009; 48:7978-7994. [PubMed: 19768817]

348. Barz M, Luxenhofer R, Zentel R, Vicent MJ. Overcoming the PEG-addiction: welldefined alternatives to PEG, from structure-property relationships to better defined therapeutics. Polymer Chemistry. 2:1900-1918.

349. Qiu LY, Yan L, Zhang L, Jin YM, Zhao QH. Folate-modified poly(2-ethyl-2-oxazoline) as hydrophilic corona in polymeric micelles for enhanced intracellular doxorubicin delivery. International journal of pharmaceutics. 2013; 456:315-324. [PubMed: 24016742]

350. Han Y, He Z, Schulz A, Bronich TK, Jordan R, Luxenhofer R, Kabanov AV. Synergistic combinations of multiple chemotherapeutic agents in high capacity poly(2-oxazoline) micelles. Molecular pharmaceutics. 2012; 9:2302-2313. [PubMed: 22681126]

351. Tong J, Zimmerman MC, Li S, Yi X, Luxenhofer R, Jordan R, Kabanov AV. Neuronal uptake and intracellular superoxide scavenging of a fullerene (C60)-poly(2-oxazoline)s nanoformulation. Biomaterials. 2011; 32:3654-3665. [PubMed: 21342705]

352. Hruby M, Filippov SK, Panek J, Novakova M, Mackova H, Kucka J, Vetvicka D, Ulbrich K. Polyoxazoline thermoresponsive micelles as radionuclide delivery systems. Macromolecular bioscience. 2010; 10:916-924. [PubMed: 20491128] 
353. Luxenhofer R, Schulz A, Roques C, Li S, Bronich TK, Batrakova EV, Jordan R, Kabanov AV. Doubly amphiphilic poly(2-oxazoline)s as high-capacity delivery systems for hydrophobic drugs. Biomaterials. 2010; 31:4972-4979. [PubMed: 20346493]

354. Hsiue GH, Wang CH, Lo CL, Wang CH, Li JP, Yang JL. Environmental-sensitive micelles based on poly(2-ethyl-2-oxazoline)-b-poly(L-lactide) diblock copolymer for application in drug delivery. International journal of pharmaceutics. 2006; 317:69-75. [PubMed: 16616820]

355. Luxenhofer R, Han Y, Schulz A, Tong J, He Z, Kabanov AV, Jordan R. Poly(2-oxazoline)s as Polymer Therapeutics. Macromolecular Rapid Communications, n/a-n/a.

356. Luxenhofer R, Schulz A, Roques C, Li S, Bronich TK, Batrakova EV, Jordan R, Kabanov AV. Doubly amphiphilic poly(2-oxazoline)s as high-capacity delivery systems for hydrophobic drugs. Biomaterials. 31:4972-4979. [PubMed: 20346493]

357. Luxenhofer R, Sahay G, Schulz A, Alakhova D, Bronich TK, Jordan R, Kabanov AV. Structureproperty relationship in cytotoxicity and cell uptake of poly(2-oxazoline) amphiphiles. J Control Release. 153:73-82. [PubMed: 21513750]

358. Mero A, Pasut G, Dalla Via L, Fijten MW, Schubert US, Hoogenboom R, Veronese FM. Synthesis and characterization of poly(2-ethyl 2-oxazoline)-conjugates with proteins and drugs: suitable alternatives to PEG-conjugates? J Control Release. 2008; 125:87-95. [PubMed: 18031860]

359. Viegas TX, Bentley MD, Harris JM, Fang Z, Yoon K, Dizman B, Weimer R, Mero A, Pasut G, Veronese FM. Polyoxazoline: chemistry, properties, and applications in drug delivery. Bioconjug Chem. 22:976-986. [PubMed: 21452890]

360. Tong J, Luxenhofer R, Yi X, Jordan R, Kabanov AV. Protein modification with amphiphilic block copoly(2-oxazoline)s as a new platform for enhanced cellular delivery. Molecular pharmaceutics. 7:984-992. [PubMed: 20550191]

361. Tong J, Yi X, Luxenhofer R, Banks WA, Jordan R, Zimmerman MC, Kabanov AV. Conjugates of superoxide dismutase 1 with amphiphilic poly(2-oxazoline) block copolymers for enhanced brain delivery: synthesis, characterization and evaluation in vitro and in vivo. Molecular pharmaceutics. 2013; 10:360-377. [PubMed: 23163230]

362. Poduslo JF, Curran GL. Increased permeability across the blood-nerve barrier of albumin glycated in vitro and in vivo from patients with diabetic polyneuropathy. Proceedings of the National Academy of Sciences of the United States of America. 1992; 89:2218-2222. [PubMed: 1549585]

363. Zhang C, Su Z, Zhao B, Qu Q, Tan Y, Cai L, Li X. Tat-modified leptin is more accessible to hypothalamus through brain-blood barrier with a significant inhibition of body-weight gain in high-fat-diet fed mice, Experimental and clinical endocrinology \& diabetes : official journal. German Society of Endocrinology [and] German Diabetes Association. 2010; 118:31-37.

364. Cai B, Lin Y, Xue XH, Fang L, Wang N, Wu ZY. TAT-mediated delivery of neuroglobin protects against focal cerebral ischemia in mice. Experimental neurology. 2011; 227:224-231. [PubMed: 21093435]

365. Blasberg RG, Fenstermacher JD, Patlak CS. Transport of alpha-aminoisobutyric acid across brain capillary and cellular membranes. J Cereb Blood Flow Metab. 1983; 3:8-32. [PubMed: 6822623]

366. Patlak CS, Blasberg RG, Fenstermacher JD. Graphical evaluation of blood-to-brain transfer constants from multiple-time uptake data. J Cereb Blood Flow Metab. 1983; 3:1-7. [PubMed: 6822610]

367. Kanoski SE, Fortin SM, Arnold M, Grill HJ, Hayes MR. Peripheral and central GLP-1 receptor populations mediate the anorectic effects of peripherally administered GLP-1 receptor agonists, liraglutide and exendin-4. Endocrinology. 2011; 152:3103-3112. [PubMed: 21693680]

368. Horvath TL, Diano S, Sotonyi P, Heiman M, Tschop M. Minireview: ghrelin and the regulation of energy balance--a hypothalamic perspective. Endocrinology. 2001; 142:4163-4169. [PubMed: 11564668]

369. Chen CY, Asakawa A, Fujimiya M, Lee SD, Inui A. Ghrelin gene products and the regulation of food intake and gut motility. Pharmacological reviews. 2009; 61:430-481. [PubMed: 20038570]

370. Kabanov AV, Batrakova EV, Melik-Nubarov NS, Fedoseev NA, Dorodnich TY, Alakho VY, Chekhonin VP, Naaarova IR, Kabanov VA. A new class of drug carriers: micelles of poly 
(oxyethylene)-poly (oxypropylene) block copolymers as microcontainers for drug targeting from blood in brain. Journal of Control Release. 1992; 22:141-158.

371. Tamariz E, Wan AC, Pek YS, Giordano M, Hernandez-Padron G, Varela-Echavarria A, Velasco I, Castano VM. Delivery of chemotropic proteins and improvement of dopaminergic neuron outgrowth through a thixotropic hybrid nano-gel. J Mater Sci Mater Med. 22:2097-2109. [PubMed: 21744103]

372. Dakwar GR, Hammad IA, Popov M, Linder C, Grinberg S, Heldman E, Stepensky D. Delivery of proteins to the brain by bolaamphiphilic nano-sized vesicles. J Control Release. 160:315-321. [PubMed: 22261280]

373. Wang S, Jiang T, Ma M, Hu Y, Zhang J. Preparation and evaluation of antineuroexcitation peptide (ANEP) loaded N-trimethyl chitosan chloride nanoparticles for brain-targeting. Int J Pharm. 386:249-255. [PubMed: 19900520]

374. Ren WH, Chang J, Yan CH, Qian XM, Long LX, He B, Yuan XB, Kang CS, Betbeder D, Sheng J, Pu PY. Development of transferrin functionalized poly(ethylene glycol)/poly(lactic acid) amphiphilic block copolymeric micelles as a potential delivery system targeting brain glioma. J Mater Sci Mater Med. 21:2673-2681. [PubMed: 20535631]

375. Huile G, Shuaiqi P, Zhi Y, Shijie C, Chen C, Xinguo J, Shun S, Zhiqing P, Yu H. A cascade targeting strategy for brain neuroglial cells employing nanoparticles modified with angiopep-2 peptide and EGFP-EGF1 protein. Biomaterials. 32:8669-8675. [PubMed: 21843903]

376. Pang Z, Gao H, Yu Y, Chen J, Guo L, Ren J, Wen Z, Su J, Jiang X. Brain delivery and cellular internalization mechanisms for transferrin conjugated biodegradable polymersomes. Int J Pharm. 415:284-292. [PubMed: 21651966]

377. Gan CW, Feng SS. Transferrin-conjugated nanoparticles of poly(lactide)-D-alphatocopheryl polyethylene glycol succinate diblock copolymer for targeted drug delivery across the bloodbrain barrier. Biomaterials. 31:7748-7757. [PubMed: 20673685]

378. Visser CC, Stevanovic S, Voorwinden LH, van Bloois L, Gaillard PJ, Danhof M, Crommelin DJ, de Boer AG. Targeting liposomes with protein drugs to the blood-brain barrier in vitro. Eur J Pharm Sci. 2005; 25:299-305. [PubMed: 15911226]

379. Xie Y, Ye L, Zhang X, Cui W, Lou J, Nagai T, Hou X. Transport of nerve growth factor encapsulated into liposomes across the blood-brain barrier: in vitro and in vivo studies. J Control Release. 2005; 105:106-119. [PubMed: 15893839]

380. van Rooy I, Mastrobattista E, Storm G, Hennink WE, Schiffelers RM. Comparison of five different targeting ligands to enhance accumulation of liposomes into the brain. J Control Release. 2011; 150:30-36. [PubMed: 21087646]

381. Roney C, Kulkarni P, Arora V, Antich P, Bonte F, Wu A, Mallikarjuana NN, Manohar S, Liang HF, Kulkarni AR, Sung HW, Sairam M, Aminabhavi TM. Targeted nanoparticles for drug delivery through the blood-brain barrier for Alzheimer's disease. J Control Release. 2005; 108:193-214. [PubMed: 16246446]

382. Chen Y, Dalwadi G, Benson HA. Drug delivery across the blood-brain barrier. Current drug delivery. 2004; 1:361-376. [PubMed: 16305398]

383. Kurakhmaeva KB, Djindjikhashvili IA, Petrov VE, Balabanyan VU, Voronina TA, Trofimov SS, Kreuter J, Gelperina S, Begley D, Alyautdin RN. Brain targeting of nerve growth factor using poly(butyl cyanoacrylate) nanoparticles. Journal of drug targeting. 2009; 17:564-574. [PubMed: 19694610]

384. Tseng YC, Mozumdar S, Huang L. Lipid-based systemic delivery of siRNA. Advanced drug delivery reviews. 2009; 61:721-731. [PubMed: 19328215]

385. Ditto AJ, Shah PN, Yun YH. Non-viral gene delivery using nanoparticles. Expert opinion on drug delivery. 2009; 6:1149-1160. [PubMed: 19780712]

386. Torchilin VP. Recent advances with liposomes as pharmaceutical carriers. Nature reviews. 2005; 4:145-160.

387. Phillips WT, Goins BA, Bao A. Radioactive liposomes. Wiley interdisciplinary reviews. 2009; 1:69-83. [PubMed: 20049780] 
388. Onodera H, Takada G, Tada K, Desnick RJ. Microautoradiographic study on the tissue localization of liposome-entrapped or unentrapped $3 \mathrm{H}$-labeled beta-galactosidase injected into rats. The Tohoku journal of experimental medicine. 1983; 140:1-13. [PubMed: 6408762]

389. Postmes TJ, Hukkelhoven M, van den Bogaard AE, Halders SG, Coenegracht J. Passage through the blood-brain barrier of thyrotropin-releasing hormone encapsulated in liposomes. The Journal of pharmacy and pharmacology. 1980; 32:722-724. [PubMed: 6107353]

390. Stanimirovic DB, Markovic M, Micic DV, Spatz M, Mrsulja BB. Liposomeentrapped superoxide dismutase reduces ischemia/reperfusion 'oxidative stress' in gerbil brain. Neurochemical research. 1994; 19:1473-1478. [PubMed: 7877716]

391. Imaizumi S, Woolworth V, Fishman RA, Chan PH. Liposome-entrapped superoxide dismutase reduces cerebral infarction in cerebral ischemia in rats. Stroke; a journal of cerebral circulation. 1990; 21:1312-1317.

392. Michelson AM, Jadot G, Puget K. Treatment of brain trauma with liposomal superoxide dismutase. Free radical research communications. 1988; 4:209-224. [PubMed: 3229660]

393. Chan PH, Longar S, Fishman RA. Protective effects of liposome-entrapped superoxide dismutase on posttraumatic brain edema. Annals of neurology. 1987; 21:540-547. [PubMed: 3037989]

394. Fresta M, Puglisi G. Reduction of maturation phenomenon in cerebral ischemia with CDPcholine-loaded liposomes. Pharmaceutical research. 1999; 16:1843-1849. [PubMed: 10644072]

395. Chapat S, Frey V, Claperon N, Bouchaud C, Puisieux F, Couvreur P, Rossignol P, Delattre J. Efficiency of liposomal ATP in cerebral ischemia: bioavailability features. Brain research bulletin. 1991; 26:339-342. [PubMed: 2049600]

396. Reddy MK, Labhasetwar V. Nanoparticle-mediated delivery of superoxide dismutase to the brain: an effective strategy to reduce ischemia-reperfusion injury. FASEB journal : official publication of the Federation of American Societies for Experimental Biology. 2009; 23:1384-1395. [PubMed: 19124559]

397. Sinha J, Das N, Basu MK. Liposomal antioxidants in combating ischemia-reperfusion injury in rat brain. Biomedicine \& pharmacotherapy = Biomedecine \& pharmacotherapie. 2001; 55:264271. [PubMed: 11428552]

398. Schackert G, Fan D, Nayar R, Fidler IJ. Arrest and retention of multilamellar liposomes in the brain of normal mice or mice bearing experimental brain metastases. Selective cancer therapeutics. 1989; 5:73-79. [PubMed: 2772429]

399. Tokes ZA, St Peteri AK, Todd JA. Availability of liposome content to the nervous system. Liposomes and the blood-brain barrier. Brain research. 1980; 188:282-286. [PubMed: 6245754]

400. Hoffmann PR, Kench JA, Vondracek A, Kruk E, Daleke DL, Jordan M, Marrack P, Henson PM, Fadok VA. Interaction between phosphatidylserine and the phosphatidylserine receptor inhibits immune responses in vivo. J Immunol. 2005; 174:1393-1404. [PubMed: 15661897]

401. Purohit VS, Ramani K, Sarkar R, Kazazian HH Jr, Balasubramanian SV. Lower inhibitor development in hemophilia A mice following administration of recombinant factor VIII-Ophospho-L-serine complex. The Journal of biological chemistry. 2005; 280:17593-17600. [PubMed: 15728582]

402. Gabizon A, Papahadjopoulos D. Liposome formulations with prolonged circulation time in blood and enhanced uptake by tumors. Proceedings of the National Academy of Sciences of the United States of America. 1988; 85:6949-6953. [PubMed: 3413128]

403. Chen H, Tang L, Qin Y, Yin Y, Tang J, Tang W, Sun X, Zhang Z, Liu J, He Q. Lactoferrinmodified procationic liposomes as a novel drug carrier for brain delivery. Eur J Pharm Sci. 2010; 40:94-102. [PubMed: 20298779]

404. Chen H, Qin Y, Zhang Q, Jiang W, Tang L, Liu J, He Q. Lactoferrin modified doxorubicinloaded procationic liposomes for the treatment of gliomas. Eur J Pharm Sci. 2011; 44:164-173. [PubMed: 21782939]

405. Rip J, Appeldoorn CCM, Manca FM, Dorland R, Van Kregten JMR, Gaillard PJ. Receptormediated delivery of drugs across the blood-brain barrier. Frontiers in Pharmacology.

406. Gaillard PJ, Appeldoorn CC, Rip J, Dorland R, van der Pol SM, Kooij G, de Vries HE, Reijerkerk A. Enhanced brain delivery of liposomal methylprednisolone improved therapeutic efficacy in a model of neuroinflammation. J Control Release. 2012; 164:364-369. [PubMed: 22732475] 
407. Gaillard PJ, Appeldoorn CC, Dorland R, van Kregten J, Manca F, Vugts DJ, Windhorst B, van Dongen GA, de Vries HE, Maussang D, van Tellingen O. Pharmacokinetics, brain delivery, and efficacy in brain tumor-bearing mice of glutathione pegylated liposomal doxorubicin (2B3-101). PloS one. 2014; 9:e82331. [PubMed: 24416140]

408. Lindqvist A, Rip J, Gaillard PJ, Bjorkman S, Hammarlund-Udenaes M. Enhanced brain delivery of the opioid peptide DAMGO in glutathione pegylated liposomes: a microdialysis study. Molecular pharmaceutics. 2013; 10:1533-1541. [PubMed: 22934681]

409. Rip J, Appeldom CCM, Manca FM, Dorland R, van Kregten JMR, Gaillard PJ. Receptormediated delivery of drugs across the blood-brain barrier. Pharmacology and Toxicology of the Blood-Brain Barrier: State of the Art, Needs for Future Research and Expected Benefits for the EU, Brussels, Belgium. 2010

410. Rip J, Chen L, Hartman R, van den Heuvel A, Reijerkerk A, van Kregten J, van der Boom B, Appeldoorn C, de Boer M, Maussang D, de Lange EC, Gaillard PJ. Glutathione PEGylated liposomes: pharmacokinetics and delivery of cargo across the blood-brain barrier in rats. Journal of drug targeting. 2014

411. Migliore MM, Vyas TK, Campbell RB, Amiji MM, Waszczak BL. Brain delivery of proteins by the intranasal route of administration: a comparison of cationic liposomes versus aqueous solution formulations. Journal of pharmaceutical sciences. 99:1745-1761. [PubMed: 19774660]

412. Giteau A, Venier-Julienne MC, Aubert-Pouessel A, Benoit JP. How to achieve sustained and complete protein release from PLGA-based microparticles? International journal of pharmaceutics. 2008; 350:14-26. [PubMed: 18162341]

413. Jiang W, Schwendeman SP. Stabilization of tetanus toxoid encapsulated in PLGA microspheres. Molecular pharmaceutics. 2008; 5:808-817. [PubMed: 18710256]

414. Schwendeman SP. Recent advances in the stabilization of proteins encapsulated in injectable PLGA delivery systems. Critical reviews in therapeutic drug carrier systems. 2002; 19:73-98. [PubMed: 12046892]

415. Carrascosa C, Torres-Aleman I, Lopez-Lopez C, Carro E, Espejo L, Torrado S, Torrado JJ. Microspheres containing insulin-like growth factor I for treatment of chronic neurodegeneration. Biomaterials. 2004; 25:707-714. [PubMed: 14607509]

416. Fernandez AM, de la Vega AG, Torres-Aleman I. Insulin-like growth factor I restores motor coordination in a rat model of cerebellar ataxia. Proceedings of the National Academy of Sciences of the United States of America. 1998; 95:1253-1258. [PubMed: 9448318]

417. Bertram JP, Rauch MF, Chang K, Lavik EB. Using polymer chemistry to modulate the delivery of neurotrophic factors from degradable microspheres: delivery of BDNF. Pharmaceutical research. 27:82-91. [PubMed: 19921405]

418. Vergoni AV, Tosi G, Tacchi R, Vandelli MA, Bertolini A, Costantino L. Nanoparticles as drug delivery agents specific for CNS: in vivo biodistribution. Nanomedicine. 2009; 5:369-377. [PubMed: 19341816]

419. Costantino L, Gandolfi F, Tosi G, Rivasi F, Vandelli MA, Forni F. Peptide-derivatized biodegradable nanoparticles able to cross the blood-brain barrier. J Control Release. 2005; 108:84-96. [PubMed: 16154222]

420. Tosi G, Costantino L, Rivasi F, Ruozi B, Leo E, Vergoni AV, Tacchi R, Bertolini A, Vandelli MA, Forni F. Targeting the central nervous system: in vivo experiments with peptide-derivatized nanoparticles loaded with Loperamide and Rhodamine-123. J Control Release. 2007; 122:1-9. [PubMed: 17651855]

421. Tosi G, Vergoni AV, Ruozi B, Bondioli L, Badiali L, Rivasi F, Costantino L, Forni F, Vandelli MA. Sialic acid and glycopeptides conjugated PLGA nanoparticles for central nervous system targeting: In vivo pharmacological evidence and biodistribution. J Control Release. 145:49-57. [PubMed: 20338201]

422. Townsend SA, Evrony GD, Gu FX, Schulz MP, Brown RH Jr, Langer R. Tetanus toxin C fragment-conjugated nanoparticles for targeted drug delivery to neurons. Biomaterials. 2007; 28:5176-5184. [PubMed: 17854886] 
423. Xu F, Lu W, Wu H, Fan L, Gao X, Jiang X. Brain delivery and systemic effect of cationic albumin conjugated PLGA nanoparticles. Journal of drug targeting. 2009; 17:423-434. [PubMed: 19527113]

424. Yu Y, Pang Z, Lu W, Yin Q, Gao H, Jiang X. Self-assembled polymersomes conjugated with lactoferrin as novel drug carrier for brain delivery. Pharm Res. 29:83-96. [PubMed: 21979908]

425. Hu K, Shi Y, Jiang W, Han J, Huang S, Jiang X. Lactoferrin conjugated PEG-PLGA nanoparticles for brain delivery: preparation, characterization and efficacy in Parkinson's disease. Int J Pharm. 415:273-283. [PubMed: 21651967]

426. Kreuter J, Ramge P, Petrov V, Hamm S, Gelperina SE, Engelhardt B, Alyautdin R, von Briesen H, Begley DJ. Direct evidence that polysorbate-80-coated poly(butylcyanoacrylate) nanoparticles deliver drugs to the CNS via specific mechanisms requiring prior binding of drug to the nanoparticles. Pharmaceutical research. 2003; 20:409-416. [PubMed: 12669961]

427. Lin Y, Pan Y, Shi Y, Huang X, Jia N, Jiang JY. Delivery of large molecules via poly(butyl cyanoacrylate) nanoparticles into the injured rat brain. Nanotechnology. 2012; 23:165101. [PubMed: 22460562]

428. Reukov V, Maximov V, Vertegel A. Proteins conjugated to poly(butyl cyanoacrylate) nanoparticles as potential neuroprotective agents. Biotechnology and bioengineering. 108:243252. [PubMed: 20939007]

429. Calvo P, Gouritin B, Chacun H, Desmaele D, D'Angelo J, Noel JP, Georgin D, Fattal E, Andreux JP, Couvreur P. Long-circulating PEGylated polycyanoacrylate nanoparticles as new drug carrier for brain delivery. Pharmaceutical research. 2001; 18:1157-1166. [PubMed: 11587488]

430. Olivier JC, Fenart L, Chauvet R, Pariat C, Cecchelli R, Couet W. Indirect evidence that drug brain targeting using polysorbate 80 -coated polybutylcyanoacrylate nanoparticles is related to toxicity. Pharmaceutical research. 1999; 16:1836-1842. [PubMed: 10644071]

431. Lode J, Fichtner I, Kreuter J, Berndt A, Diederichs JE, Reszka R. Influence of surface-modifying surfactants on the pharmacokinetic behavior of 14C-poly (methylmethacrylate) nanoparticles in experimental tumor models. Pharmaceutical research. 2001; 18:1613-1619. [PubMed: 11758771]

432. Olivier JC, Vauthier C, Taverna M, Puisieux F, Ferrier D, Couvreur P. Stability of orosomucoidcoated polyisobutylcyanoacrylate nanoparticles in the presence of serum. Journal of Controlled Release. 1996; 40:157-168.

433. Kreuter J, Shamenkov D, Petrov V, Ramge P, Cychutek K, Koch-Brandt C, Alyautdin R. Apolipoprotein-mediated transport of nanoparticle-bound drugs across the blood-brain barrier. Journal of drug targeting. 2002; 10:317-325. [PubMed: 12164380]

434. Wang H, Eckel RH. What are lipoproteins doing in the brain? Trends in endocrinology and metabolism: TEM. 2014; 25:8-14. [PubMed: 24189266]

435. Getz GS, Reardon CA. Apoprotein E as a lipid transport and signaling protein in the blood, liver, and artery wall. Journal of lipid research. 2009; 50(Suppl):S156-161. [PubMed: 19018038]

436. Zensi A, Begley D, Pontikis C, Legros C, Mihoreanu L, Wagner S, Buchel C, von Briesen H, Kreuter J. Albumin nanoparticles targeted with Apo E enter the CNS by transcytosis and are delivered to neurones. J Control Release. 2009; 137:78-86. [PubMed: 19285109]

437. Kanehisa M, Asayama S, Kawakami H. Design of lipoprotein-adsorbed liposomes retaining Mnporphyrins for SOD mimic delivery to brains. Desalin. Water Treat. 17:31-36.

438. Kabanov AV, Vinogradov SV, Suzdaltseva YG, Alakhov V. Water-soluble block polycations as carriers for oligonucleotide delivery. Bioconjug Chem. 1995; 6:639-643. [PubMed: 8608176]

439. Harada A, Kataoka K.

440. Harada A, Kataoka K. Chain length recognition: core-shell supramolecular assembly from oppositely charged block copolymers. Science. 1999; 283:65-67. [PubMed: 9872741]

441. Nguyen HK, Lemieux P, Vinogradov SV, Gebhart CL, Guerin N, Paradis G, Bronich TK, Alakhov VY, Kabanov AV. Evaluation of polyether-polyethyleneimine graft copolymers as gene transfer agents. Gene therapy. 2000; 7:126-138. [PubMed: 10673718]

442. Zhang GD, Harada A, Nishiyama N, Jiang DL, Koyama H, Aida T, Kataoka K. Polyion complex micelles entrapping cationic dendrimer porphyrin: effective photosensitizer for photodynamic therapy of cancer. J Control Release. 2003; 93:141-150. [PubMed: 14636720] 
443. Jaturanpinyo M, Harada A, Yuan X, Kataoka K. Preparation of bionanoreactor based on coreshell structured polyion complex micelles entrapping trypsin in the core crosslinked with glutaraldehyde. Bioconjug Chem. 2004; 15:344-348. [PubMed: 15025530]

444. Bronich TK, Cherry T, Vinogradov SV, Eisenberg A, Kabanov VA, Kabanov AV. Self-Assembly in Mixtures of Poly(ethylene oxide)-graft-Poly(ethyleneimine) and Alkyl Sulfates. Langmuir. 1998; 14:6101-6106.

445. Bronich TK, Kabanov AV, Kabanov VA, Yu K, Eisenberg A. Soluble Complexes from Poly(ethylene oxide)-block-polymethacrylate Anions and N-Alkylpyridinium Cations. Macromolecules. 1997; 30:3519-3525.

446. Bronich TK, Nehls A, Eisenberg A, Kabanov VA, Kabanov AV. Novel drug delivery systems based on the complexes of block ionomers and surfactants of opposite charge. Colloids and Surfaces B: Biointerfaces. 1999; 16:243-251.

447. Bronich TK, Popov AM, Eisenberg A, Kabanov VA, Kabanov AV. Effects of Block Length and Structure of Surfactant on Self-Assembly and Solution Behavior of Block Ionomer Complexes. Langmuir. 2000; 16:481-489.

448. Solomatin SV, Bronich TK, Bargar TW, Eisenberg A, Kabanov VA, Kabanov AV. Environmentally Responsive Nanoparticles from Block Ionomer Complexes: Effects of pH and Ionic Strength. Langmuir. 2003; 19:8069-8076.

449. Solomatin SV, Bronich TK, Eisenberg A, Kabanov VA, Kabanov AV. Colloidal Stability of Aqueous Dispersions of Block Ionomer Complexes: Effects of Temperature and Salt. Langmuir. 2004; 20:2066-2068. [PubMed: 15835652]

450. Yusa T, Crapo JD, Freeman BA. Liposome-mediated augmentation of brain SOD and catalase inhibits CNS O2 toxicity, Journal of applied physiology: respiratory. environmental and exercise physiology. 1984; 57:1674-1681.

451. Manickam DS, Brynskikh AM, Kopanic JL, Sorgen PL, Klyachko NL, Batrakova EV, Bronich TK, Kabanov AV. Well-defined cross-linked antioxidant nanozymes for treatment of ischemic brain injury. J Control Release. 2012; 162:636-645. [PubMed: 22902590]

452. Gaydess A, Duysen E, Li Y, Gilman V, Kabanov A, Lockridge O, Bronich T. Visualization of exogenous delivery of nanoformulated butyrylcholinesterase to the central nervous system. Chemico-biological interactions. 2010; 187:295-298. [PubMed: 20060815]

453. Klyachko NL, Manickam DS, Brynskikh AM, Uglanova SV, Li S, Higginbotham SM, Bronich TK, Batrakova EV, Kabanov AV. Cross-linked antioxidant nanozymes for improved delivery to CNS. Nanomedicine. 8:119-129. [PubMed: 21703990]

454. Rosenbaugh EG, Roat JW, Gao L, Yang RF, Manickam DS, Yin JX, Schultz HD, Bronich TK, Batrakova EV, Kabanov AV, Zucker IH, Zimmerman MC. The attenuation of central angiotensin II-dependent pressor response and intra-neuronal signaling by intracarotid injection of nanoformulated copper/zinc superoxide dismutase. Biomaterials. 31:5218-5226. [PubMed: 20378166]

455. Dou H, Destache CJ, Morehead JR, Mosley RL, Boska MD, Kingsley J, Gorantla S, Poluektova L, Nelson JA, Chaubal M, Werling J, Kipp J, Rabinow BE, Gendelman HE. Development of a macrophage-based nanoparticle platform for antiretroviral drug delivery. Blood. 2006; 108:2827-2835. [PubMed: 16809617]

456. Klyachko NL, Haney MJ, Zhao Y, Manickam DS, Mahajan V, Suresh P, Hingtgen SD, Mosley RL, Gendelman HE, Kabanov AV, Batrakova EV. Macrophages offer a paradigm switch for CNS delivery of therapeutic proteins. Nanomedicine (Lond). 2013

457. Haney MJ, Zhao Y, Harrison EB, Mahajan V, Ahmed S, He Z, Suresh P, Hingtgen SD, Klyachko NL, Mosley RL, Gendelman HE, Kabanov AV, Batrakova EV. Specific transfection of inflamed brain by macrophages: a new therapeutic strategy for neurodegenerative diseases. PloS one. 2013; 8:e61852. [PubMed: 23620794]

458. Haney MJ, Suresh P, Zhao Y, Kanmogne GD, Kadiu I, Sokolsky-Papkov M, Klyachko NL, Mosley RL, Kabanov AV, Gendelman HE, Batrakova EV. Blood-borne macrophage-neural cell interactions hitchhike on endosome networks for cell-based nanozyme brain delivery. Nanomedicine (Lond). 2012; 7:815-833. [PubMed: 22236307] 
459. Zhao Y, Haney MJ, Mahajan V, Reiner BC, Dunaevsky A, Mosley RL, Kabanov AV, Gendelman HE, Batrakova EV. Active Targeted Macrophage-mediated Delivery of Catalase to Affected Brain Regions in Models of Parkinson's Disease. Journal of nanomedicine \& nanotechnology. 2011; S4

460. Zhao Y, Haney MJ, Klyachko NL, Li S, Booth SL, Higginbotham SM, Jones J, Zimmerman MC, Mosley RL, Kabanov AV, Gendelman HE, Batrakova EV. Polyelectrolyte complex optimization for macrophage delivery of redox enzyme nanoparticles. Nanomedicine (Lond). 2011; 6:25-42. [PubMed: 21182416]

461. Haney MJ, Zhao Y, Li S, Higginbotham SM, Booth SL, Han HY, Vetro JA, Mosley RL, Kabanov AV, Gendelman HE, Batrakova EV. Cell-mediated transfer of catalase nanoparticles from macrophages to brain endothelial, glial and neuronal cells. Nanomedicine (Lond). 2011; 6:12151230. [PubMed: 21449849]

462. Brynskikh AM, Zhao Y, Mosley RL, Li S, Boska MD, Klyachko NL, Kabanov AV, Gendelman HE, Batrakova EV. Macrophage delivery of therapeutic nanozymes in a murine model of Parkinson's disease. Nanomedicine (Lond). 2010; 5:379-396. [PubMed: 20394532]

463. Zhao Y, Haney MJ, Klyachko NL, Li S, Booth SL, Higginbotham SM, Jones J, Zimmerman MC, Mosley RL, Kabanov AV, Gendelman HE, Batrakova EV. Polyelectrolyte complex optimization for macrophage delivery of redox enzyme nanoparticles. Nanomedicine (London, England). 6:25-42.

464. Zhao Y, Haney MJ, Mahajan V, Reiner BC, Dunaevsky A, Mosley RL, Kabanov AV, Gendelman HE, Batrakova EV. Active Targeted Macrophage-mediated Delivery of Catalase to Affected Brain Regions in Models of Parkinson's Disease. J Nanomed Nanotechnol. S4

465. Haney MJ, Zhao Y, Li S, Higginbotham SM, Booth SL, Han HY, Vetro JA, Mosley RL, Kabanov AV, Gendelman HE, Batrakova EV. Cell-mediated transfer of catalase nanoparticles from macrophages to brain endothelial, glial and neuronal cells. Nanomedicine (London, England). 6:1215-1230.

466. Haney MJ, Suresh P, Zhao Y, Kanmogne GD, Kadiu I, Sokolsky-Papkov M, Klyachko NL, Mosley RL, Kabanov AV, Gendelman HE, Batrakova EV. Blood-borne macrophage-neural cell interactions hitchhike on endosome networks for cell-based nanozyme brain delivery. Nanomedicine (London, England). 7:815-833.

467. Batrakova EV, Gendelman HE, Kabanov AV. Cell-mediated drug delivery. Expert opinion on drug delivery. 2011; 8:415-433. [PubMed: 21348773] 


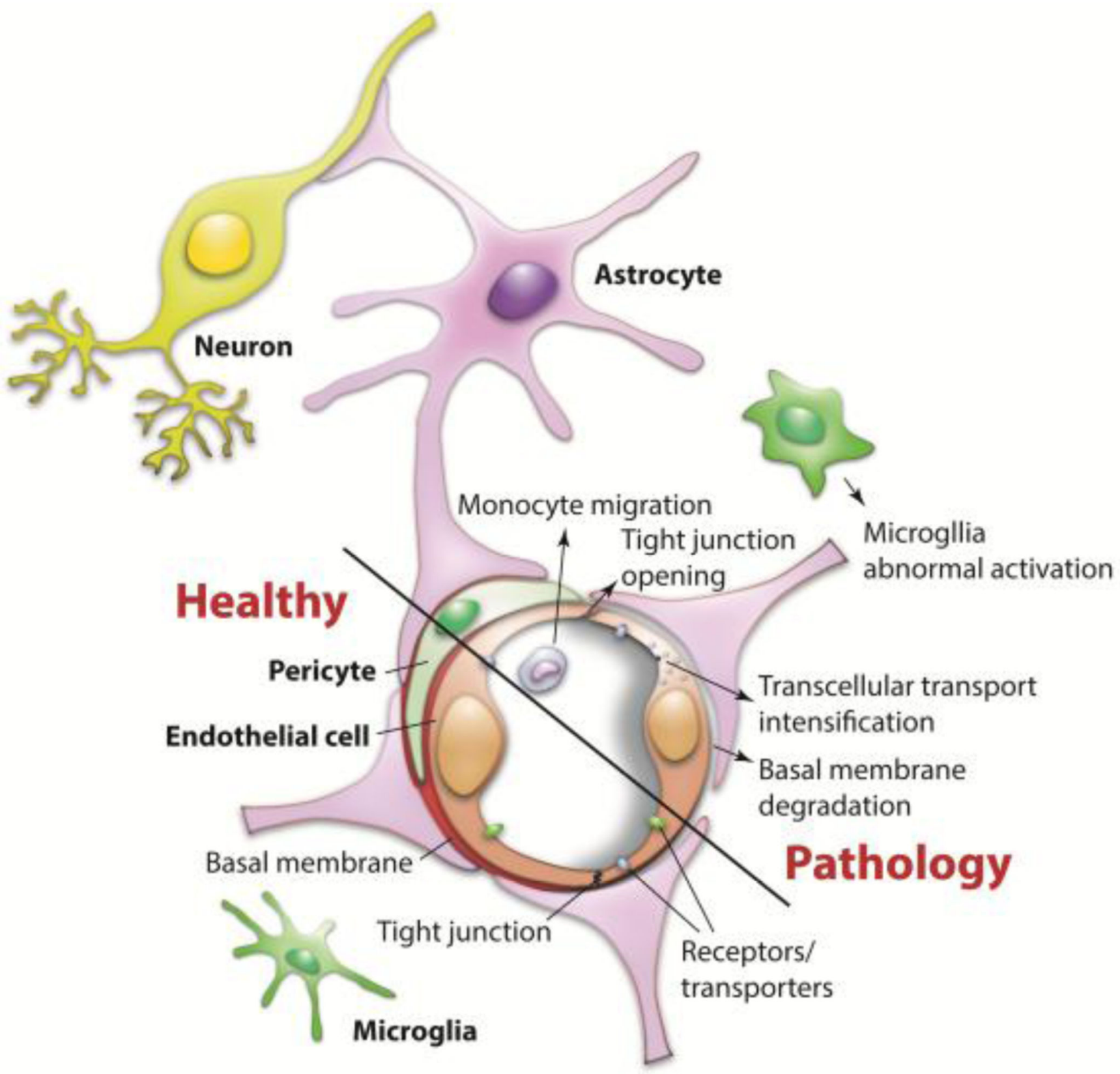

Figure 1. BBB and NVU in physiological and pathological conditions

In normal CNS brain microvessel endothelial cells (BMECs) are sealed by tight junction (TJ). They are surrounded at the apical side by a thin basement membrane (BM), which also surrounds the pericytes adjacent to BMEC. Along with astrocytes, microglia and neurons, these cells comprise the neuron vascular unit (NVU). During the disease progression, the TJ can be disrupted and BBB breached [51], BM degraded [30], immune cells migrate from blood to brain, microglia abnormally activated [32], pinocytosis and transcytosis intensified $[52,53]$, and inwardly and outwardly transporters of various substances modified. 


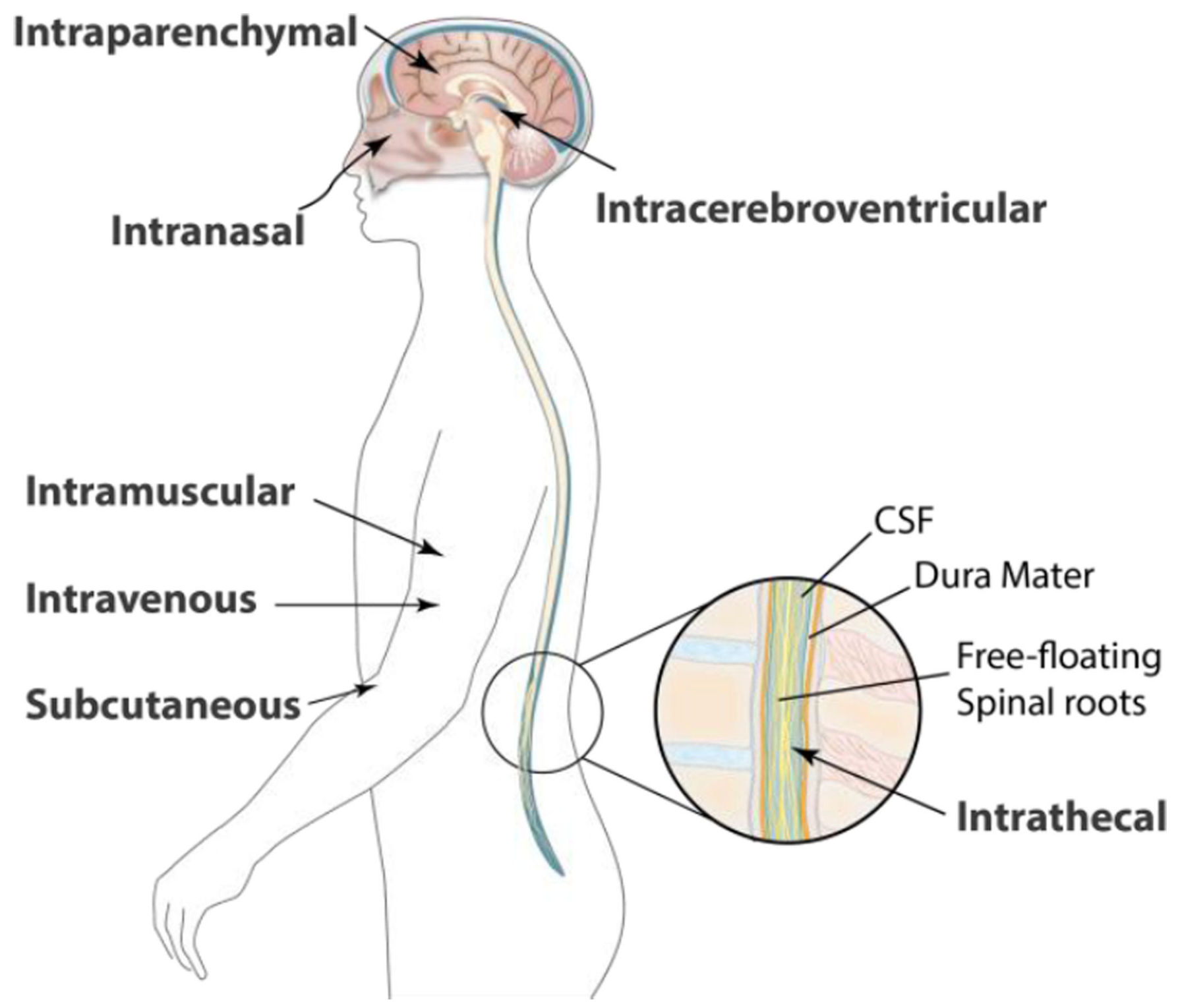

Figure 2. Administration routes of protein therapeutics for CNS delivery Early approaches to CNS protein delivery involved common parenteral injection via intramuscular, intravenous, and subcutaneous routes. In these cases proteins are ultimately distributed within systemic vasculature including brain capillaries. Therefore, brain entry of proteins following parenteral administration requires crossing the BBB. Central administration routes such as intraparenchymal and intracerebroventricular allow bypassing the BBB. Intrathecal administration has been used as a less-invasive alternative to central administration. Intranasal route has been recently explored as a minimally invasive delivery strategy allowing to bypass the BBB. It opens up a new avenue since drug administration at the level of the nasal cribriform plate can facilitate brain delivery with minimal serum exposure. 

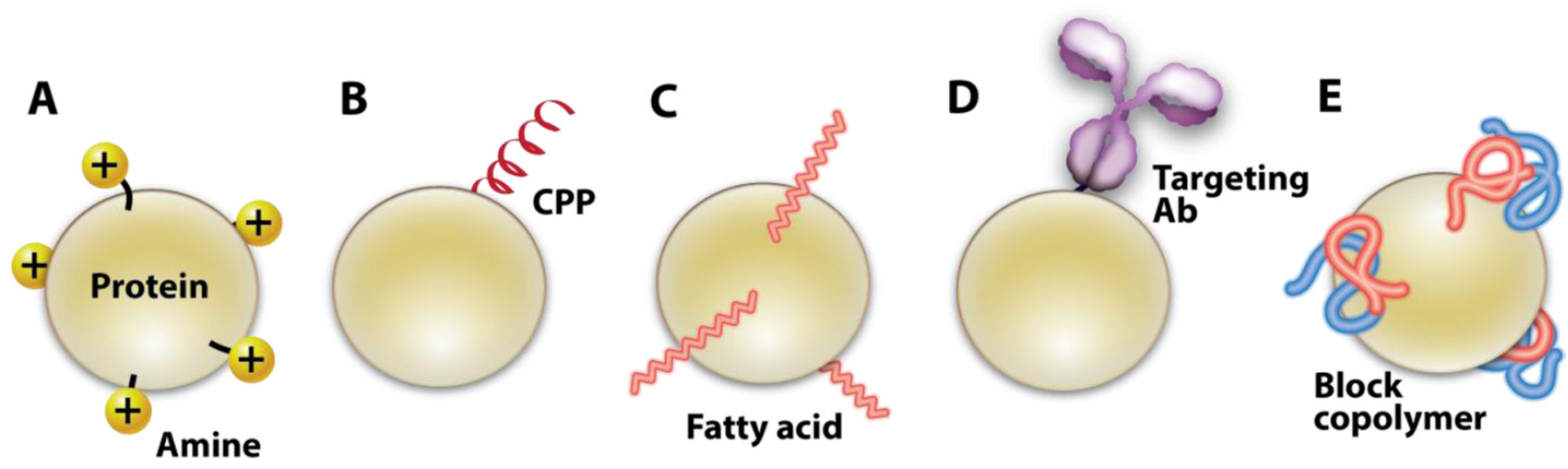

Figure 3. CNS Delivery of Proteins by Chemical Modification

(A) Cationization: Chemical modification of a protein's carboxylic acid groups with natural or synthetic amines has shown to improve cellular uptake and delivery of the cationized protein into the brain parenchyma. (B) Fusion protein constructs with CPPs: CPPs are peptides composed of basic amino acid residues that are believed to traverse across cell membranes thus resulting in intracellular delivery of the attached cargo. (C) Fatty acid acylation: This strategy involves modification of proteins with fatty acid residues that increase proteins membrane binding and subsequent cellular uptake. (D) Conjugation with brain targeting ligands: This strategy involves conjugation of protein of interest with antibodies or ligands of receptors expressed on the brain endothelium that provide for active transport of the conjugates to the brain. (E) Modification with amphiphilic polymers. Pluronic and poly(2-oxazoline) block copolymers have been successfully used to modify proteins to improve their peripheral pharmacokinetic properties and their uptake in the brain parenchyma. 


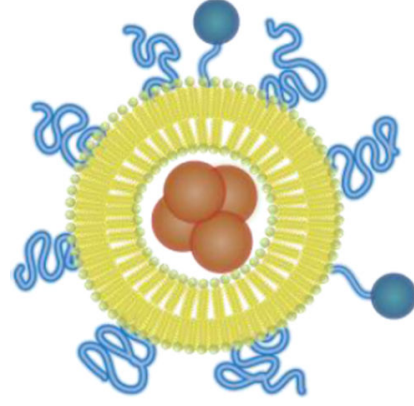

Liposome

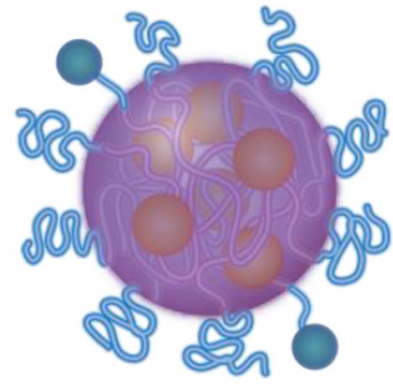

PLGA particle

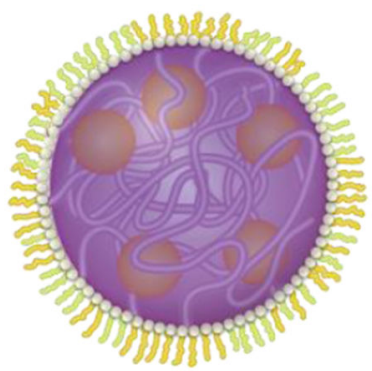

PBCA nanoparticle

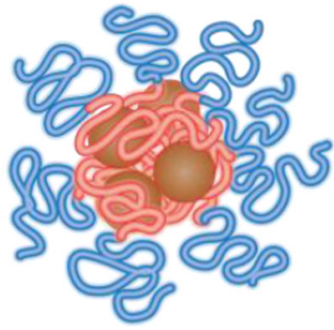

Block ionomer complex (BIC)
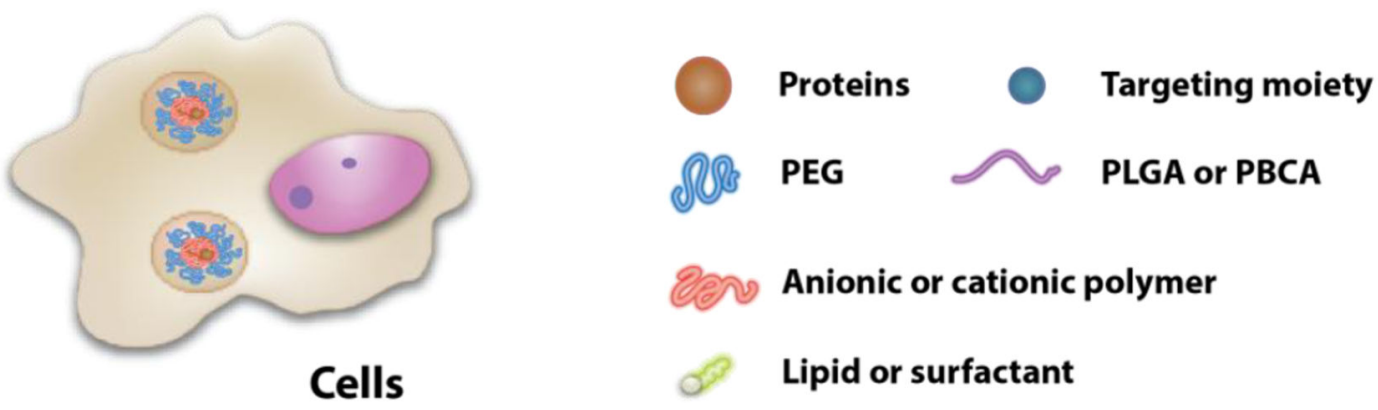

\section{Anionic or cationic polymer}

\section{Lipid or surfactant}

Figure 4. Particulate Carriers for CNS delivery of Proteins

Liposomes are one early strategy used for delivery of proteins. They have been modified with PEG to increase blood circulation time as well as targeting ligands to increase cellular uptake at the brain endothelium. PLGA micro- and nanoparticles have been extensively studied for protein delivery. Their unique advantages include biodegradability and possibility to be used as sustained release formulations. PEGylated PLGA nanoparticles were modified with targeting moieties to improve delivery to the brain. PBCA nanoparticles coated with non-ionic surfactants were shown to deliver low molecular mass drugs and proteins to the brain albeit the mechanism of their delivery to the brain is not understood. BIC are formed by facile self-assembly of charged proteins and block ionomers of opposite charge. The advantages of this strategy include ease of formulation, high loading efficiency and capacity and retention of protein activity in BIC. Albeit in early stage of investigation this strategy has shown promise in several animal models of disease. Cellmediated nanoparticle delivery is a novel approach that has been successfully demonstrated for delivery of catalase BICs to treat PD in animal models. This strategy involves loading of BICs into the immune cells that respond to pathological inflammation and migrate to the brain tissue thereby facilitating drug delivery. 


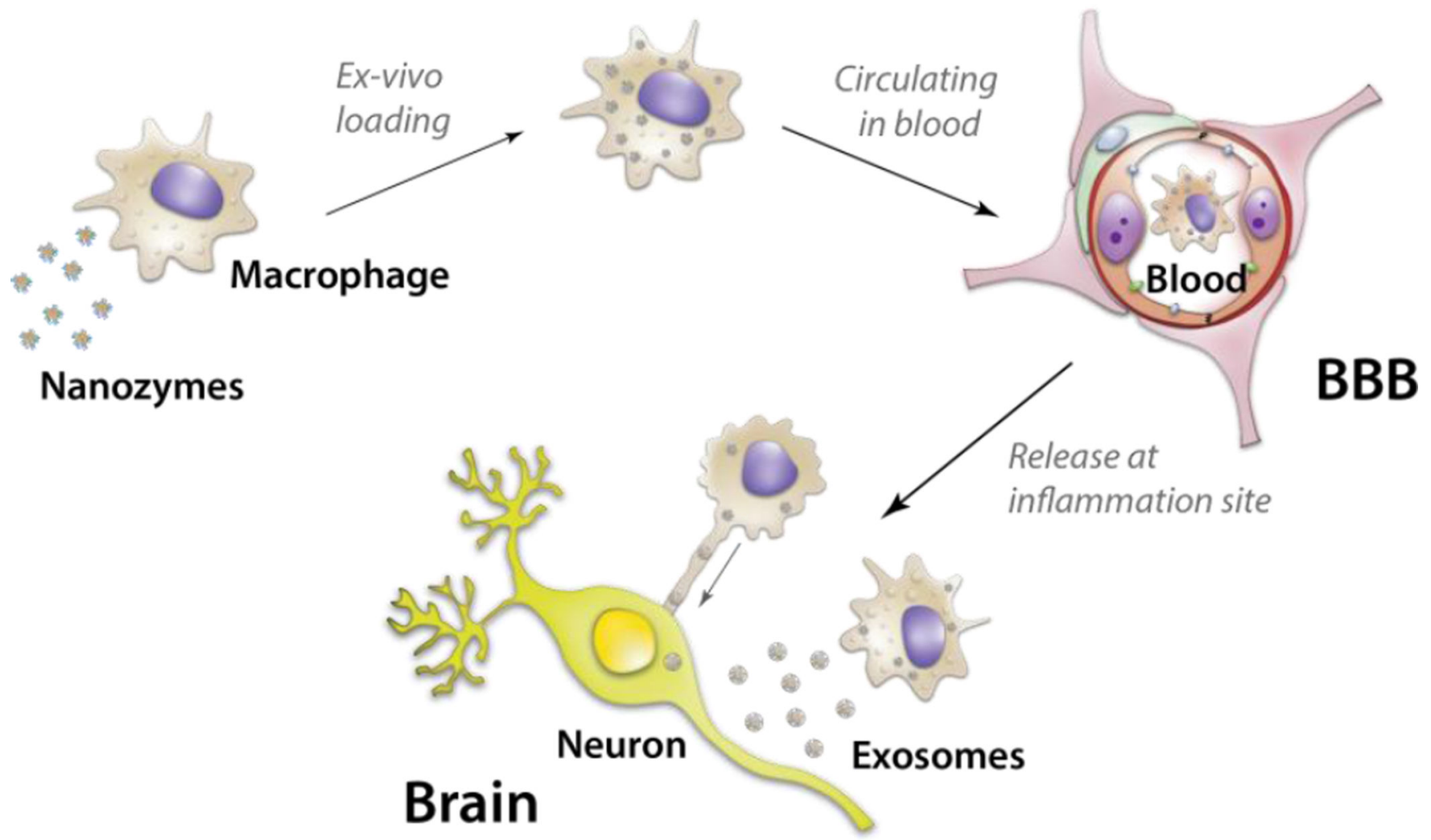

Figure 5. Cell-mediated nanoparticle delivery to the brain

Bone marrow-derived macrophages are ex vivo loaded with nanozymes and administered i.v. into bloodstream. They reach sites of inflammation in the brain, extravasate into the brain parenchyma and transfer the nanoparticles into brain cells by either 1) directly transducing surrounding cells (neurons) through cell-cell contacts (e.g. via filopodia) and/or 2) releasing exosomes containing repackaged nanozymes into extracellular space, followed by the exosomes internalization into brain cells. 

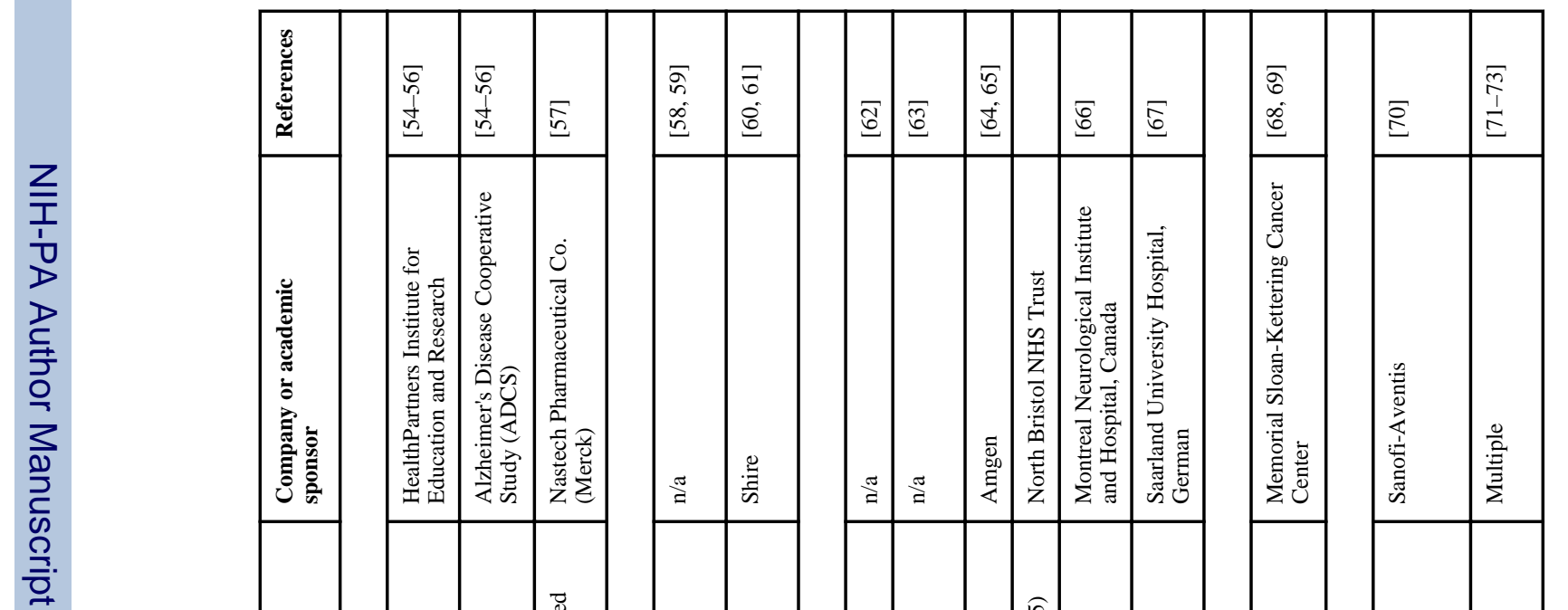

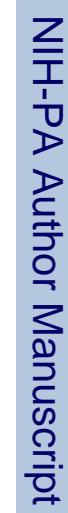

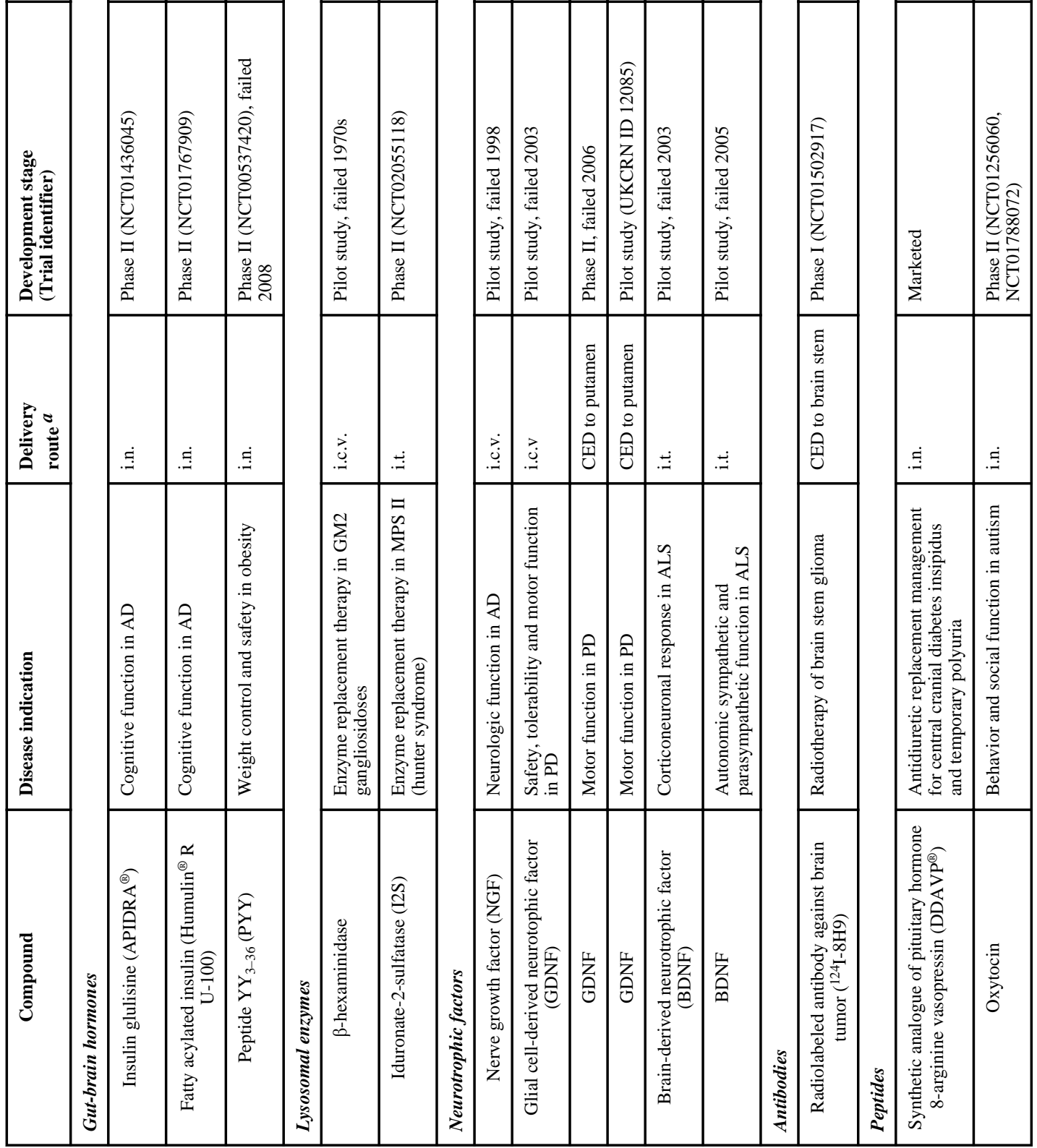

J Control Release. Author manuscript; available in PMC 2015 September 28. 


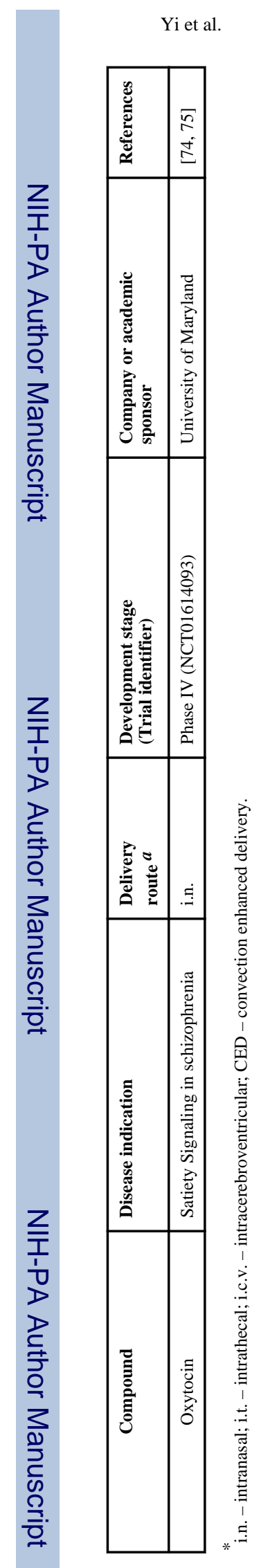

Page 70 


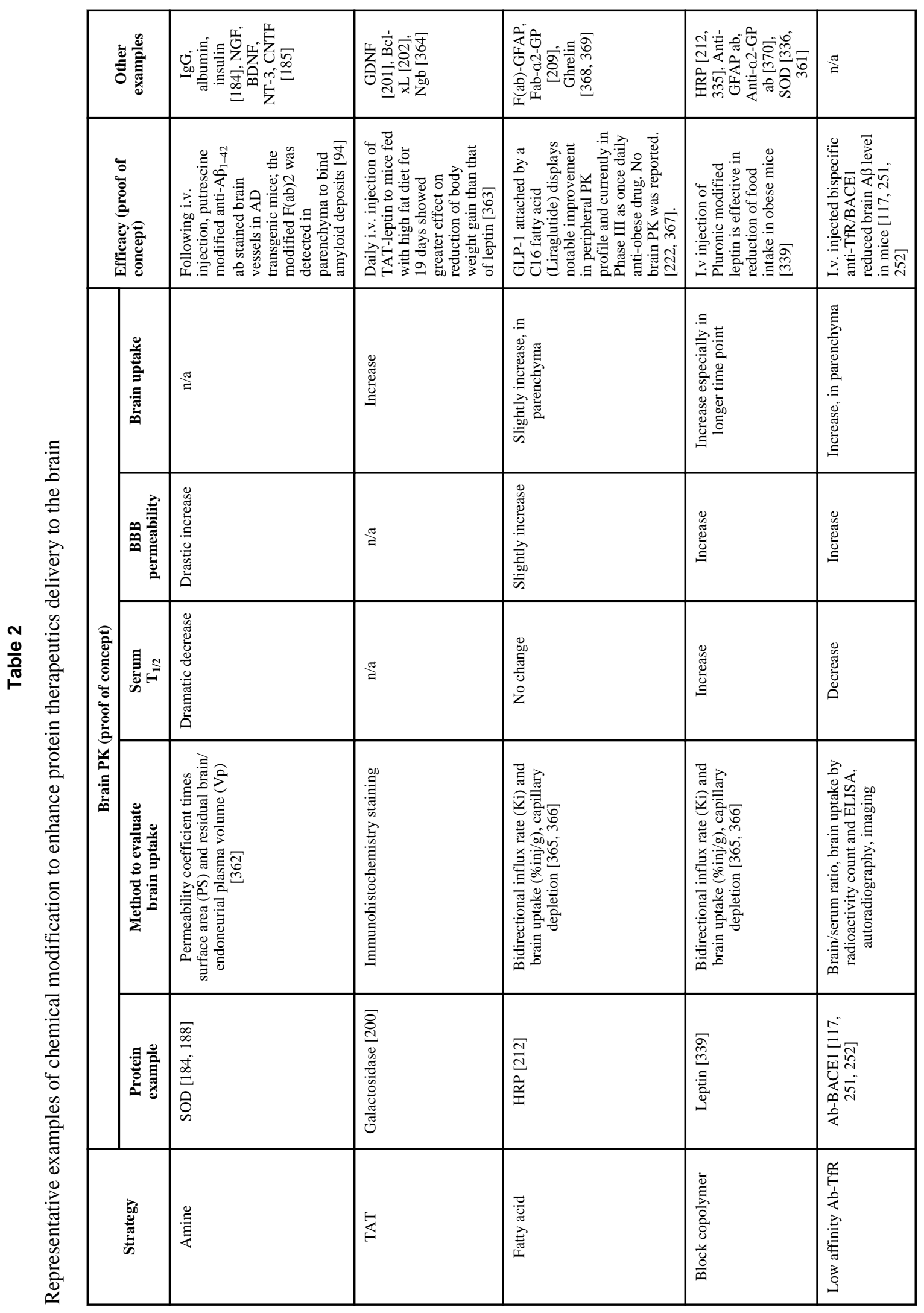




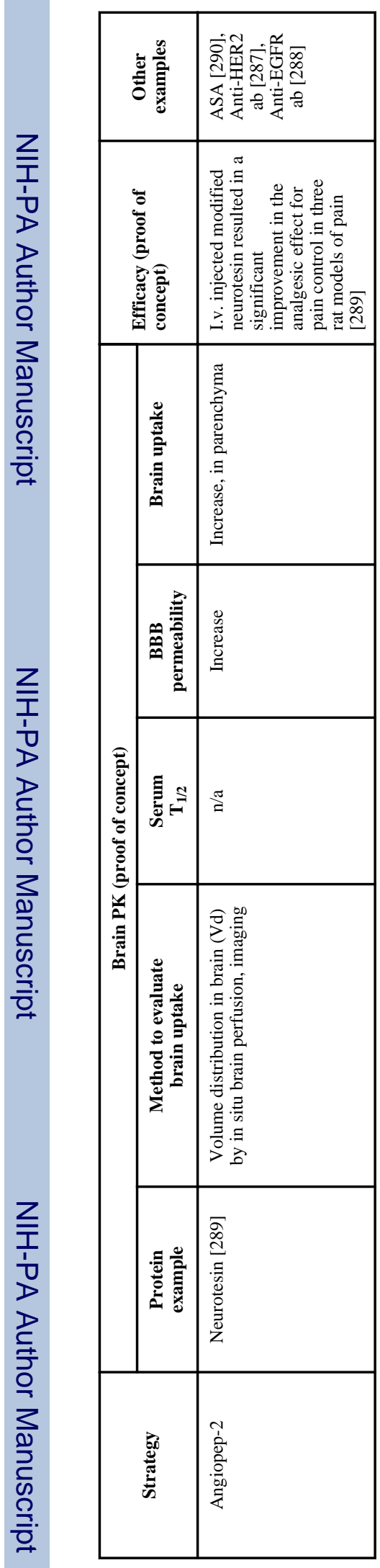

J Control Release. Author manuscript; available in PMC 2015 September 28. 